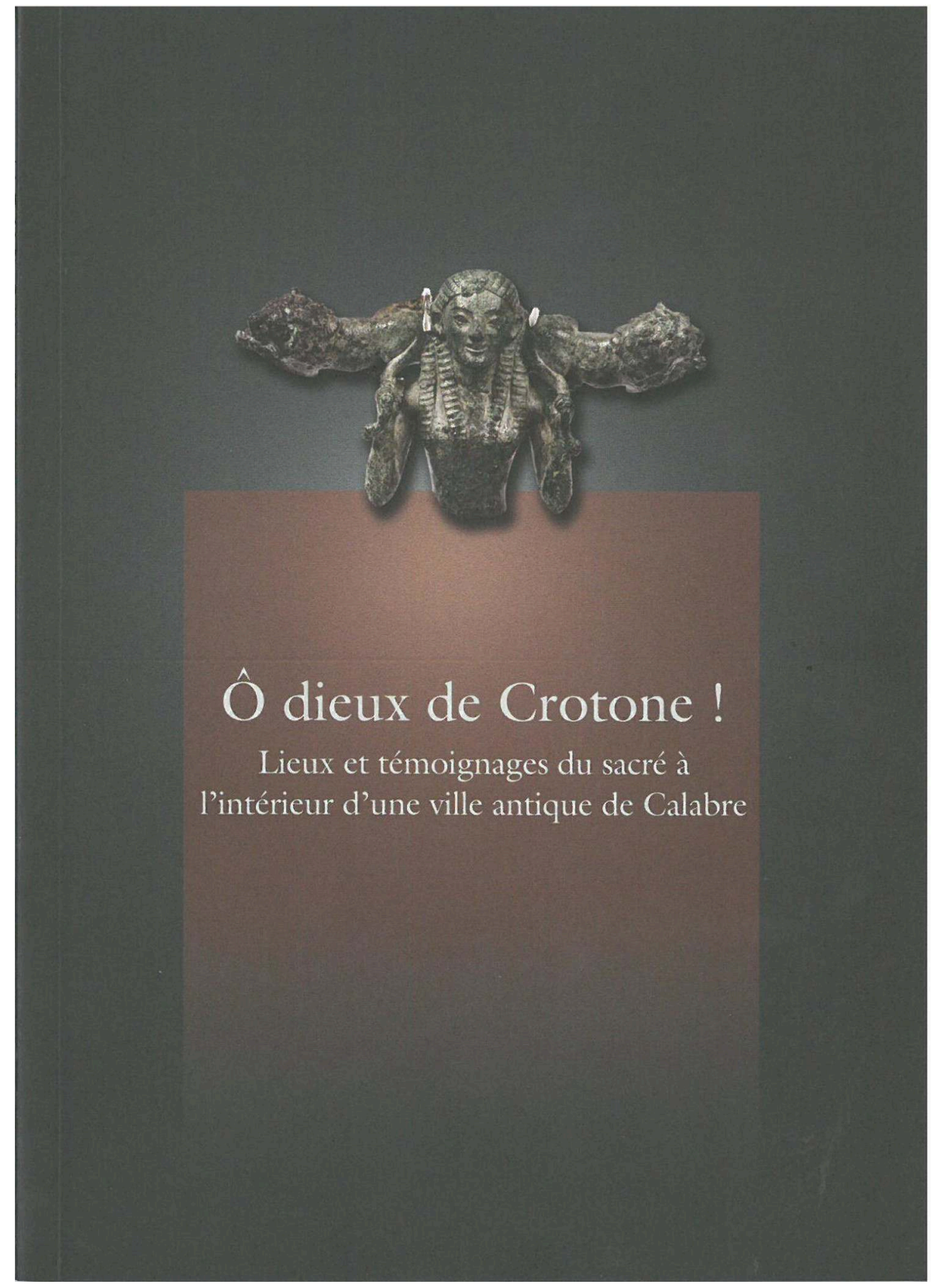




\title{
Ô dieux de Crotone ! Lieux et témoignages du sacré à l'intérieur d'une ville antique de Calabre
}

\author{
Lorenz E. Baumer, Simonetta Bonomi et Domenico Marino (dir.)
}

DOI : 10.4000/books.inha.2949

Éditeur : Publications de l'Institut national d'histoire de l'art

Lieu d'édition : Paris

Année d'édition : 2010

Date de mise en ligne : 5 décembre 2017

Collection : Catalogues d'exposition

ISBN électronique : 9782917902776

\section{oponatibiton ebooks}

http://books.openedition.org

Édition imprimée

Date de publication : 13 janvier 2011

ISBN : 9782917902073

Nombre de pages : 80

\section{Référence électronique}

BAUMER, Lorenz E. (dir.) ; BONOMI, Simonetta (dir.) ; et MARINO, Domenico (dir.). Ô dieux de Crotone! Lieux et témoignages du sacré à l'intérieur d'une ville antique de Calabre. Nouvelle édition [en ligne]. Paris : Publications de l'Institut national d'histoire de l'art, 2010 (généré le 18 décembre 2020). Disponible sur Internet : <http://books.openedition.org/inha/2949>. ISBN : 9782917902776. DOI : https://doi.org/ 10.4000/books.inha.2949

Ce document a été généré automatiquement le 18 décembre 2020.

(c) Publications de l'Institut national d'histoire de l'art, 2010

Conditions d'utilisation:

http://www.openedition.org/6540 
Parmi les nombreuses colonies fondées par les Grecs de l'Antiquité, Crotone, en Grande Grèce, était célèbre et prestigieuse : Pythagore y avait vécu et développé son école ; la cité était fameuse pour son école de médecine; elle abritait aussi de nombreux sanctuaires réputés. Aux sources littéraires anciennes qui témoignaient déjà de sa grandeur s'ajoutent les découvertes archéologiques qui encore aujourd'hui livrent de précieux renseignements sur l'histoire de cette cité florissante et en particulier sa vie religieuse.

Cette exposition raconte la présence du sacré dans cette cité grecque du sud de l'Italie (Paris, INHA, 15 janvier - 31 mars 2011). Des photographies donnent à voir une sélection des trouvailles des archéologues qui nous font découvrir l'histoire et les sanctuaires de cette cité puissante.

Exposition réalisée en collaboration avec l'office territorial de Crotone et Sila de la Surintendance pour le patrimoine archéologique de la Calabre, et le département des sciences de l'Antiquité de l'université de Genève.

\section{LORENZ E. BAUMER}

Professeur ordinaire d'archéologie classique, département des Sciences de l'Antiquité, université de Genève.

\section{SIMONETTA BONOMI}

Surintendant pour le patrimoine archéologique de la Calabre, Reggio Calabria.

\section{DOMENICO MARINO}

Archéologue, directeur de l'Office territorial de Crotone et Sila, Surintendance pour le patrimoine archéologique de la Calabre. 
SOMMAIRE

\section{Présentation}

Lorenz E. Baumer et Domenico Marino

Crotone : le destin évanescent d'une cité célèbre

Michel Aberson

Une cité entre légende et histoire

Cité et religion

Anne-Françoise Jaccottet

Des rituels dans l'espace

La monnaie de Crotone

Matteo Campagnolo et Virginie Nobs

Témoignages d'une cité puissante

Trois sanctuaires extra-urbains

Lorenz E. Baumer

Le sanctuaire d'Héra Lacinia

Le sanctuaire d'Apollon Alaios

Le sanctuaire d'Héra de Vigna Nuova

Cultes et sanctuaires dans la zone urbaine

Margherita Corrado et Domenico Marino

Les indices

Héra

Apollon

Athéna

Héraclès

Bibliographie

Catalogue

Virginie Nobs

Les sanctuaires urbains de Crotone dans la tradition littéraire et les sources antiquaires Margherita Corrado et Domenico Marino

Le territoire de Crotone

Domenico Marino

Bibliographie générale 


\title{
Présentation
}

\author{
Lorenz E. Baumer et Domenico Marino
}

1 Les dieux grecs n'ont, depuis l'Antiquité, rien perdu de leur pouvoir de fasciner. Ils nous font découvrir une facette du monde antique qui a laissé son reflet dans des bâtiments, simples ou magnifiques, et dans d'innombrables œuvres d'art. Qu'elles soient en marbre ou en terre cuite, en bronze ou en argent, ou même en or ou en ivoire, elles sont souvent d'une qualité exceptionnelle. Les dieux ont été représentés par des statues, sur des reliefs sculptés, sur les monnaies ou sur les vases peints.

2 Mais les œuvres d'art étaient beaucoup plus que de simples illustrations et les dieux beaucoup plus que des manifestations de la pensée religieuse ou des personnifications abstraites : les rites qui leur étaient destinés faisaient partie de la vie de la cité, non seulement pendant les grands jours de fête, mais encore dans la vie quotidienne. Des sanctuaires, monumentaux ou modestes, se trouvaient dans la zone urbaine aussi bien que dans les régions éloignées où ils marquaient notamment les limites du territoire de la cité. Les dieux et leurs sanctuaires étaient, en particulier dans la culture grecque, un élément central et formateur de la vie privée, sociale et politique. Ainsi, chaque cité grecque avait son propre caractère religieux, son propre panthéon.

3 Les sources littéraires nous parlent souvent de la grandeur des cités antiques et de l'importance de leurs sanctuaires. C'est aussi le cas de l'antique Crotone, une des plus importantes villes de la Grande Grèce, en particulier aux $\mathrm{VI}^{\mathrm{e}}$ et $\mathrm{v}^{\mathrm{e}}$ siècle avant J.-C. Crotone a hébergé de grands personnages comme le philosophe Pythagore et son école, ou le célèbre général Milon, pour ne mentionner que les deux plus éminents. De Crotone venaient les meilleurs athlètes et les plus belles filles, comme on l'assurait jusqu'en Grèce. Le sanctuaire d'Héra Lacinia sur le Capo Colonna était un centre religieux dont le rayonnement dépassait de beaucoup les frontières de la cité.

Aujourd'hui, cette grandeur de Crotone s'est largement estompée, et la ville antique est presque entièrement recouverte par la ville moderne. Les sanctuaires ont disparu, enfouis sous terre, à l'exception de l'unique colonne qui reste encore du temple d'Héra Lacinia et qui a donné son nom au cap qu'elle marque de son empreinte depuis l'Antiquité (Capo Colonna). Crotone antique semble dormir, dans un paysage qui n'a 
rien perdu de sa beauté, adossé à la mer Ionienne, avec ses grandes plaines entourées de collines et de magnifiques montagnes.

5 Le temple de Capo Colonna n'était pas le seul sanctuaire de la cité de Crotone, comme nous le révèlent les textes littéraires. Les pelles des archéologues en ont découvert d'autres, comme celui d'Apollon Alaios situé de l'autre côté du territoire crotoniate. Et on peut s'attendre à ce que d'autres s'y cachent encore.

6 Assez souvent, à l'occasion de travaux d'aménagement ou de construction, on dégage dans la Crotone moderne quelques vestiges antiques, restes d'habitat, de monuments publics ou de sanctuaires. Ce sont moins les murs qui impressionnent l'œil du spectateur que les œuvres d'art que l'on y trouve. Pour autant que l'on relève soigneusement tous les indices, les vestiges archéologiques permettent de reconstituer ce que le sol de Crotone n'a à ce jour que très partiellement livré : ils nous parlent des dieux. Et ils nous en parlent avec une beauté et dans une qualité assez souvent exceptionnelle, qu'il s'agisse d'un relief en marbre dédié à Héra, qui est unique, d'une petite tête sculptée d'Apollon ou du fragment d'un acrolithe, seul vestige d'une statue de culte d'Athéna autrement perdue.

7 L'exposition et cette petite publication qui l'accompagne invitent donc les visiteurs et les lecteurs à partir pour un voyage de découverte : découverte d'une cité oubliée et de ses dieux, à travers les vestiges archéologiques, en particulier dans la zone urbaine. Ce sont les œuvres qui nous parlent de ces dieux qui sont le cœur de cette exposition, les sculptures de grand format, les reliefs ou les statuettes en bronze, mais aussi les petits objets d'usage quotidien comme les tuiles estampillées ou les monnaies qui portent les images ou les symboles d'Apollon, d'Héraclès, d'Héra ou d'Athéna.

8 Pour raconter l'histoire des sanctuaires et cultes de Crotone, nous avons choisi la photographie. Ainsi au talent de l'artisan qui a créé les objets antiques s'allie la sensibilité du photographe qui sait, par sa maitrise de la lumière et de l'ombre, souligner la beauté et rendre visibles les détails de chaque œuvre, qui risqueraient autrement d'échapper au regard du spectateur. Chaque image est le résultat d'une intense collaboration entre le photographe et l'archéologue. Elle est en même temps une œuvre d'art photographique qui permet littéralement de voir les objets antiques sous une nouvelle lumière.

\section{AUTEURS}

\section{LORENZ E. BAUMER}

Professeur ordinaire d'archéologie classique, département des Sciences de l'Antiquité, université de Genève

\section{DOMENICO MARINO}

Archéologue Directeur de l'Office territorial de Crotone et Sila, Surintendance pour le patrimoine archéologique de la Calabre 


\title{
Crotone : le destin évanescent d'une cité célèbre
}

\author{
Michel Aberson
}

\section{Une cité entre légende et histoire}

1 On peut avoir été riche et célèbre et, pourtant, tomber dans l'oubli, ou presque. N'est-ce pas là le destin de Crotone ? Fondée, d'après la tradition, à la fin du viII e siècle avant J.C. par des colons grecs venus d'Achaïe, au nord-ouest du Péloponnèse, Crotone nous est décrite par les historiens antiques comme «illustre et opulente ${ }^{1} »$. Seul bon mouillage naturel sur la côte de la mer Ionienne entre le détroit de Messine et le port de Tarente, dotée d'une citadelle difficile à prendre d'assaut, bénéficiant d'un climat sain, située dans une contrée fertile, cette ville nous apparaît comme réellement bénie des dieux! Et pourtant, son destin, comme celui de la plupart des autres cités grecques de l'Italie du Sud, nous échappe bien souvent. Nous l'entrevoyons par flashes, dans des récits plus ou moins mythiques, des anecdotes ou des épisodes historiques épars que nous livrent les auteurs anciens au gré de leurs ouvrages, dont aucun ne concerne jamais Crotone au premier chef.

2 La légende, d'abord. Ce serait l'Achéen Myscellos qui aurait reçu d'Apollon l'ordre de fonder « la grande Crotone au milieu de beaux labours » (Diodore de Sicile, Bibliothèque historique, 8,17). Devenue rapidement riche et peuplée, la ville aurait, dès ses origines, fourni un nombre impressionnant de vainqueurs aux Jeux Olympiques. Quoi de meilleur, en effet, qu'un climat sain pour favoriser le développement harmonieux des corps? On y aurait ainsi vu fleurir l'exercice physique, la valeur guerrière - pour les Anciens, les deux choses étaient clairement liées - et l'une des meilleures écoles de médecine de la Grèce antique.

3 L'athlète crotoniate le plus célèbre est sans aucun doute Milon. Présenté parfois comme une réincarnation d'Héraclès ou du héros Achille, ce grand sportif et homme politique, lié selon certains à la secte des pythagoriciens, aurait pris part à une bataille contre les Sybarites, voisins des Crotoniates, vêtu d'une peau de lion et portant la massue (Diodore de Sicile, Bibliothèque historique, 12,9). Le géographe Strabon nous raconte ses 
exploits; en particulier comment il soutint quelques instants par la seule force de ses bras le plafond d'une salle de banquet qui menaçait de s'écrouler, sauvant ainsi les convives d'une mort certaine ; et aussi sa triste fin, qui illustre son orgueil démesuré : lors d'une promenade en forêt, Milon aurait aperçu un tronc d'arbre dans lequel des bûcherons avaient laissé des coins en bois - sans doute parce qu'ils n'étaient pas parvenus à le fendre complètement. L'athlète songea qu'il pouvait, lui, y parvenir à mains nues. Il élargit la fente, les coins tombèrent, mais le tronc se referma, le retenant prisonnier. Les bêtes sauvages firent le reste (Strabon, Géographie, 6,1,12).

Milon avait une fille qui, selon l'historien Hérodote, aurait épousé le meilleur médecin de son époque, Démodokos. Parti de Crotone dans sa jeunesse, celui-ci exerça d'abord son art auprès de Polycrate, le tyran de Samos. Fait prisonnier par les Perses lorsque ces derniers s'emparèrent de cette île, Démodokos croupit un certain temps parmi les esclaves de Darius, le Grand Roi, jusqu'à ce qu'il parvînt à soigner son épouse Atossa, qui souffrait d'une tumeur au sein. Couvert d'honneurs par son maître, il fut envoyé en mission auprès des Grecs d'Italie avec obligation de revenir en Perse à l'issue de son voyage. Mais, arrivé à Tarente, il parvint à échapper à son escorte et à gagner Crotone, où il épousa la fille de Milon. Et les Crotoniates refusèrent de le livrer aux Perses qui le réclamaient (Hérodote, L'Enquête, 3,130-137).

On nous parle aussi d'une grande bataille - la date n'en est pas assurée : vers le milieu $\mathrm{du} \mathrm{VI}{ }^{\mathrm{e}}$ siècle, semble-t-il - où dix mille Locriens taillèrent en pièces cent trente mille Crotoniates $^{2}$. Selon Justin, historien romain tardif, les Dioscures, jumeaux mythiques, fils de Zeus, auraient pris part au combat aux côtés des habitants de Locres. Et c'est Apollon lui-même qui aurait décidé du sort, inattendu, de la bataille. En effet, alors que les Crotoniates avaient promis, en cas de victoire, de lui offrir un dixième du butin, les Locriens élevèrent l'enchère à un neuvième, emportant ainsi le soutien du dieu (Justin, Histoires philippiques, 20, 3, 2-8)!

6 À la suite de cette défaite, les Crotoniates se seraient détournés de la guerre; ils s'apprêtaient même à sombrer dans le luxe et la mollesse, lorsqu'apparut une autre figure semi-mythique qui, selon certains, les en dissuada: le célèbre philosophe Pythagore (Justin, Histoires philippiques, 20, 4,1). Exilé de son île natale de Samos, cet étrange personnage, qui avait beaucoup voyagé et s'était instruit auprès des mages de la Perse, des prêtres de l'Égypte et des prophètes phéniciens, vint s'établir à Crotone, où il fonda - vers 530, semble-t-il - une sorte de secte aristocratique non-violente qui prônait l'amitié, la retenue et le végétarisme. La doctrine pythagoricienne connut un certain succès dans la région, auprès des Grecs d'Italie et de Sicile, et même des indigènes. Mais à Crotone, ses adeptes, appartenant tous à la classe aristocratique au pouvoir, se trouvèrent en butte aux accusations des leaders du peuple, qui leur reprochaient leur exclusivité et réclamaient un gouvernement plus démocratique. Plusieurs auteurs anciens nous relatent, de manière plus ou moins romancée, un épisode tragique où soixante jeunes pythagoriciens périrent dans l'incendie de la maison dans laquelle ils s'étaient réunis, et où les partisans de la démocratie, prenant le pouvoir, contraignirent à l'exil ceux qui avaient réussi à échapper aux flammes³

7 En réalité, l'art de la guerre ne semble pas avoir déserté Crotone. De nombreuses sources nous relatent - et il s'agit là d'un fait historique incontesté même si le récit qui nous en est donné est largement agrémenté d'éléments fabuleux - la prise et la destruction de l'opulente cité de Sybaris par les Crotoniates, sans doute en 511 ou $510^{4}$; 
et ce serait cette victoire, plutôt que la défaite subie quelque trente ans plus tôt contre les Locriens, qui aurait été la cause du luxe excessif affectant la cité.

Avec la fin $\mathrm{du} \mathrm{VI}^{\mathrm{e}}$ siècle avant J.-C. et surtout le début du siècle suivant, le destin de Crotone s'éloigne ainsi peu à peu de la légende et s'approche davantage de ce que nous concevons comme de l'Histoire. Mais il demeure malgré tout bien évanescent. On entend parler d'un régime oligarchique, reposant sur une assemblée restreinte de mille citoyens, bientôt remplacé par une démocratie ; puis d'un tyran - peut-être un chef du parti populaire - nommé Clinias, qui fait libérer des esclaves et rétablir dans leurs droits des citoyens exilés (Denys d'Halicarnasse, Antiquités romaines, 20,7). Il est aussi question d'une fusion entre les trois cités de Crotone, Caulonia et Sybaris qui, à un certain moment, sur le modèle des Achéens du Péloponnèse, décidèrent d'un commun accord de ne former plus qu'une seule entité politique tout en gardant une certaine autonomie locale ${ }^{5}$. Ainsi Crotone semble se tailler une sorte de petit empire au sud de la botte italienne, donnant à la fois sur la mer Ionienne et sur la Tyrrhénienne. Mais cette prospérité va bientôt se trouver menacée: en effet, au cours $d u v^{e}$ siècle, les populations indigènes, qui avaient été bousculées dans un premier temps par l'arrivée des colons grecs, se structurent peu à peu en entités politiques dynamiques, prenant à leur compte de nombreux éléments du mode de vie des nouveaux arrivants, comme l'écriture, l'art, mais aussi les techniques de combat. Ainsi se forme, à cette période, le peuple des Lucaniens, qui menacera bientôt la suprématie des villes de la région, allant même jusqu'à prendre le contrôle d'une partie d'entre elles. Et, plus tard, en 356, un rameau de cette nation, prenant son indépendance, donnera naissance à un nouveau peuple: les Bruttiens. Ceux-ci n'auront alors cesse de vouloir s'emparer des cités grecques, dont une partie grandissante de la population, mais non des citoyens de plein droit, semble même avoir été d'origine indigène ${ }^{6}$.

Devant cette menace, les cités grecques d'Élée, Thourioï, Hipponion et Rhégion s'allient bientôt à Crotone et forment une sorte de ligue défensive dont le fonctionnement est garanti par un traité: "Dans leurs accords", écrit l'historien Diodore de Sicile (Bibliothèque historique, 14,101), «figurait une clause prévoyant que si une cité voyait son territoire ravagé par les Lucaniens, toutes les autres devaient venir à son secours. Et si l'une d'entre elles ne mobilisait pas son armée à cet effet, les stratèges qui y exerçaient leurs fonctions devaient être mis à mort. » Mais les peuples indigènes ne sont pas les seuls à poser problème aux Crotoniates : de manière générale, la région est l'objet des convoitises croisées de diverses puissances impérialistes extérieures. Le tyran Denys de Syracuse, d'abord, qui, dans les années 390-380, tente de se tailler une zone d'influence en Italie du Sud et sur la côte adriatique, et réussit à prendre par surprise la citadelle de Crotone, pourtant réputée inexpugnable ${ }^{7}$. Agathocle ensuite, autre leader syracusain, roi autoproclamé, qui prend la ville par traîtrise et y installe une garnison ${ }^{8}$. Il faut dire qu'à cette époque, les luttes continuelles entre factions politiques - oligarques contre démocrates - à l'intérieur même des cités grecques offrent à tout intervenant extérieur d'excellentes occasions de prise de contrôle : ainsi, dans les années 310, des aristocrates exilés de Crotone tentent de reprendre le pouvoir avec l'aide des Bruttiens (Diodore de Sicile, Bibliothèque historique, 19,10). Et ce phénomène semble s'amplifier encore dès la fin $\mathrm{du}_{\mathrm{IV}}{ }^{\mathrm{e}}$ siècle avec l'arrivée dans la région des Romains et de divers aventuriers venus de Grèce, en particulier le roi d'Épire, le célèbre Pyrrhus. En 303, une coalition de cités grecques, conduite par Tarente - plus puissante désormais que Crotone - s'oppose aux Lucaniens et à leurs 
alliés romains avec l'aide d'un roi de Sparte, Cléonyme, venu chercher fortune à l'Ouest avec cinq mille mercenaires grecs. L'historien latin Tite-Live (Histoire romaine, 10,2.1-3) nous assure que ce dernier fut battu par une armée romaine et forcé de se rembarquer ; mais selon Diodore de Sicile (Bibliothèque historique, 20,104), devant ce front uni, les Lucaniens demandèrent la paix. Ce n'était que partie remise.

En 282, la coalition des cités grecques demanda l'aide de Pyrrhus contre l'avancée romaine. Et cette fois-ci, les Lucaniens étaient de leur côté, ainsi que les Bruttiens. On ne sait pas très bien quelle fut l'attitude des Crotoniates dans cette histoire. Ils étaient bien évidemment pris entre deux feux! Peut-être ont-ils été d'abord aux côtés des Romains mais, après la défaite de ceux-ci à Héraclée, en 280 , ils ont dû rejoindre l'autre camp. En effet, l'historien byzantin Zonaras (Épitomé, 8,6) nous raconte qu'en 277 le général romain Publius Cornelius Rufinus réussit à s'emparer la ville, tenue par les partisans du roi, avec l'aide d'" amis " qu'il avait dans la place. Crotone doit avoir en tout cas considérablement souffert de ces conflits internes répétés et de ces constants changements d'alliance, lesquels se soldaient à chaque fois par une prise plus ou moins violente de la ville, des actes de pillage, des exils forcés ou des massacres de citoyens. À en croire Tite-Live (Histoire romaine, 23,30,6 et 24,3,1-2), la ville, qui, avant l'arrivée de Pyrrhus en Italie, était encore protégée par une enceinte de douze mille pas de circonférence - soit près de dix-huit kilomètres - se trouvait à moitié déserte quelque soixante-dix ans plus tard et ne comptait plus que vingt mille habitants. Elle n'est même pas mentionnée dans la liste des cités grecques qui, au cours de la première guerre entre Rome et Carthage, de 262 à 242, durent fournir des bateaux à la flotte romaine. Preuve désormais, sans doute, de sa faible capacité économique.

Lorsqu'en 216 le général carthaginois Hannibal, qui, deux ans plus tôt, avait pénétré en Italie avec ses éléphants, écrase l'armée romaine à Cannes, en Apulie, Lucaniens et Bruttiens lui apportent aussitôt leur soutien; du coup, par contraste, la plupart des cités grecques de la région, dont Crotone, décident de rester fidèles à Rome. Mais, devant les succès répétés d'Hannibal, nous trouvons à nouveau les habitants divisés. "Une sorte de maladie ", écrit Tite-Live (Histoire romaine, 24,2,8), "s'était répandue dans toutes les cités d'Italie: le désaccord entre les classes populaires et les aristocrates. Les sénats locaux étaient favorables aux Romains; la plèbe lorgnait du côté des Carthaginois. »Crotone n'échappe pas à ce cas de figure : un leader du parti populaire se déclare prêt à livrer la ville aux Bruttiens, qui réussissent ainsi à s'emparer des bas quartiers. Mais la citadelle, occupée par les nobles, résiste toujours aux forces désormais conjointes des envahisseurs et du petit peuple. Finalement, le général carthaginois Hannon propose un arbitrage basé sur l'incorporation d'un certain nombre d'indigènes parmi les citoyens. Crotone, bien dépeuplée, aurait tout à y gagner ! Mais il reçoit cette réponse surprenante de la part de ceux qui tiennent encore l'acropole: "Plutôt mourir que d'adopter ainsi, nous mélangeant aux Bruttiens, les coutumes, les lois et, pour finir, la langue d'une autre nation!» Finalement, un arrangement est trouvé grâce à l'intervention des Locriens, alliés des Carthaginois mais restés autonomes. Les irréductibles aristocrates doivent abandonner la place forte et s'exiler à Locres. Crotone devient une ville mixte, gréco-bruttienne (Tite-Live, Histoire romaine, 24,2-3).

Lorsque les Carthaginois, qui sont restés longtemps dans le Bruttium, abandonnent finalement l'Italie, Crotone ne retrouve pas sa liberté. Aux Grecs et aux Bruttiens qui la peuplaient encore viennent s'adjoindre, dès 194, des colons romains ; l'essentiel de son 
territoire étant alors confisqué par les conquérants. Les anciens habitants eurent-ils encore leur mot à dire dans l'administration de la cité, ou celle-ci passa-t-elle entièrement sous le contrôle des nouveaux maitres? Nous n'en savons rien. En tout cas, elle apparaît bien affaiblie. Une vingtaine d'années plus tard, en effet, un haut magistrat romain corrompu, Quintus Fulvius Flaccus, fit enlever toutes les tuiles de marbre du temple d'Héra Lacinia pour les réutiliser dans la couverture d'un édifice votif qu'il faisait construire à grands frais dans la capitale. Sur plainte des habitants, le Sénat l'obligea bien à ramener les tuiles à Crotone; mais celles-ci demeurèrent entassées dans l'enceinte du sanctuaire car, si le sacrilège commis se trouvait ainsi formellement réparé, on ne parvint pas à trouver des artisans capables de les remettre en place (Tite-Live, Histoire romaine, 42,3).

Dès lors, le destin de Crotone devient pour nous plus évanescent encore. Nous savons certes qu'en Italie, à partir de 90 avant J.-C., toute la population libre obtint la citoyenneté de Rome. Ceux des Crotoniates qui n'avaient pas encore été incorporés dans la colonie romaine ont donc dû accéder dès lors à ce statut. Mais pour le reste, seuls les résultats de l'investigation archéologique peuvent nous permettre de nous faire une idée de l'histoire de la ville à l'époque romaine ; ou presque. De temps à autre, une bribe de texte nous offre quelque éclairage sur elle, de manière parfois très anecdotique. Ainsi cette inscription du $\mathrm{I}^{\mathrm{er}}$ siècle avant J.-C. relatant la construction par deux magistrats romains locaux d'un bain public à proximité du sanctuaire d'Héra ${ }^{9}$; ou ce passage du romancier Pétrone (Satyricon, 116) qui décrit Crotone, "une ville très ancienne, jadis la première d'Italie ", comme un lieu de perdition où tout le monde trompe tout le monde et où, « comme dans une contrée ravagée par une épidémie, il n'y a que des cadavres déchiquetés et des corbeaux qui les déchiquètent ». Mais chacun sait qu'il ne faut pas ajouter foi à ce que racontent les romanciers... Les mythes sur la fin de la Crotone antique sont-ils vraiment plus crédibles que ceux qui racontent sa fondation?

\section{BIBLIOGRAPHIE}

E. M. De Juliis, Magna Grecia, L'Italia meridionale dalle origini leggendarie alla conquista romana, Bari, 1996.

G. De Sensi Sestito, M. Intrieri, «Crotone in età greca e romana », dans F. Mazza (dir.), Crotone, storia cultura economia, $2^{\text {e }}$ éd., Soveria Mannelli, 2001, p. 23-90.

E. Greco, La Grande Grèce. Histoire et archéologie, traduit de l'italien par A. Schnapp, Paris, 1996 (original en italien : Archeologia della Magna Grecia, Rome/Bari, 1992).

P. G. Guzzo, I Brettii. Storia e archeologia della Calabria preromana, Milan, 1989.

K. Lomas, Rome and the Western Greeks, 350 BC - AD 200, Londres, 1993.

G. Pugliese Carratelli (dir.), I Greci in Occidente, [Milan], 1996. 
G. Pugliese Carratelli (dir.), The Western Greeks : Classical Civilization in the Western Mediterranean, Londres, 1996 (traduction anglaise de l'ouvrage précédent).

\section{NOTES}

1. Nobilem atque opulentam, chez Tite-Live, Histoire romaine, 24,2,7. Dans la suite de cet article, toutes les dates, sauf mention contraire, se situent avant l'ère chrétienne.

2. Ces chiffres, certainement exagérés, sont donnés par Strabon, Géographie, 6,1,10.

3. Voir notamment Polybe, Histoire, 2,39; Jamblique, Vie de Pythagore, § 248; Justin, Histoires philippiques, 20,4,14-17. En fait, ce coup d'État démocratique pourrait se situer bien plus tard, au $\mathrm{V}^{\mathrm{e}}$ siècle.

4. Voir notamment Hérodote, L’Enquête, 5,45,1; Strabon, Géographie, 6,1,13 ; Diodore de Sicile, Bibliothèque historique, 12,9-10.

5. Voir Polybe, Histoire, 2,39 (qui parle d'une Sybaris dont on ne sait s'il s'agit de l'ancienne cité, détruite par les Crotoniates en 511/510, ou, plus probablement, de la «Nouvelle Sybaris", reconstruite ultérieurement à quelque distance de l'ancienne sur les bords du fleuve Trionto). Jamblique, Vie de Pythagore, § 255, fait allusion à une telle fusion de cités (en grec synoikismós), qu'il semble situer avant l'arrivée de Pythagore à Crotone. Mais cet auteur est peu fiable sur le plan chronologique.

6. Pour les Lucaniens, voir notamment Strabon, Géographie, 6,1,2. La naissance du peuple des Bruttiens est racontée par le même auteur (Géographie, 6,1,4), par Diodore de Sicile (Bibliothèque historique, 16,15) et, de manière nettement plus romancée, par Justin (Histoires philippiques, 23,1,3-14).

7. Diodore de Sicile, Bibliothèque historique, 14,103-105 ; Tite-Live, Histoire romaine, 24,3,8.

8. En 295 : cf. Diodore de Sicile, Bibliothèque historique, 21,4.

9. L'Année épigraphique, Paris, 1912, nº 245 : «[...] Lucilius Macer, fils d'Aulus, et Titus Annæus Thraso, fils de Sextus, les deux magistrats chargés du recensement quinquennal, ont fait construire ce bain sur décision du Sénat (local).» On notera que le second personnage mentionné porte un nom grec : Thraso. Peut-être s'agit-il d'un descendant des anciens Crotoniates incorporé dans la nouvelle cité romaine?

\section{AUTEUR}

\section{MICHEL ABERSON}

Université de Genève 


\title{
Cité et religion
}

\author{
Anne-Françoise Jaccottet
}

\section{Des rituels dans l'espace}

1 La religion grecque fascine. Comment les Grecs concevaient-ils leurs rapports avec le divin? Quels dieux invoquaient-ils, par quels rituels, à quels moments et dans quels espaces? Comment le religieux s'articulait-il au quotidien social et politique? Ces questions nous interpellent aujourd'hui dans leur dimension et leur intérêt historiques, mais pas seulement. À l'heure où notre monde moderne se trouve en prise directe avec la question de la place du religieux dans la société, il n'est pas inutile de déplacer et dépasser le débat actuel en s'interrogeant sur le sens et la fonction de la religion dans les cités grecques. Cette plongée dans un univers religieux marqué du sceau de l'altérité permet une prise de conscience de notre propre identité culturelle, sociale et religieuse, par le contraste et le décalage inévitables et féconds auxquels cette approche nous confronte.

2 Approcher la religion grecque, c'est d'abord se départir de nombreux réflexes culturels ou fausses évidences. On notera pour commencer que les Grecs ne connaissent pas de terme pour désigner ce que nous appelons «religion». La religion n'est pas une catégorie en soi dans l'Antiquité. Là où nous voyons un concept unitaire, les Grecs évoquaient la réalité religieuse par une multitude de termes, adaptés à chaque situation, à chaque cas de figure. Cette disparité et cette absence de concept unifié ne doivent cependant pas être comprises comme la marque d'un désintérêt des Anciens. Le religieux est bien au contraire omniprésent, marquant et rythmant naturellement toutes les phases de la vie sociale ou politique, privée ou publique (encore des catégories modernes!). Autres notions étrangères à la conception religieuse antique, celles d'Église ou de dogme, issues des religions révélées ou religions du Livre. Dans une culture axée sur la pratique des rituels ancestraux et sans référence à des textes fondateurs, tout se joue dans la performance rituelle du moment. C'est le rite qui est au centre du religieux, pas un dogme ni une foi. Il est dès lors illusoire de raisonner, comme nous le ferions spontanément, en termes de croyance ou non-croyance, ou de 
croyance juste ou hérétique. Les Grecs en matière religieuse sont avant tout des pratiquants, dans un sens absolu.

3 C'est ainsi à un effort considérable de dépouillement culturel qu'il convient de s'astreindre pour entrer dans l'univers religieux des Grecs afin d'éviter autant que faire se peut d'appliquer les catégories modernes au travers desquelles nous voyons le monde à une culture qui ne les connaît pas.

À qui s'adressaient les cultes et les rites des Grecs? Nous avons tous appris à l'école la liste canonique des douze dieux grecs, avec leurs spécificités: Zeus, roi des dieux, maitre de la foudre, Poséidon, dieu de la mer, responsable des tempêtes et des tremblements de terre, Héra, épouse de Zeus et déesse du mariage, Apollon, dieu de la lumière, archégète des muses... point n'est besoin ici de les énumérer tous. Nous avons de fait une certaine conception de ce panthéon où les dieux se partagent le pouvoir et les sphères d'influence, permettant aux hommes de trouver en toute circonstance le dieu ou la déesse à même de répondre à leurs besoins, d'apaiser leurs craintes ou de combler leurs espoirs; nous avons culturellement assimilé ce panthéon partagé par tous les Grecs qui forme le fondement de leur identité d'Hellènes, au même titre que la langue, le sang et les mœurs (Hérodote, VIII, 144). Mais cette image est loin d'expliciter dans sa complexité et ses nuances la vie religieuse des anciens Grecs. Il y a tout d'abord d'autres dieux que les douze "canoniques", dont la liste a d'ailleurs passablement varié dans l'Antiquité. Mais l'important ne réside pas dans le nombre des dieux honorés. Chaque dieu varie et se pare différemment au gré des épiclèses qu'il porte ; il est très rare de voir un culte adressé à un "simple » Zeus, un "simple » Apollon, une « simple » Athéna, à ces images archétypales de dieux que reconnaissent unanimement ceux qui se disent grecs; on sacrifiera à Zeux Olympios, à Zeus Herkeios ou à Zeus Agoraios, à Apollon Lykeios, Smintheus ou Pythios; et chaque Zeus, chaque Apollon, sera distingué par son épiclèse qui le personnalise en délimitant son rayon d'action privilégié et sera honoré d'un sacrifice suivant des rites particuliers. Les dieux euxmêmes et les rites qui les honorent varient ainsi dans une mesure plus ou moins grande d'une cité à l'autre, puisque chaque cité, en tant qu'État indépendant, s'appuie sur ses propres coutumes ou règles de vie, qu'elles soient politiques, sociales ou religieuses. Qui plus est, au sein d'une même cité, plusieurs cultes différents dédiés à une même divinité, déclinée en autant d'épiclèses, coexistent sans aucun problème et se complètent à merveille.

5 On voit ainsi se complexifier notablement la notion que l'on croyait pertinente et bien cernée de polythéisme, concept soit dit en passant inventé par les cultures monothéistes : non seulement ce sont plusieurs dieux qui sont honorés, mais chacun de ces dieux est lui-même potentiellement multiple. Et il ne saurait être question de choisir entre ces différents dieux ou épiclèses; c'est bien d'un cumul et d'une complémentarité qu'il s'agit, jamais d'une quelconque exclusivité au profit d'un dieu particulier ou de quelques-uns. Mais il faut encore pousser plus loin la complexité. En dehors des dieux, il y a également les nombreux héros que l'on honore par des cultes; le héros, le plus souvent fruit de l'union d'un dieu ou d'une déesse avec un humain, se distingue du dieu par sa nature mortelle; car si les dieux naissent et ne sont donc pas éternels, ils naissent immortels: ils ne meurent pas au contraire des héros. C'est justement à son tombeau que le héros recevra un culte de type chtonien, c'est de son tombeau qu'il enverra sa protection à ceux qui habitent son territoire. Car le héros, par sa sépulture, est profondément ancré dans le sol et voit sa puissance limitée au 
territoire qui l'accueille. L'histoire a d'ailleurs retenu plusieurs épisodes de déplacement ou rapt d'ossements de héros afin de s'en approprier la protection et la puissance.

6 Après ces quelques considérations, on comprendra qu'il est difficile de proposer une synthèse satisfaisante sur «la religion dans la cité grecque ». Même si l'ensemble des cités grecques reconnaît les mêmes divinités fondamentales, chaque cité aura ainsi un panthéon particulier de dieux et de héros articulé autour d'une divinité poliade ou tutélaire, et connaîtra des rites particuliers que des récits étiologiques à forte connotation locale ancrent dans leur spécificité. Il n'y a qu'à lire Pausanias, auteur, au $\mathrm{II}^{\mathrm{e}}$ siècle de notre ère, d'une sorte de "Guide bleu » des principaux sites de Grèce, pour se rendre compte de la richesse et de la diversité des traditions rituelles des différentes cités grecques.

7 Mais cette multiplicité essentielle n'empêche pas certaines constantes fondamentales dans l'organisation des cultes des diverses cités. Même si les rituels varient d'un culte à l'autre, ils restent cantonnés dans certaines catégories d'action que l'on peut cataloguer en quelques points: procession, libation, sacrifice, repas rituel, offrande, prière; l'organisation de "performances» comme des chœurs de danse, des concours musicaux, poétiques ou athlétiques, ou encore des représentations dramatiques sont aussi à considérer dans une grande mesure comme des actes cultuels, effectués en l'honneur d'un dieu ou d'une déesse. Ces différents actes cultuels permettent aux hommes d'entrer en contact avec les dieux, de les honorer dignement et de s'assurer ainsi de leur soutien ou au moins de leur neutralité garante de paix. Encore faut-il, pour assurer leur succès, qu'ils soient accomplis selon les règles. En l'absence de dogme, c'est la tradition qui fait office de référent absolu. Les rites, quels qu'ils soient, doivent être exécutés "selon la tradition ancestrale", kata ta patria; ce recours unanimement respecté à la tradition justifie les rites particuliers tout en garantissant leur efficacité. Pour éviter les faux pas ou les oublis, chaque cité mettra sur pied un calendrier sacrificiel, qui répertoriera, au fil des jours de l'année, à quelle divinité sacrifier quelle victime, quel jour précis, ou quelle fête célébrer selon quel rituel, etc.

Les calendriers sacrificiels peuvent même se superposer, car les rituels sont organisés à tous les échelons de la structure sociale. Les cultes fondent et nourrissent la sociabilité à tous les niveaux : dans le cadre de la famille, plus petit groupe social reconnu, mais aussi dans le cadre des structures de plus en plus larges qui assurent les liens sociaux et l'enracinement des individus dans le tissu social, comme la phratrie, le génos, la tribu, la classe d'âge; la cité n'est en fin de compte que la clé de voûte de ces structures sociales en poupées russes. Les rites à effectuer au long de l'année sont donc fonction de tous ces différents étages de sociabilité. Chaque individu d'une même cité suivra ainsi un calendrier sacrificiel différencié au gré de son appartenance à telle tribu, telle phratrie, tel clan familial. Seuls les rites célébrés au nom de la cité regrouperont l'ensemble de la communauté civique.

Pour pratiquer ces rites, point n'est besoin de structures élaborées, un autel suffit le plus souvent à leur bon accomplissement ; mais cet autel doit faire partie d'un espace particulier, coupé du reste du territoire et ainsi consacré : c'est cette notion de coupure que l'on retrouve dans la racine du principal terme désignant le sanctuaire, téménos. Le temple que l'on assimile, dans notre conception judéo-chrétienne, au cœur de l'acte rituel, n'est dans l'Antiquité qu'un "plus », une demeure pour le dieu (naos vient du verbe qui signifie « habiter»), un espace auquel la monumentalisation fera prendre des 
dimensions et une esthétique tout à fait remarquables mais qui n'est pas à proprement parler un lieu de culte. Chaque sanctuaire aura son règlement, dans lequel les préceptes de pureté réclamés de la part de celui qui y entre sont une constante absolue dans tout le monde grec. Pour entrer en contact avec le divin, il faut soi-même être exempt de toute souillure, provoquée par exemple par un contact avec la mort (deuil), mais aussi par la violence (subie ou portée), ou encore par les accouchements ou les menstruations pour les femmes. En dehors de ces prescriptions générales, on trouvera des règles parfois très précises qui déterminent le bon déroulement des cérémonies, publiques ou privées (sorte de sacrifice, manière de procéder, taxes à payer, gestes ou habits à proscrire ou à respecter, etc.).

De même que les cultes structurent la société dans ses différentes composantes, de même les sanctuaires rythment et organisent le paysage. Placés à l'intérieur de la ville, à ses portes ou aux confins du territoire, les différents sanctuaires forment l'ossature visible de l'espace civilisé. Qu'ils soient placés sur l'agora, sur l'acropole ou dans un quartier plus excentré, la localisation de ces lieux de culte est déjà un discours sur leur rôle social ou politique. Et les parcours processionnels qui lient souvent plusieurs sanctuaires entre eux, ou qui matérialisent le lien entre le cœur de la cité et la limite de son territoire, sont une expression rituelle de l'articulation de la société dans sa spatialité. Tout comme la société, l'espace de la cité, comprise comme la ville et son territoire, est ainsi scandé par le religieux qui le forme et lui donne son sens et son essence.

11 Les prêtres ou les prêtresses, on le comprendra aisément, ont en conséquence un rôle éminemment social ou plus exactement civique : ils matérialisent par les actes du culte le lien nécessaire entre la communauté civique et les dieux dont les caprices peuvent élever comme abaisser les hommes. Conçu comme médiateur entre la cité et le divin, le prêtre ou la prêtresse n'est pas pour autant un «spécialiste ». La Grèce connaît avant tout une prêtrise de milice. On devient prêtre de la même manière qu'on endosse une charge politique : on est élu prêtre ou prêtresse par les organes politiques, ou mieux encore, par tirage au sort. La fonction de prêtre n'est pas une « ordination » conférant des pouvoirs généraux et illimités dans le temps: on devient prêtre de tel dieu déterminé par son épiclèse particulière, affecté à tel sanctuaire précis et pour une charge limitée dans le temps (le plus souvent une année). On peut d'ailleurs endosser successivement ou même simultanément la prêtrise de différentes divinités. Seuls quelques rituels spéciaux, impliquant des rapports particuliers entre l'individu et le dieu, nécessitent une spécialisation et sont confiés à des familles sacerdotales ou des individus sélectionnés pour leurs capacités : c'est le cas des mystères, des oracles ou des rituels impliquant la transe.

12 Toutes ces composantes de la vie religieuse de l'Antiquité grecque trouvent une expression particulière dans le cadre des colonies, dont Crotone est un exemple. La plupart des récits de fondation insistent sur l'autorité divine, origine et garantie de ces nouvelles implantations: dans le cas de Crotone, comme dans une grande majorité d'exemples, c'est l'oracle d'Apollon à Delphes qui envoie Myscellos fonder la cité, en lui fournissant les indices nécessaires à la localisation de la nouvelle fondation. En tant que sanctuaire panhellénique, Delphes représente un des points focaux de la culture religieuse de la Grèce ancienne. Échappant au contrôle d'une cité particulière, ce sanctuaire unanimement reconnu offre à tous une égalité de statut devant la divinité : chaque cité vient y afficher son identité propre, ses particularités locales, tout en 
participant à la création d'une culture unifiée et commune. Par l'entremise de l'oracle delphique, la légitimité d'une fondation nouvelle est ainsi assurée et acceptée par tous ceux qui reconnaissent Apollon comme dieu. À Crotone, le trépied delphique représenté sur les monnaies de la cité est peut-être bien le rappel de cette légitimité religieuse.

13 Mais l'installation d'une colonie suppose encore une réflexion urbanistique, sociale et religieuse de la part de ses fondateurs. Comment va-t-on répartir les espaces dans cette nouvelle cité ? Où implanter les sanctuaires intra et extra muros et à quelles divinités les consacrer? Quels rites fonder? Questions que l'on ne se posait pas dans une cité au passé immémorial et aux structures bien en place de longue date. Fonder une colonie pose ainsi des problèmes nouveaux, en termes cultuels comme en bien d'autres domaines: que va-t-on importer, que va-t-on inventer, que va-t-on emprunter aux populations locales?

14 À ces questions que devaient résoudre les colons s'ajoutent nos questions d'archéologues modernes : Héra, Apollon, Athéna, Héraclès, Hermès sont bien attestés à Crotone mais de quelle Héra, de quel Apollon s'agit-il ? Que nous disent les épithètes d'Héra Lacinia ou d'Apollon Alaios, tous deux honorés dans des sanctuaires extraurbains ? Est-ce bien une Héra qui, dans un autre sanctuaire extra muros, préside à la libération d'esclaves ou de prisonniers, et si oui, pourquoi elle? Les sanctuaires extraurbains qui jalonnent le paysage et régissent le territoire de Crotone sont-ils en relation rituelle ou processionnelle avec d'autres sanctuaires situés dans l'enceinte de la cité ? Que doivent les cultes de Crotone à la religiosité des premiers habitants de la région? Si l'on constate le plus souvent un lien manifeste entre les cultes de la cité ou de la contrée d'origine des colons et ceux de sa colonie, l'implantation d'une cité grecque dans une région peuplée d'autochtones aux coutumes cultuelles propres donne toutes sortes d'adaptations et de compromis qui révèlent bien des choses sur les fondements d'une nouvelle communauté. Qui se cache donc derrière ces dieux aux noms grecs honorés dans des écrins architecturaux grecs ? C'est en cela, entre autres, qu'étudier les dieux de Crotone se révèle un défi passionnant!

\section{BIBLIOGRAPHIE}

L. BRUIT, P. SCHMITT-PANTEL, La Religion grecque, Paris, 2007 (1 ère éd. 1989).

P. BRULÉ, La Cité grecque à l'époque classique, Rennes, 1994 (chapitre 9 : la religion, p. 169-185).

M. JOST, Aspects de la vie religieuse en Grèce : du début du $V^{e}$ siècle à la fin du III siècle avant J.-C,

Paris, 1992.

J. D. MIKALSON, La Religion populaire à Athènes, Paris, 2009 (éd. originale anglaise, North Carolina

Press, 1983).

V. PIRENNE-DELFORge (éd.) Les Panthéons des cités grecques des origines à la Périégèse de Pausanias, Revue Kernos 11, 1998 ( $1^{\text {ère }}$ partie) ; Kernos supplément 8, Liège, 1998 (2 ème partie). 
P. REICHERT-SÜDBECK, Kulte von Korinth und Syrakus. Vergleich zwischen einer Metropolis und ihrer Apoikia, Dettelbach, 2000.

\section{AUTEUR}

ANNE-FRANÇOISE JACCOTTET

Université de Genève 


\title{
La monnaie de Crotone
}

\author{
Matteo Campagnolo et Virginie Nobs
}

\section{Témoignages d'une cité puissante}

1 Par son abondance et sa richesse en types et en variantes, le monnayage de Crotone reflète le statut de puissance régionale - politique et économique - atteint par la cité à la fin de l'époque archaïque.

2 Les choix iconographiques véhiculés par la monnaie fournissent de nombreuses informations sur la religion de Crotone. Cet apport de la monnaie a constitué et constitue toujours pour les archéologues un guide précieux dans le progrès de la connaissance de la cité, encore méconnue avant les dernières campagnes de fouilles.

3 Les premières frappes de Crotone sont à placer vers 530 avant J.-C. Elles sont à peu près contemporaines de celles des autres grandes villes de la région, Métaponte et Sybaris. Ces cités commencent à battre monnaie environ une génération après les débuts de la monnaie à Athènes.

4 Les frappes de ces colonies achéennes de Grande Grèce ont une particularité commune et immédiatement reconnaissable, dont l'origine demeure mystérieuse (fig. 1) : le sujet représenté au droit - nommé type du droit ou d'avers - est repris au revers, où il se présente en creux et non en relief. 
1. Monnaie crotoniate incuse, droit et revers, avec représentation du trépied

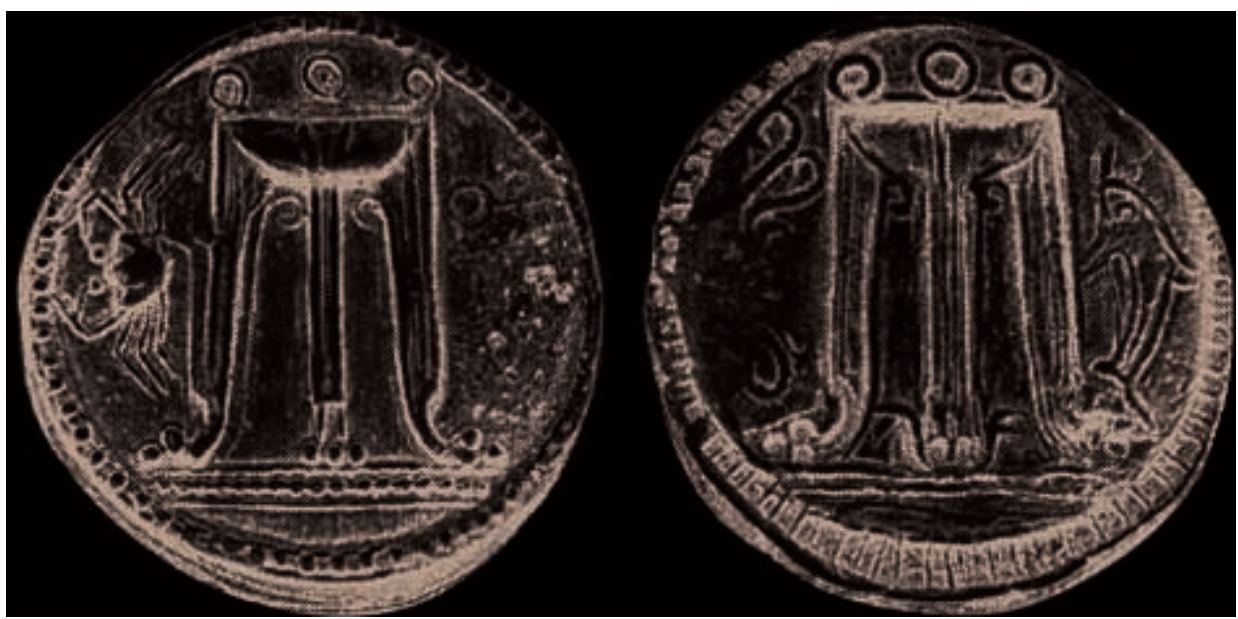

Dernier tiers du Vle siècle avant J.-C.

(c) Surintendance pour le patrimoine archéologique de la Calabre

On nomme ce phénomène type incus. Il ne s'agit pas simplement du négatif de la face principale, visible à travers la monnaie, mais d'une face obtenue par l'utilisation d'un second coin travaillé en relief et non en creux. Quand on sait que ces cités frappaient en suivant le même étalon monétaire, l'étalon achéen de $8 \mathrm{~g}$, on comprend qu'une sorte d'union monétaire devait lier ces monnayages. Cette relation devait être très similaire à l'Union latine du XIX siècle, ou à l'euro d'aujourd'hui. Il s'agissait de monnayages tout à fait indépendants quant aux choix iconographiques et portant, bien qu'abrégé, le nom de la cité émettrice. Dans le cas de Crotone, le type caractéristique principal est le trépied delphique, et les lettres $\ \mathrm{PO}$, avec l'ancienne consonne qoppa, remplacée par le kappa à la fin $\mathrm{du} \mathrm{V}^{\mathrm{e}}$ siècle avant J.-C. Le revers incus se maintint sur la monnaie de Crotone pendant un siècle environ.

6 L'interprétation de l'iconographie monétaire de Crotone connaît deux courants principaux. Les savants français du XIX ${ }^{\mathrm{e}}$ siècle y voyaient l'affirmation de l'influence de la philosophie pythagoricienne sur la société crotoniate alors que l'école anglaise préfère y reconnaître l'importance donnée par les cités de Grande Grèce aux concours athlétiques. Ces derniers constituaient à la fois une affirmation de l'appartenance des colonies à l'Hellade et de leur puissance, par le nombre de victoires remportées. Alors que la théorie pythagoricienne est insuffisamment étayée par les textes antiques et les découvertes archéologiques, l'excellence des athlètes italiotes, notamment crotoniates, aux divers concours helléniques montre qu'il s'agissait d'un point fort, encouragé par les cités. Le meilleur exemple est Milon de Crotone, à qui l'on prête une trentaine de victoires aux divers jeux panhelléniques et qui joua par la suite un important rôle politique.

7 Le trépied des monnaies crotoniates a même été perçu par certains comme un substitut de l'Apollon de Delphes.

8 La variété des émissions est compliquée par la diversité des types de revers : trépied donc, mais aussi aigle en vol ou casque corinthien. Ces deux derniers ont été interprétés comme les marques des ateliers de Temesa et d'Hipponion, deux villes appartenant au territoire de Crotone. 
9 À partir de 425 avant J.-C., le monnayage de la cité a abandonné la singularité du revers incus. Héraclès (fig. 2-3) et Héra acquièrent alors une importance qui dépasse celle d'Apollon, pourtant représenté sur des statères de la fin du IV ${ }^{\mathrm{e}}$ siècle avant J.-C., et de l'aigle de Jupiter.

2 et 3 . Monnaies crotoniates, avec représentation d'Héraclès et d'Athéna
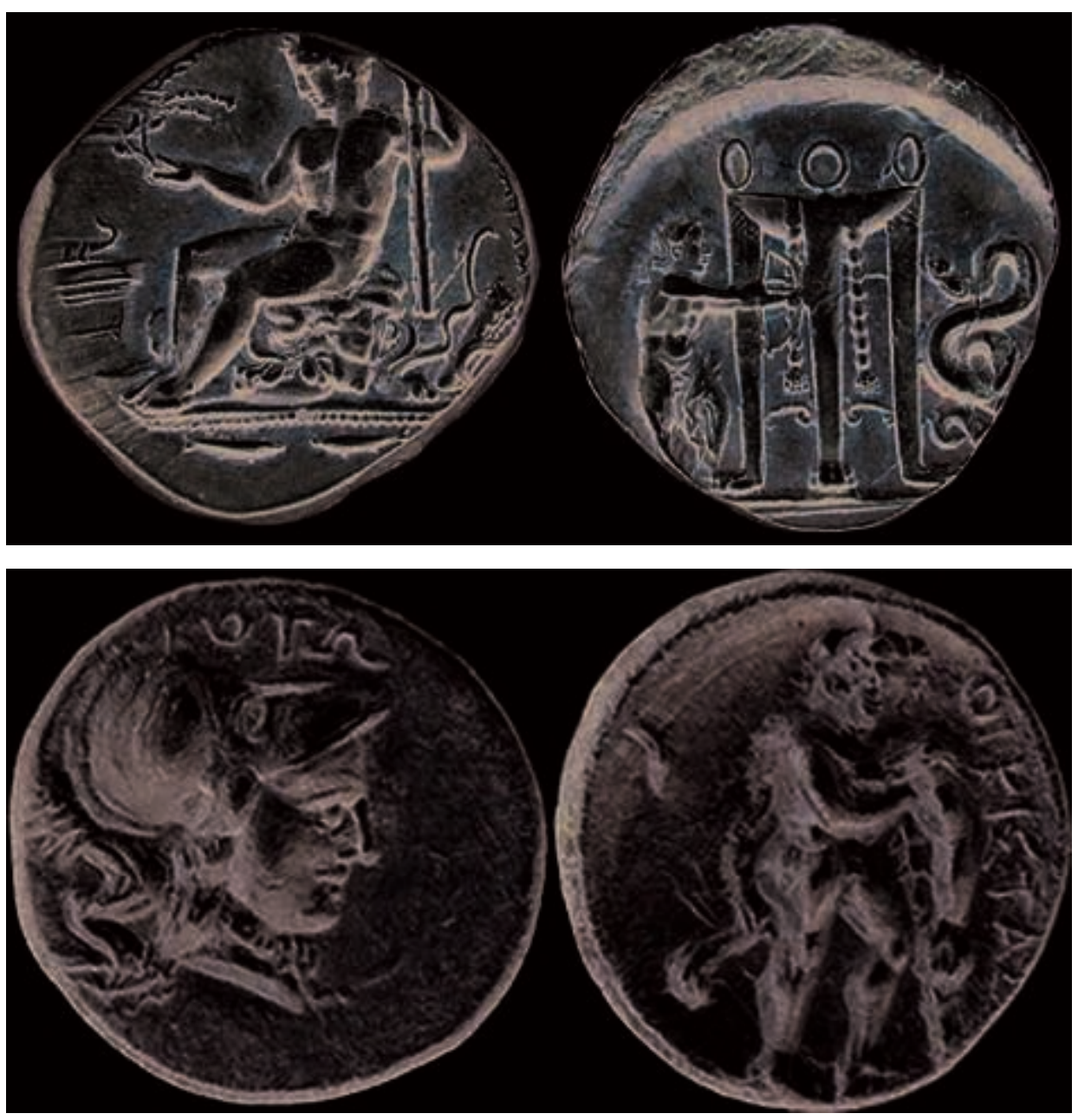

Ve siècle avant J.-C.

(c) Surintendance pour le patrimoine archéologique de la Calabre

10 Malgré une lente décadence, Crotone continua à frapper monnaie jusqu'à la prise de la ville par les Romains en 277 avant. J.-C., et même au-delà.

\section{BIBLIOGRAPHIE}

P. ATTIANESE, Kroton, le monete di bronzo, s.l.n.d., Rubbettino, 2005

N. K. RUTTER (dir.), Historia numorum Italy, Londres, 2001. 
C. M. KRAAY, Archaic and classical Greek coins, Londres, 1976.

B. V. HEAD, Historia numorum. A manual of Greek numismatics, Oxford, 1911.

\section{AUTEURS}

\section{MATTEO CAMPAGNOLO}

Musée d'Art et d'Histoire de Genève

VIRGINIE NOBS

Université de Genève 


\title{
Trois sanctuaires extra-urbains
}

\author{
Lorenz E. Baumer
}

$1 \quad$ L'image de la vie religieuse d'une cité grecque serait incomplète si le regard ne portait que sur les sanctuaires situés à l'intérieur de la ville. Un grand nombre de sites cultuels étaient à l'extérieur de l'enceinte urbaine où ils assuraient, à des niveaux bien différents, le lien entre les hommes et les dieux. Il faut tout d'abord considérer que le territoire extra-urbain d'une cité était couvert de petits sanctuaires, désignés d'habitude comme des "sanctuaires ruraux" qui répondaient aux besoins de la population locale. Le petit sanctuaire du Timpone del Gigante, situé dans l'arrière-pays de Crotone à une hauteur de $1090 \mathrm{~m}$ au-dessus de la mer en est un exemple parmi d'autres. Le matériel archéologique, récupéré en 1974 et actuellement en cours d'étude, comprend une bonne centaine de vases miniatures de la deuxième moitié du $\mathrm{VII}^{\mathrm{e}}$ et du $\mathrm{VI}^{\mathrm{e}}$ siècle avant J.-C. (fig. 1), alors qu'aucune structure architecturale n'a été dégagée ${ }^{1}$. La divinité honorée dans ce petit sanctuaire local reste - comme c'est souvent le cas pour les sanctuaires ruraux - pour l'instant inconnue. 


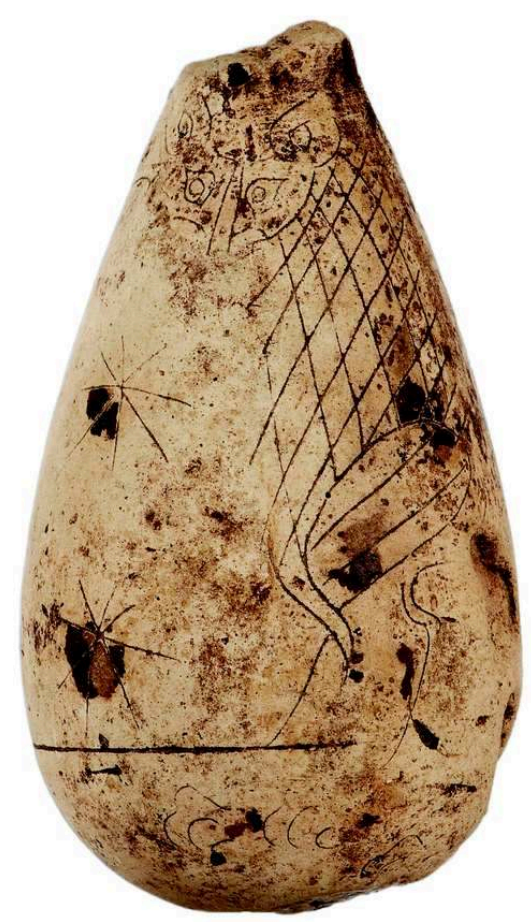

(c) J. Zbinden, université de Berne

2 Les sanctuaires extra-urbains qui nous intéressent ici sont autrement plus grands. Le plus important centre religieux de Crotone était en effet le sanctuaire d'Héra Lacinia, situé à environ dix kilomètres au sud-ouest de la ville sur le Capo Colonna qui offre une vue assez spectaculaire sur la baie de Crotone (fig. 2). Au IV siècle avant J.-C., il servait en outre de lieu de réunion de la Ligue italiote. À l'autre extrémité du territoire de la cité, une bonne quarantaine de kilomètres au nord-est de Crotone, à Punta Alice, près de la ville moderne de Cirò Marina et à une courte distance de l'antique Krimissa, se trouve le temple d'Apollon Alaios dont nous parlerons plus bas. 


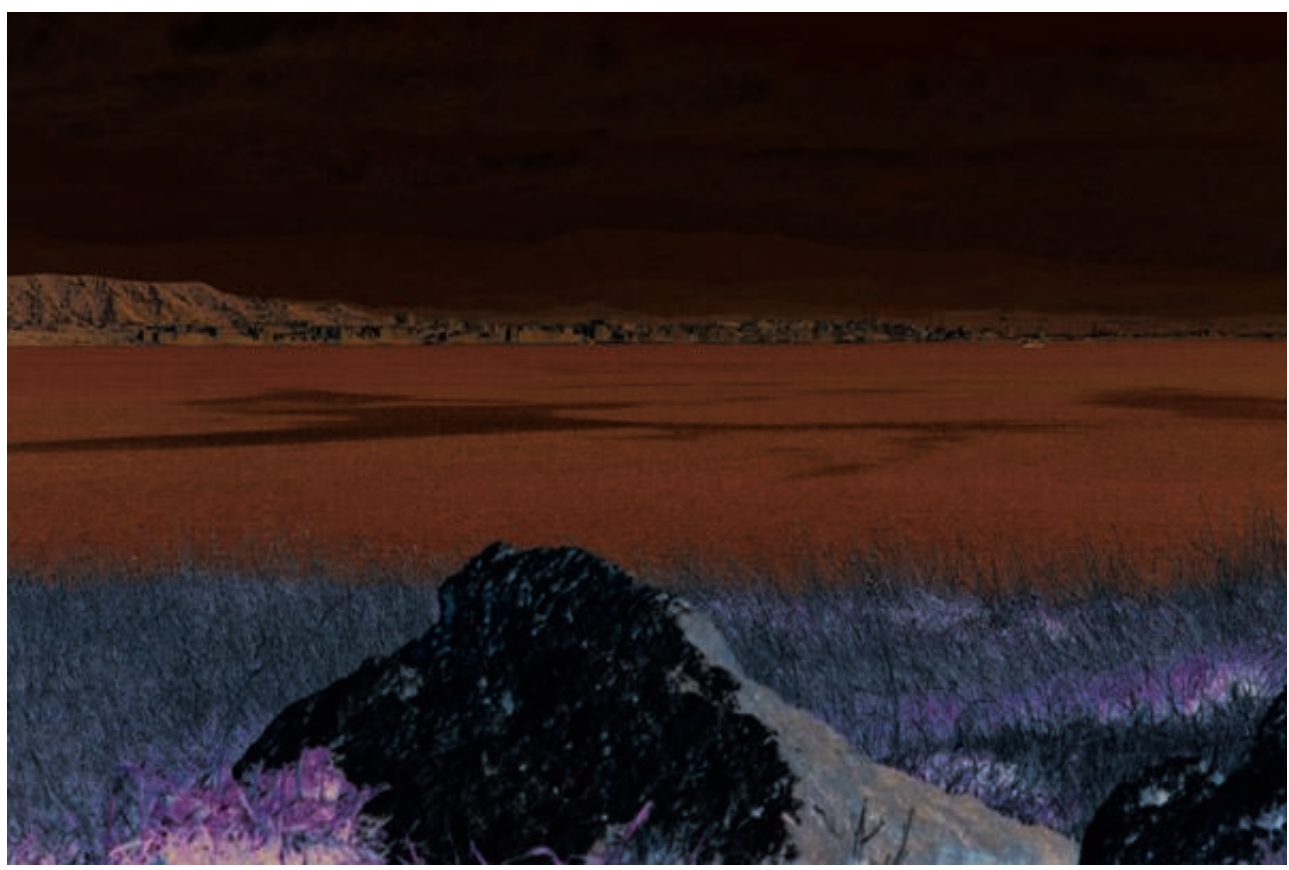

(c) J. Zbinden, université de Berne

\section{Le sanctuaire d'Héra Lacinia}

Située sur le promontoire du Capo Colonna et visible de loin, la seule colonne encore debout du temple d'Héra Lacinia sert jusqu'à nos jours de point de repère important pour la navigation entre Tarente et la pointe Stilo (fig. 3$)^{2}$. Le monument a attiré depuis longtemps l'intérêt des voyageurs et des chercheurs et il est ainsi devenu le symbole de la Crotone antique. En 1767, le baron allemand Johann Hermann von Riedesel (1740-1784) a rédigé à l'occasion de son voyage en Sicile et en Grande-Grèce pour son ami Johann Joachim Winckelmann (qu'on désigne souvent comme le «fondateur » de l'archéologie classique moderne) une première description précise des vestiges du temple.

\section{Le baron Johann Hermann von Riedesel à Capo Colonna (1767)}

Capo Colonna est le Promontorium Lacinium, proche Crotone, sur lequel étoit bâti le fameux temple de Junon Lacinie, dont il s'est conservé des débris assez considérables. Ce temple étoit du même ancien ordre dorique que ceux de Pestum, de Girgenti [Agrigente], etc. Sa largeur est de soixante-six de mes pas, et sa longueur de cent trente-deux, cette mesure approchante suffit pour vous faire juger qu'il étoit d'une belle grandeur. Il subsiste encore d'un côté une partie des murs de la nef, auxquels j'ai observé comme une chose fort singulière qu'ils étoient construits par lits qui sont alternativement en pierres et en briques. Le premier lit est en pierres; il a sept palmes et demi de haut; le second que je n'ai pu mesurer à cause de son élévation est d'ouvrage réticulaire de briques. Il est clair qu'on a voulu par là donner plus de légèreté à ces murs. Je ne vous dirai point si à ce lit de briques, il en succédoit un de pierres, ou si l'ouvrage réticulaire continuoit dans tout le reste de la hauteur du mur; il ne s'en est pas assez conservé pour en juger : cependant, ce dernier sentiment me paroît le plus vraisemblable, parce qu'un nouveau lit de pierres auroit enfoncé les briques. Ce temple, comme tous ceux qui 
ont été bâtis par les Grecs, est tourné vers le levant, et l'on y entroit du côté du couchant. Il n'existe plus qu'une seule colonne de tout l'édifice ; elle faisoit partie de la colonnade qui passoit derrière la nef ; l'ordre de cette colonne est, comme j'ai déjà dit, d'ancien dorique, sans base. Elle n'a de remarquable que sa petitesse en proportion de la grandeur du temple, de plus, elle n'a que vingt cannelures au lieu de vingt-une qu'on trouve à toutes les autres colonnes de cet ordre ; c'est un fait que je puis affirmer et constater, ayant compté moi-même ces cannelures à trois ou quatre reprises. On montoit à ce temple par quatre marches, et l'on en descendoit par quatre autres. Encore une particularité de ce même temple, c'est que la nef en étoit enfoncée de quatre marches, chacune d'un palme et demie de Naples de hauteur.

Le pavé de la nef est couvert de terre, qu'on pourroit aisément déblayer, ce qui serviroit à reconnoître plus facilement la forme de l'édifice; à moins que ce pavé n'eût déjà été détruit, car il n'y a que très-peu de tems que cette terre a été jetée dans cet endroit, lorsqu'on fit la belle opération de déterrer les gradins des faces latérales du temple ; non point, comme vous pourriez l'imaginer, pour les voir et les mettre à découvert, mais pour les enlever et les employer à la construction du nouveau port de Crotone. M'étant plaint à l'ingénieur de ce port, il crut me calmer, en me disant qu'on en voyoit assez dans ce qu'il restoit du posticon, pour se dispenser de conserver le reste du temple. La situation de ce temple est tout ce qu'on peut imaginer de plus admirable pour un pareil édifice. Le promontoire sur lequel il est bâti s'étend à huit milles dans la mer, et l'on jouit de chaque côté de la vue d'un golphe et de celle de la vaste étendue de pays qui embrasse chacun de ces golphes. Il est vraisemblable que la ville entière de Crotone étoit située dans ce même endroit, à en juger du moins par la quantité de vestiges de tombeaux et de maisons qu'on y trouve ; mais ils sont dans un état de dégradation si complet, qu'il n'est pas possible d'y rien reconnoître.

Je cherchai dans ce même emplacement ce qu'on nomme l'école de Pythagore (Scuola Pythogorica), dont j'avois oui parler, et dont il se trouvoit encore, me disoiton, des traces très-apparentes : toutes mes recherches ayant été vaines, et après les informations plus exactes que je pris à Crotone, je découvris l'erreur qui a donné lieu à cette conjecture. On s'est représenté le temple dont je viens de vous parler pour beaucoup plus petit qu'il n'a été, on l'on a pris les murs de la nef pour un bâtiment particulier; alors il a nécessairement fallu que ce fut là l'école de Pythagore, parce qu'on sait que ce philosophe a enseigné à Crotone. On pourroit tout aussi aisément faire voir la maison de l'athlète Milon, qui étoit crotoniate.

Voyages en Sicile, dans la Grande Grèce et au Levant par le Baron de Riedesel; suivis de l'histoire de la Sicile par le Novaïri, Paris, chez H. J. Jansen, 1802, p.151-154.

4 Les informations données par Riedesel souffrent du fait qu'il a, par inadvertance, interprété le mur d'enceinte romain comme faisant partie du temple, ce qui explique les dimensions immenses qu'il lui donne : « sa largeur est de soixante-six de mes pas, et sa longueur de cent trente-deux » (environ 56 x $112 \mathrm{~m}$ ), s'étonnant en même temps au sujet de la colonne de sa « petitesse en proportion de la grandeur du temple ». 


\section{La colonne du temple d'Héra Lacinia à Capo Colonna}

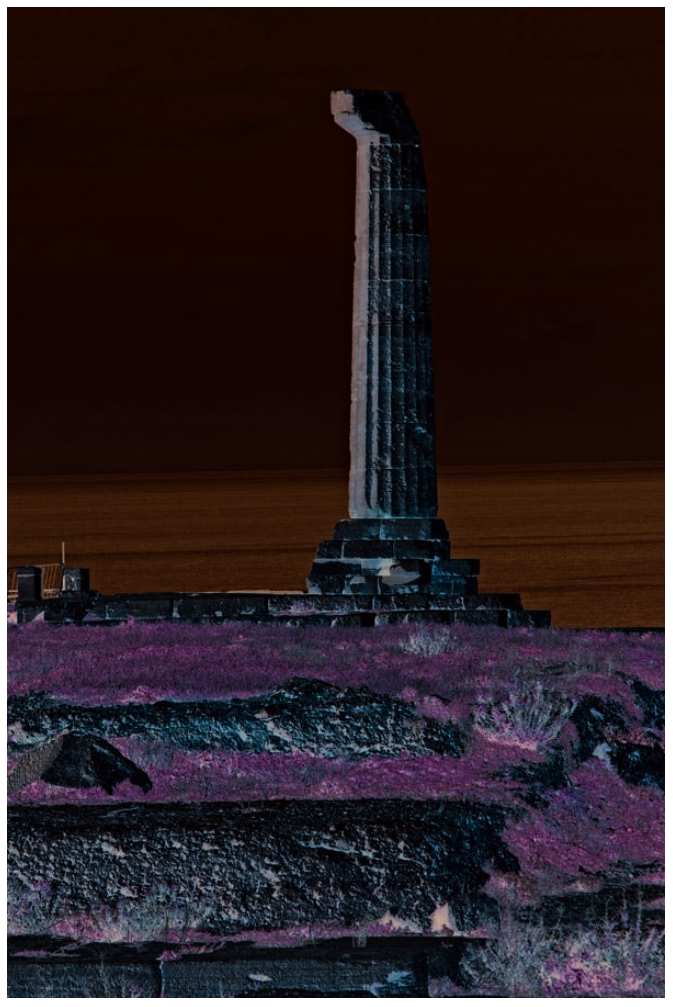

(c) J. Zbinden, université de Berne

5 De décembre 1886 à janvier 1887, les Américains Joseph T. Clarke et Alfred Emerson entreprirent les premières fouilles dont les résultats n'ont malheureusement jamais été publiés, et, en 1899, l'architecte Robert Koldewey et l'archéologue Otto Puchstein publièrent les premiers relevés du temple. Une décennie plus tard, de nombreux sondages permirent à Paolo Orsi de mieux définir l'extension du sanctuaire et de préciser partiellement le plan et le décor du temple. Des fouilles plus récentes ont en outre mis au jour plusieurs autres bâtiments ainsi qu'une partie de la voie sacrée (fig. 4). 
4. Plan du sanctuaire d'Héra Lacinia, avec l'enceinte romaine (" cinta muraria »), le temple d'Héra (" tempio A »), le bâtiment B (" edificio B »), la voie sacrée (" via sacra ») et les deux édifices pour les pèlerins (" edificio $\mathrm{H}$ » et " edificio $\mathrm{K}$ »). Au nord les maisons romaines.

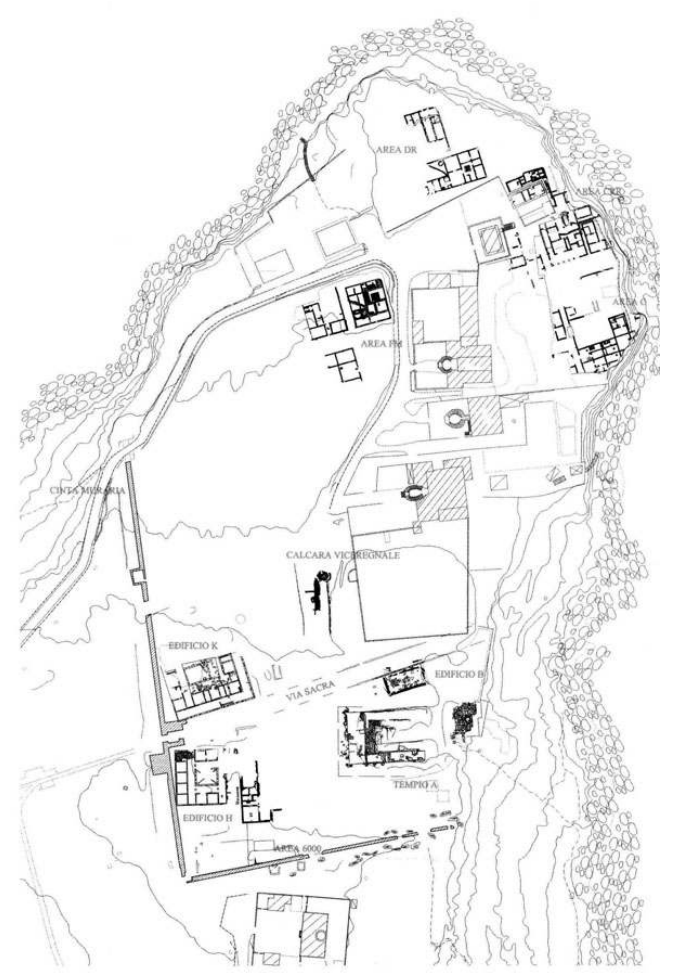

D'après R. Spadea (dir.), Ricerche nel santuario di Hera Lacinia a Capo Colonna di Crotone. Risultati e prospettive, Rome, 2006, p. 16, fig. 5.

6 Mais ce ne sont pas seulement les fouilles archéologiques qui nous renseignent sur le développement de ce lieu de culte important et monumental. L'historien romain TiteLive ne se contente pas de mentionner un bois sacré ainsi qu'un autel miraculeux dans le vestibule du temple où les vents ne soulevaient jamais la cendre des sacrifices (Histoire romaine 24,3,1-7) ; il raconte aussi qu'en 173 avant J.-C., le censeur Q. Fulvius Flaccus fit bâtir à Rome un temple de la Fortune équestre et qu'il aurait démonté pour ce faire le toit en marbre du temple d'Héra Lacinia. Même si Flaccus essaya de dissimuler l'origine des précieuses tuiles, le sacrilège fut découvert, et Flaccus dut les restituer. Mais comme manquaient à Crotone "des ouvriers capables de les replacer » (Tite-Live, Histoire romaine 42,3,1-10), le matériel fut tout simplement déposé dans le sanctuaire, sans qu'on en ait retrouvé trace à ce jour, à l'exception de quelques petits fragments de la décoration. D'après le récit de Tite-Live, il faut partir du principe que le temple d'Héra était au plus tard à partir de ce moment crucial de son histoire partiellement en ruine, même s'il semble toujours avoir servi à un modeste culte ${ }^{3}$.

7 Le temple, un périptère dorique de 6 colonnes sur 13 ou 15 sur ses côtés, a été érigé au deuxième quart du $\mathrm{v}^{\mathrm{e}}$ siècle avant $\mathrm{J}$.-C. Le chapiteau de la seule colonne encore en place, haute de $8,3 \mathrm{~m}$, présente une parenté chronologique et stylistique étroite avec le temple d'Athéna de Syracuse, ce qui pourrait indiquer que le temple a été construit sous la direction d'un architecte sicilien. La plus grande partie de l'architecture et de la décoration du temple est aujourd'hui perdue, mais l'inclinaison légère de la colonne $(6,7 \mathrm{~cm}$ vers l'ouest et $3 \mathrm{~cm}$ vers le sud) indique au moins que son socle était légèrement courbé pour harmoniser son apparence, comme c'est aussi le cas pour d'autres temples 
doriques de l'époque classique. Quelques éléments conservés de sa décoration ont de plus permis de reconstituer le profil de l'entablement (fig. 5), alors qu'il n'est pas sûr que des fragments de sculptures trouvés dans les environs du temple aient vraiment appartenu, comme on l'a proposé, à la décoration des frontons ${ }^{4}$.

5. Restitution de l'entablement du temple classique d'Héra Lacinia à Capo Colonna

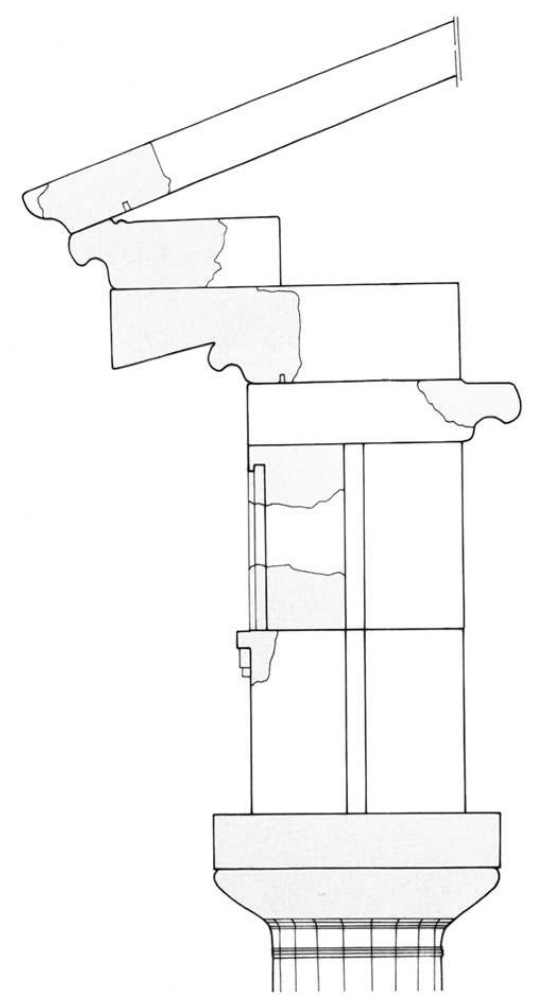

D'après R. Spadea (dir.), Ricerche nel santuario di Hera Lacinia a Capo Colonna di Crotone. Risultati e prospettive, Rome, 2006, p. 43, fig. 32.

Quelques blocs réutilisés dans les fondations du temple classique et des fragments d'un toit de grandeur importante ont amené l'architecte allemand Dieter Mertens à supposer sur ce même emplacement un temple antérieur, construit vers 540/30 avant J.-C. Mais des sondages archéologiques effectués en 2003 n'ont pas permis de confirmer cette hypothèse, et il faut pour l'instant partir du principe que ce premier temple d'époque archaïque se trouvait ailleurs dans le sanctuaire et qu'il n'est pas encore localisé.

Une autre question pendante est l'emplacement de l'autel, le véritable centre du sanctuaire, dont on n'a pas trouvé à ce jour la moindre trace ${ }^{5}$.

Mais l'histoire du sanctuaire d'Héra Lacinia commence bien avant. Sous le «bâtiment B », situé à côté du temple, ont été trouvées en 1987 les plus anciennes traces d'occupation du site, datant du début du viI ${ }^{\mathrm{e}}$ siècle avant J.-C., suivies un siècle plus tard par la construction d'un premier bâtiment. Durant la première moitié du ve $\mathrm{s}$., le «bâtiment $\mathrm{B}$ " a été reconstruit à deux reprises avant d'être définitivement abandonné vers le milieu du même siècle. Il s'agit d'un simple oikos de $22 \mathrm{~m}$ sur 9 , comprenant à l'arrière un socle fait de 16 blocs dont la fonction est inconnue (fig. 6). On a aussi trouvé à l'intérieur du "bâtiment B » plusieurs tambours de colonnes ainsi qu'un nombre important de dédicaces en céramique et en métal : nous ne mentionnons 
ici qu'une couronne en or et un modèle de bateau nuraghe en bronze, exposés au Musée archéologique national de Crotone.

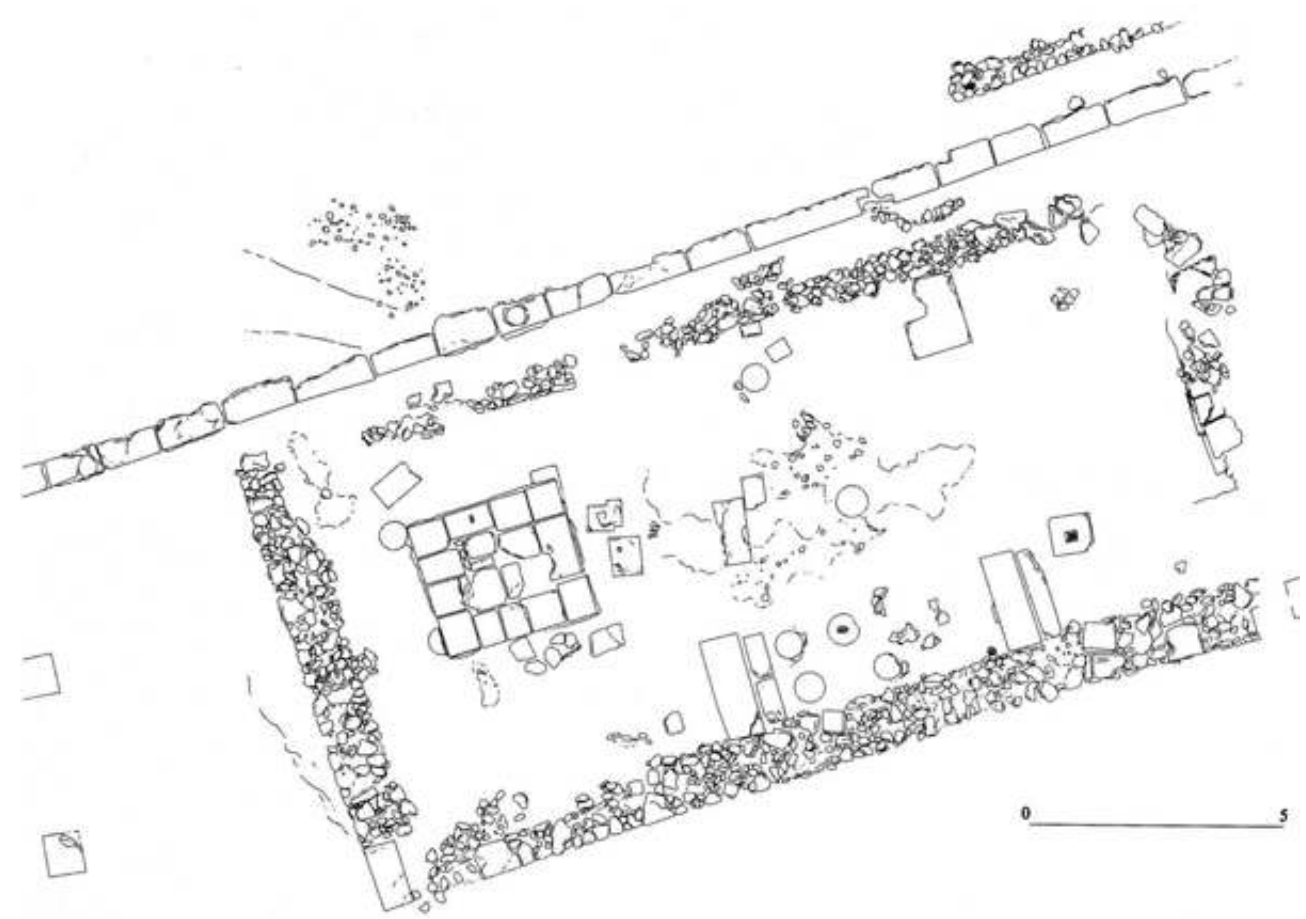

D'après R. Spadea (dir.), Ricerche nel santuario di Hera Lacinia a Capo Colonna di Crotone. Risultati e prospettive, Rome, 2006, p. 22, fig. 13a.

11 À côté du "bâtiment $\mathrm{B}$ " a été aussi découverte une partie de la voie sacrée, large de $8 \mathrm{~m} 50$ et dégagée par les archéologues sur une longueur de $58 \mathrm{~m}$. Sa construction, qui respecte l'orientation du « bâtiment $\mathrm{B}$ », date du premier quart du v viècle avant J.-C.

Des fragments de plusieurs toits, datant du milieu du vi jusqu'au $\mathrm{V}^{\mathrm{e}}$ siècle, indiquent que devaient exister aux époques archaïque et classique d'autres constructions encore à l'intérieur du sanctuaire dont nous ne connaissons ni les plans ni l'emplacement précis. Dans la deuxième phase importante au $\mathrm{IV}^{\mathrm{e}}$ siècle avant $\mathrm{J}$.-C., on a construit à environ $50 \mathrm{~m}$ à l'ouest du temple deux bâtiments qui servaient probablement aux pèlerins (fig. 4). Il s'agit des bâtiments $\mathrm{H}$ et $\mathrm{K}$, d'après la nomenclature des archéologues, dont le premier, de $26,30 \mathrm{~m}$ sur $29 \mathrm{~m}$, comprenait autour d'un péristyle central 14 chambres carrées de 4,75 m sur 4,76 m, qu'on peut identifier sans difficultés comme des salles de banquets. Alors que le «bâtiment $\mathrm{H}$ » correspond dans son orientation au temple d'Héra, son voisin, le « bâtiment $\mathrm{K}$ », s'aligne sur la voie sacrée. Il mesure $38 \mathrm{~m}$ sur 34 et il est bordé sur ses côtés sud et est d'une colonnade en forme de L. Son plan avec la cour péristyle centrale rappelle par exemple le léonidaion d'Olympie, ce qui permet de l'identifier comme un katagogion, une auberge de pèlerins. On suppose d'habitude que ces deux bâtiments sont restés en service au moins jusqu'à la fin du III siècle avant J.-C., peut-être même encore plus longtemps, parce que le mur d'enceinte construit à la fin de la République romaine respecte les deux bâtiments. crucial dans la vie du sanctuaire, mais elle ne mit pas fin à la vie au Capo Colonna. 
L'installation du mur d'enceinte déjà mentionné mise à part, les fouilles archéologiques ont dégagé dans la zone nord du promontoire un certain nombre de maisons romaines ainsi qu'un balneum. Ces petits thermes sont décorés au centre avec une belle mosaïque montrant dans un cadre de méandre quatre dauphins ainsi qu'une inscription qui nous informe que deux magistrats, les duoviri quinquennali Lucilius Macer et T. Annaeus Thraso, étaient les responsables de l'installation. Le nombre de constructions romaines a suscité l'hypothèse que l'ancienne ville de Crotone aurait été entièrement abandonnée au $\mathrm{II}^{\mathrm{e}}$ siècle avant J.-C. et que les habitants se seraient installés au Capo Colonna qui correspondrait à ce moment à la colonie romaine de Crotone dont nous parle Tite-Live (Histoire romaine 44,45,4-5). Mais en l'absence d'autres bâtiments publics et au vu de notre connaissance archéologique très rudimentaire de la ville antique de Crotone, cette proposition n'est pas encore définitivement prouvée.

À ce jour, et pas seulement pour l'époque romaine, le Capo Colonna et le sanctuaire d'Héra Lacinia gardent une bonne partie de leur mystère.

\section{Le sanctuaire d'Apollon Alaios}

15 Le sanctuaire d'Apollon Alaios, où ont été déposés après la victoire de Crotone sur Sybaris en 510 avant J.-C., l'arc et les flèches d'Héraclès, marque la limite nord-est du territoire de la cité de Crotone (fig. 7). En comparaison avec le sanctuaire d'Héra Lacinia au Capo Colonna, centre religieux d'importance pour l'ensemble de la Grande Grèce au $\mathrm{IV}^{\mathrm{e}}$ siècle avant $\mathrm{J} . \mathrm{C}$., le sanctuaire d'Apollon se présente de manière bien différente : il est un creuset de la fusion des cultures grecques et italiotes qui se rencontraient à l'arrivée des Grecs en Italie du Sud.

7. Vue du temple d'Apollon Alaios

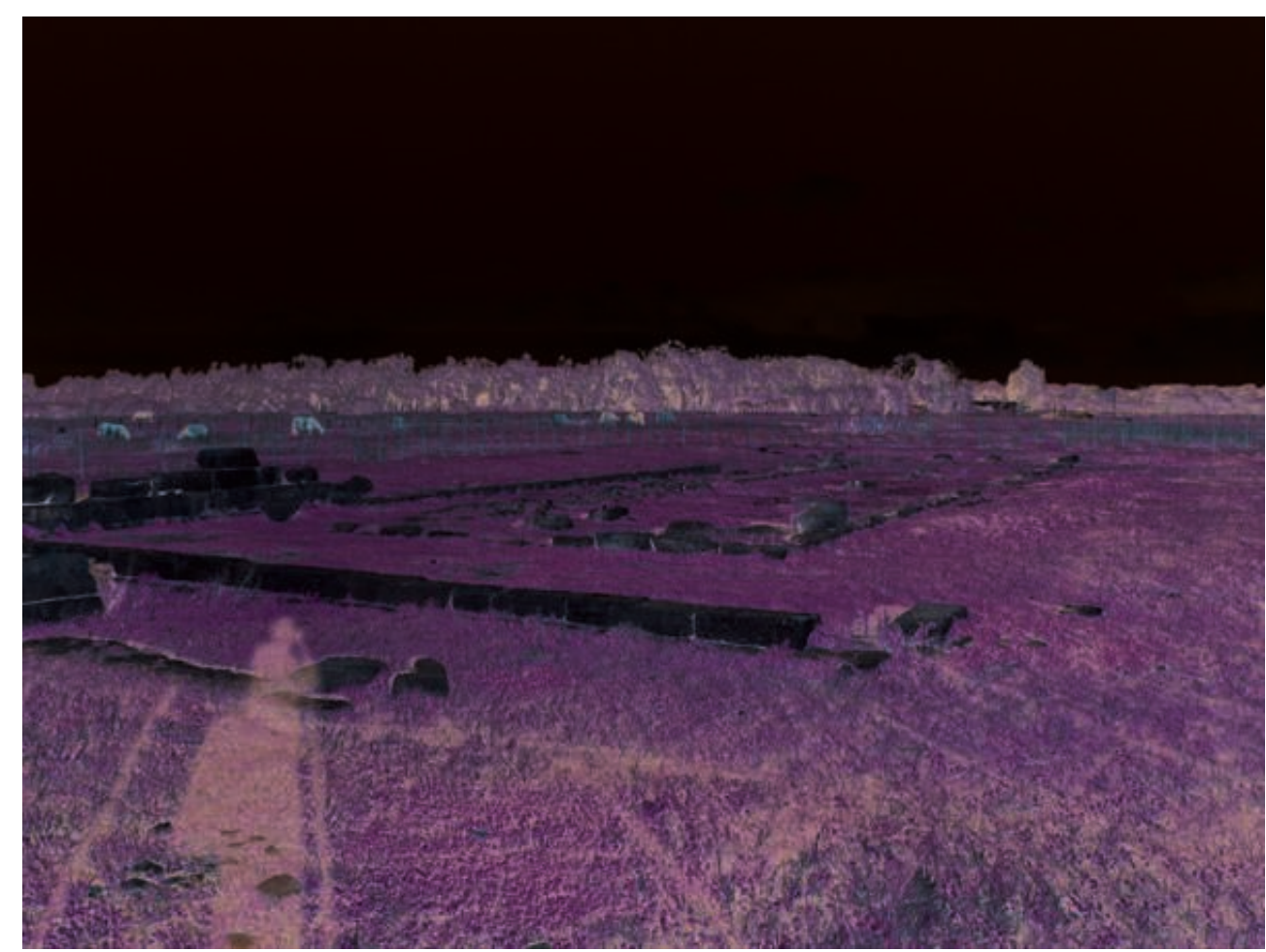

(c) L. E. Baumer 
Les fouilles de Paolo Orsi ont mis au jour les fondations d'un temple dont la première phase de construction remonte à la deuxième moitié du VIe siècle avant J.-C. (fig. 8). Il s'agit d'un bâtiment avec une cella de $27 \mathrm{~m}$ sur 7,90, entièrement ouverte vers l'est et avec un adyton qui occupait un quart de la partie arrière. Les parois, élevées en briques crues, reposaient sur une fondation de calcaire, et une colonnade centrale portait le poids du toit. À l'extérieur, le bâtiment a été entouré par un péristyle de 7 sur 15 colonnes en bois qui reposaient sur des bases en pierre.

\section{Plan de fouilles du temple d'Apollon Alaios}

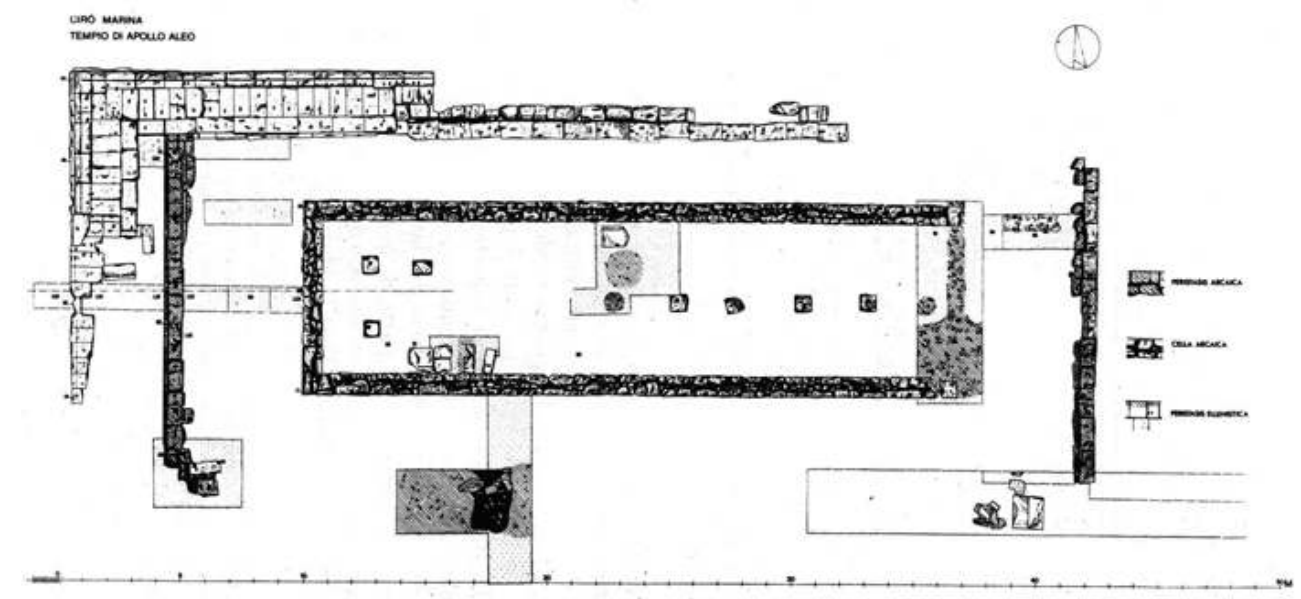

D'après D. Mertens, «I santuari di Capo Colonna e Crimisa: Aspetti dell'architettura crotoniate », dans Crotone. Atti del ventitreesimo convegno di studi sulla Magna Grecia, Taranto, 7-10 ottobre 1983, Tarente, 1984, p. 209, fig. 3.

Le plan du temple, qui reprend un ancien modèle qu'on retrouve - mais un siècle plus tôt ! - en Grèce (par exemple à Thermos, temple C), ne s'inscrit pas facilement dans la tradition de l'architecture grecque de la Grande Grèce et de la Sicile, alors que les terres cuites qui décoraient son toit sortent sans doute d'un atelier de Crotone. Dieter Mertens a expliqué ce mélange de traditions par le fait que le temple d'Apollon était en réalité moins un sanctuaire qui marquait la frontière de la cité, qu'un point de focalisation où se rencontraient les Grecs et les indigènes.

$\mathrm{Au} \mathrm{V}^{\mathrm{e}}$ siècle avant J.-C., on a installé dans le temple une nouvelle statue de culte: le fameux acrolithe d'Apollon dont on parlera dans un chapitre ultérieur (voir l'article de Margherita Corrado et Domenico Marino). Il semble que le temple, qui a livré pendant les fouilles un très riche matériel votif, n'a plus connu à partir de ce moment de grands changements jusqu'à la fin du IV ${ }^{\mathrm{e}}$ siècle avant J.-C. ${ }^{6}$

Dans la première moitié du III siècle avant $\mathrm{J} .-\mathrm{C}$., le temple a été soigneusement démantelé et - y compris la statue d'Apollon - enterré sous une couche de sable, de terre et de débris en calcaire, avant qu'on commence la construction d'un nouveau temple à un niveau surélevé de $0,75 \mathrm{~m}$. Mais ce nouveau temple a su aussi garder ses particularités : il s'agit du seul temple périptère qui a été construit en Grande Grèce durant l'époque hellénistique, entouré d'après la reconstitution de Dieter Mertens d'une péristasis de 8 sur 19 colonnes (fig. 9-10). Il possédait de plus un proptéron, c'est-àdire une rangée de colonnes devant la cella qui semble avoir aussi gardé son plan étroit et allongé. Les fragments de l'entablement qui assurent d'après leurs détails stylistiques la datation hellénistique du monument, et les fondations conservées ont permis de 
reconstituer l'ensemble du temple, qui mesurait à la base des colonnes $16 \mathrm{~m}$ sur environ 42.

\section{9. Élévation (restitution) du temple d'Apollon Alaios de l'époque hellénistique}

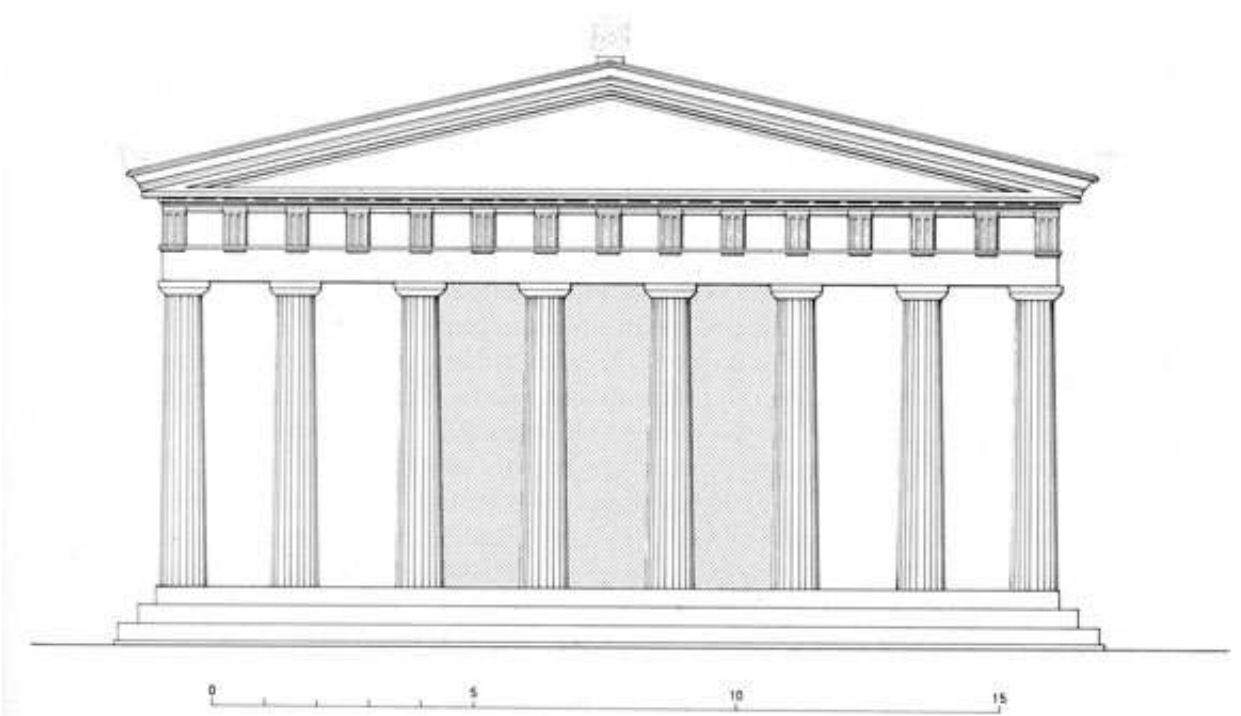

D'après D. Mertens, « Per l'architettura nel primo Ellenismo. Il tempio ed il santuario di Apollo Aleo a Cirò », dans M. L. Napolitano (dir.), Crotone e la sua storia tra IV e III secolo a.C., Naples, 1993, p. 77, fig. 10.

10. Plan restitué du temple d'Apollon Alaios de l'époque hellénistique
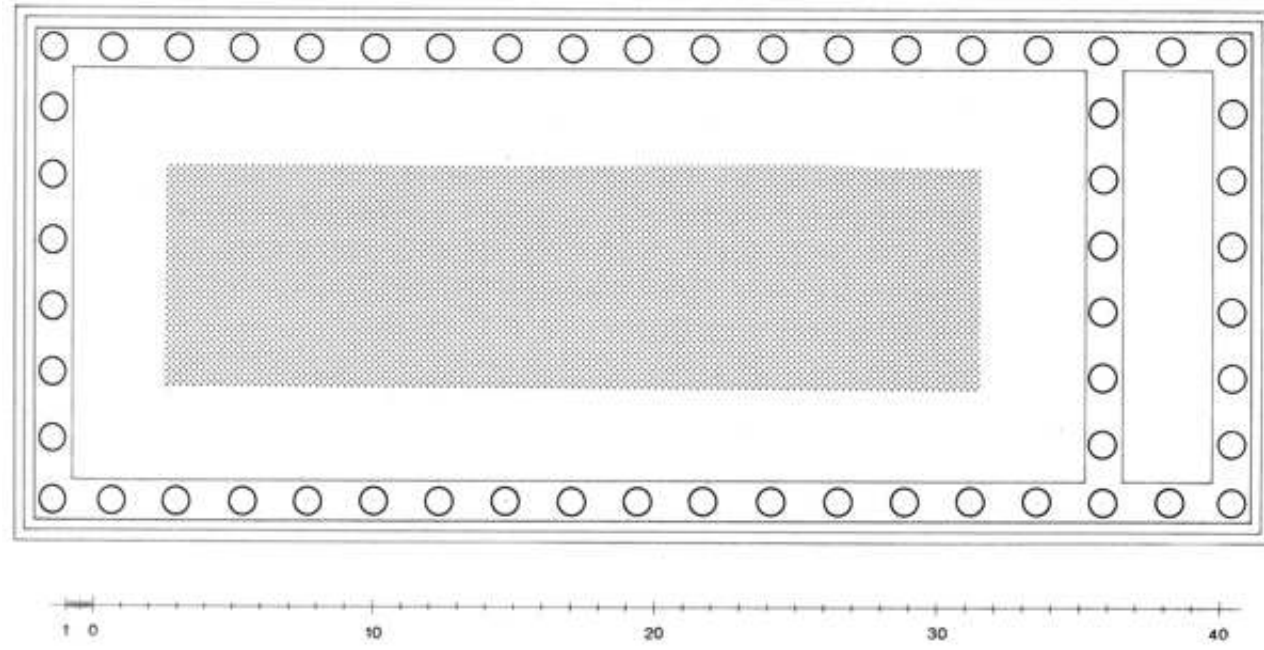

D'après D. Mertens, «Per l'architettura nel primo Ellenismo. Il tempio ed il santuario di Apollo Aleo a Cirò », dans M. L. Napolitano (dir.), Crotone e la sua storia tra IV III secolo a.C., Naples, 1993, p. 77, fig 11.

Les fouilleurs ont dégagé, plus près du temple, plusieurs fondations de bâtiments que Paolo Orsi a interprétés comme des maisons de prêtres. Un des bâtiments, mesurant $28,20 \mathrm{~m}$ sur 31,10 , comprend au moins quatre salles carrées et orientées vers une cour centrale à colonnes. Il semble naturel de l'interpréter plutôt comme une maison de banquets, comme on en retrouve aussi une à Capo Colonna (voir plus haut, \$10). Des autres structures du sanctuaire, rien n'est connu, et il manque aussi, comme dans le 
sanctuaire d'Héra Lacinia, toute trace de l'autel. À ce jour, le temple d'Apollon Alaios, lui aussi, n’a révélé qu'une partie de ses secrets.

\section{Le sanctuaire d'Héra de Vigna Nuova}

21 Au sens strict du terme, le sanctuaire de Vigna Nuova, situé dans le quartier industriel de la Crotone moderne, à quelques pas seulement de l'enceinte des murs de la ville antique, doit être identifié plutôt comme un sanctuaire suburbain qu'extra-urbain. Découvert en 1975 et mis au jour pendant plusieurs campagnes de fouilles jusqu'en 1993, les structures architectoniques se limitent à l'heure actuelle à un bâtiment rectangulaire dont la forme rappelle immédiatement celle du «bâtiment $B$ » du sanctuaire d'Héra Lacinia (voir plus haut, \$3). Mesurant 22,50 m sur 8,85, l'oikos de Vigna Nuova, qui est aussi dans ses dimensions très proche de son parent à Capo Colonna, comprend comme celui-ci dans sa partie est une structure rectangulaire de 2,10 m sur 2,09 - dont la fonction précise reste de nouveau énigmatique (fig. 11).

\section{Planimétrie de l'oikos de Vigna Nuova}

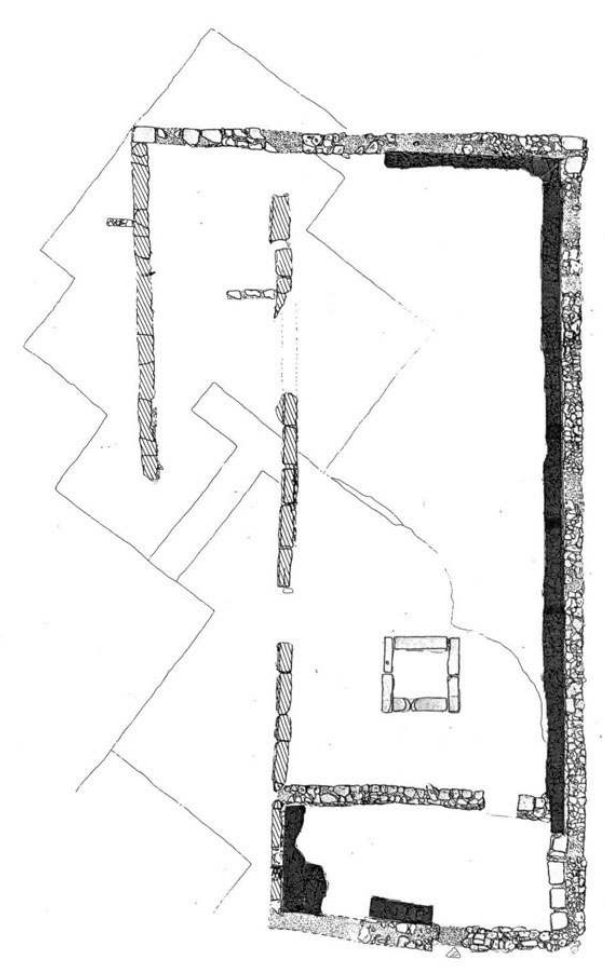

D'après R. Spadea, « Santuari di Hera a Crotone », dans J. de La Genière (dir.), Héra. Images, espaces, cultes, actes du Colloque International du Centre de Recherches Archéologiques de I'Université de Lille III et de I'Association P.R.A.C., Lille, 29-30 novembre 1993, Naples, 1997, p. 252, fig. 19.

L'analyse des murs et de la stratigraphie a permis de préciser la chronologie du bâtiment qui a été inauguré dans la première moitié du VI ${ }^{e}$ siècle avant J.-C. pour être partiellement rénové peu après. La structure rectangulaire n'a été installée que dans la première moitié du $\mathrm{V}^{\mathrm{e}}$ siècle avant J.-C. Après un incendie, l'oikos de Vigna Nuova a été entièrement reconstruit dans le dernier quart $\mathrm{du} \mathrm{V}^{\mathrm{e}}$ ou le premier quart du IV $\mathrm{V}^{\mathrm{e}}$ siècle et a connu une dernière restauration partielle vers le milieu du siècle. Il semble avoir été 
définitivement abandonné à un moment qui reste impossible à préciser, dans les trois dernières décennies $\mathrm{du} \mathrm{IV}^{\mathrm{e}}$ siècle.

Si le parallèle avec le «bâtiment B » de Capo Colonna est impressionnant, le matériel trouvé à l'intérieur du sanctuaire l'est encore davantage. Mentionnons en particulier les maillons de chaînes et les menottes qui ont été enfouis dans le sol ou déposés dans des pythoi en terre cuite. Un dépôt particulier est constitué par un chaudron en bronze qui contenait un nombre important de ces mêmes objets, combinés avec des anneaux en bronze, comme on en a aussi trouvé dans les autres dépôts (voir fig. 12 et cat. 5). D'autres objets exceptionnels retiennent encore l'attention, comme l'anse d'hydrie en bronze qui montre un kouros portant deux lions sur ses épaules ou des talons de lances avec des inscriptions qui mentionnent les dédicants (voir cat. 6 et cat. 7).

\section{Trouvailles en fer du sanctuaire de Vigna Nuova}

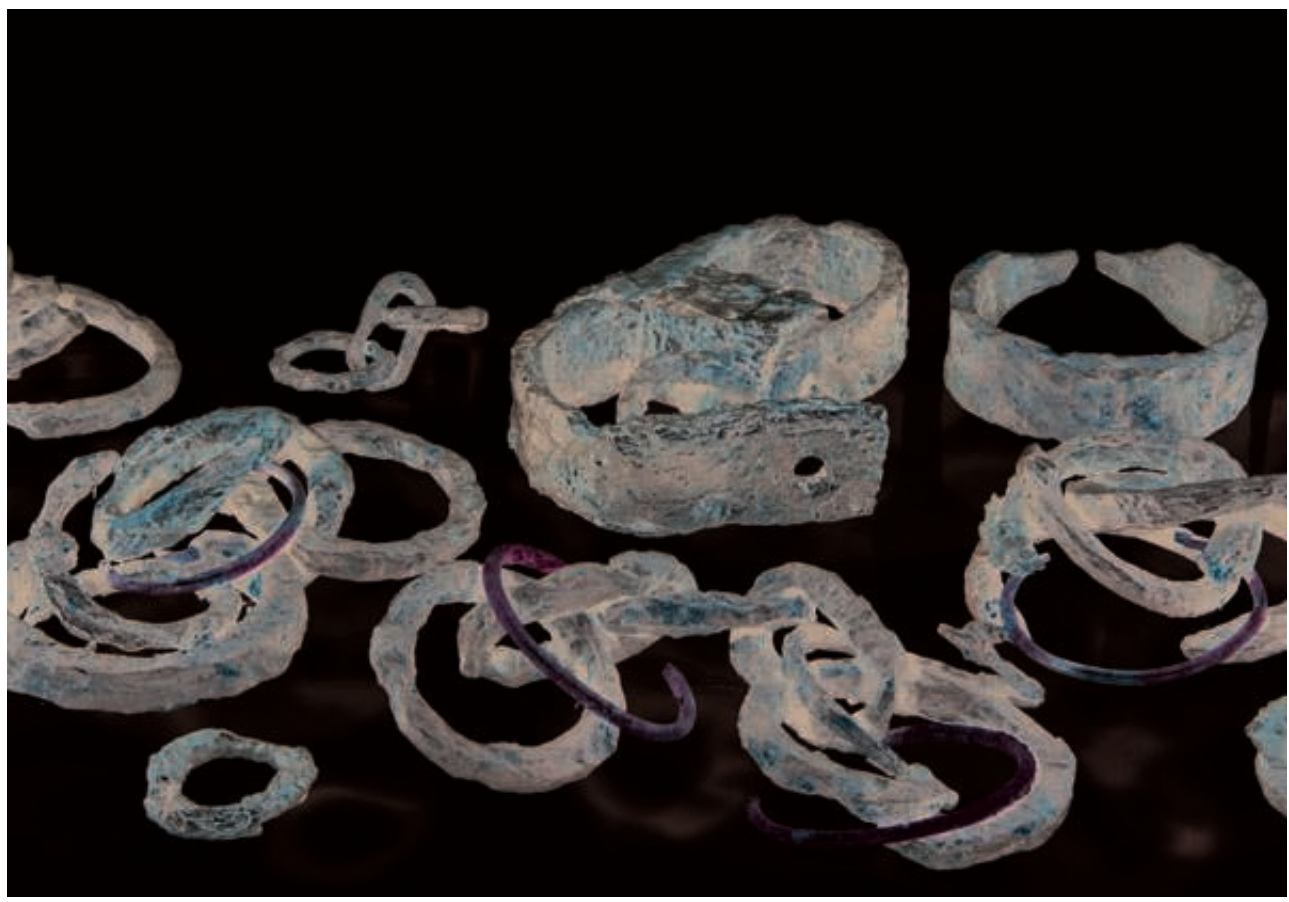

(c) J. Zbinden, université de Berne

La structure du bâtiment a conduit Roberto Spadea à identifier ce lieu de culte avec un sanctuaire d'Héra Éleuthéria ou libératrice, ainsi désigné dans une inscription du Capo Colonna. L'archéologue a proposé de mettre en rapport les dédicaces de chaînes et de menottes avec une manumissio ou libération d'esclaves. Mais les talons de lances semblent indiquer plutôt une victoire militaire (voir cat. 6), et il ne semble pas exclu qu'il s'agisse d'offrandes de prisonniers de guerre libérés par les Crotoniates. Cela pourrait aussi expliquer l'offrande d'une muserolle en bronze, trouvée en 1977-1978 et malheureusement disparue aujourd'hui, qui montre Héraclès enfant maîtrisant avec ses mains deux serpents ainsi qu'un combat entre deux hoplites, et qui pourrait bien avoir été offerte par un cavalier.

L'identification de la divinité avec Héra semble néanmoins possible, étant donné qu'il s'agissait de la plus importante déesse de Crotone. Mais d'autres dieux ne peuvent pour l'instant pas être exclus. On peut aussi s'attendre à ce que nous ne connaissions à ce jour qu'une partie du sanctuaire. Quoi qu'il en soit, la ville, mais aussi le territoire 
extra-urbain de la cité de Crotone, sont loin d'avoir révélé tous leurs trésors aux yeux curieux des archéologues...

\section{BIBLIOGRAPHIE}

G. GENOVESE, I santuari rurali nella Calabria greca, Rome, 1999.

\section{Le sanctuaire d'Héra Lacinia}

D. MERTENS, «I santuari di Capo Colonna e Crimisa: Aspetti dell'architettura crotoniate », dans Crotone. Atti del ventitreesimo convegno di studi sulla Magna Grecia, Taranto 7-10 ottobre 1983, Tarente, 1984, p. 189-230, pl. 16-29 : 190-207 pl. 16-28.

F. SEILER, « Un complesso di edifici pubblici nel Lacinio a Capo Colonna », dans Crotone. Atti del ventitreesimo convegno di studi sulla Magna Grecia, Taranto 7-10 ottobre 1983, Tarente, 1984, p. 231-242. R. SPADEA, « Santuari di Hera a Crotone », dans J. DE LA GENIÈRE (dir.), Héra. Images, espaces, cultes. Actes du Colloque International du Centre de Recherches Archéologiques de l'Université de Lille III et de l'Association P.R.A.C., Lille, 29-30 novembre 1993, Naples, 1997, p. 235-259 : 236-251.

R. SPADEA (dir.), Ricerche nel santuario di Hera Lacinia a Capo Colonna di Crotone. Risultati e prospettive, Rome, 2006.

\section{Le sanctuaire d'Apollon Alaios}

D. MERTENS, « I santuari di Capo Colonna e Crimisa: Aspetti dell'architettura crotoniate », dans : Crotone. Atti del ventitreesimo convegno di studi sulla Magna Grecia, Taranto 7-10 ottobre 1983, Tarente, 1984, p. 189-230, pl. 16-29 : 207-228 pl. 29.

D. MERTENS, «Per l'architettura nel primo Ellenismo. Il tempio ed il santuario di Apollo Aleo a Cirò, dans M. L. NAPOLITANO (dir.), Crotone e la sua storia tra IV e III secolo a.C., Naples, 1993, p. 61-80, pl. 8-12.

P. ORSI, Templum Apollinis Alaei ad Crimisa promontorium, Rome, 1933.

\section{Le sanctuaire d'Héra de Vigna Nuova}

J. DE LA GENIÈRE, « Note sur une muserolle disparue », dans J. DE LA GENIÈRE (dir.), Héra. Images, espaces, cultes. Actes du Colloque International du Centre de Recherches Archéologiques de l'Université de Lille III et de l'Association P.R.A.C., Lille, 29-30 novembre 1993, Naples, 1997, p. 261-265.

R. SPADEA, « Santuari di Hera a Crotone », dans J. DE LA GENIÈRE (dir.), Héra. Images, espaces, cultes. Actes du Colloque International du Centre de Recherches Archéologiques de l'Université de Lille III et de l'Association P.R.A.C., Lille, 29-30 novembre 1993, Naples, 1997, p. 235-259 : 251-258. 


\section{NOTES}

1. Le matériel est actuellement en cours d'étude à l'université de Genève dans le cadre d'un mémoire de master (A. Valticos).

2. La colonne a dû être stabilisée à plusieurs reprises et a été nettoyée et restaurée pour la dernière fois en 2003.

3. L'interprétation est renforcée par le fait que l'autel à cendres se trouvait d'après la description de Tite-Live dans le vestibule du temple (voir plus haut). Il faut aussi se demander si Q. Fulvius Flaccus aurait osé s'emparer du toit si le temple avait été encore en fonction.

4. Une partie au moins des sculptures est à dater plutôt des années 420 avant J.-C., ce qui pourrait indiquer qu'elles appartenaient à une phase de réparation, comme l'a proposé U. STEININGER, Die archaische und frühklassische Grossplastik Unteritaliens und ihr Verhältnis zum Mutterland, Charybdis 11, Münster 1996, p. 65.

5. Pour l'autel à cendres qui correspond probablement seulement à la phase tardive du sanctuaire, voir plus haut, note 3 .

6. Il semble, en comparaison avec d'autres sanctuaires, étonnant que le temple semble resté inchangé à l'époque classique. Des indices qui parleraient en faveur d'une phase de construction intermédiaire à l'époque classique n'ont pas été publiés.

\section{AUTEUR}

\section{LORENZ E. BAUMER}

Professeur ordinaire d'archéologie classique, département des Sciences de l'Antiquité, université de Genève 


\section{Cultes et sanctuaires dans la zone urbaine}

Margherita Corrado et Domenico Marino

Traduction : Patrizia Birchler-Emery, Virginie Nobs et Lorenz E. Baumer

\section{Les indices}

1 Les traces archéologiques signalent l'existence de plusieurs sanctuaires urbains à Crotone : dans le secteur sud de la cité, le long de l'actuelle Via Tedeschi, au centre près de la coopérative Uranio et dans le quartier nord à «ex ampliamento Montedison » (fig. 1). 


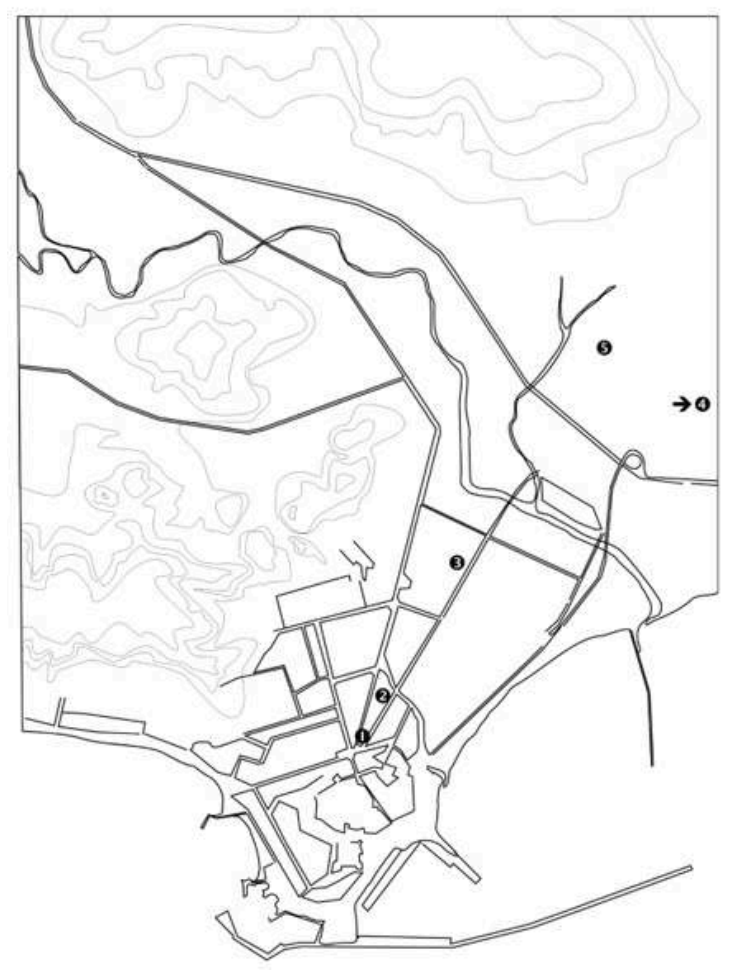

1 - Via Tedeschi, 2 - Via Firenze, 3 - Cooperative Pertusola, 4 - Montedison, 5 - Vigna Nuova.

2 Les évidences monumentales et le mobilier archéologique découvert dans la partie orientale de la Via Veneto et les zones immédiatement attenantes au sud signalent des aires cultuelles. La dispersion de ces documents sur une vaste superficie indique qu'ils ne proviennent pas tous d'un seul lieu. Un sanctuaire repéré à la Via Tedeschi comprenait, pour ne mentionner que les éléments les plus significatifs, une tête de kouros archaïque en terre cuite (fig. 2), celle de l'acrolithe en marbre d'Athéna (cat. 3 et fig. 18-21) ainsi qu'un autel en calcaire (fig. 3). En 1932, Raffaele Lucente écrit dans son rapport de fouilles sur une nécropole de l'époque romaine tardive, découverte à l'occasion de la construction du bâtiment de la Banca d'Italia, un peu plus au nord de la Via Tedeschi : "Sur l'autre côté et pour toute la largeur de la fouille, il apparaît une autre construction orientée nord-ouest/sud-est. Des segments de murs perpendiculaires sont conservés par quelques blocs seulement. Ils ont été documentés sur une longueur de 23 mètres sur 6 . Aucune division interne n'a été observée. " Il pourrait s'agir d'une partie d'un grand temenos déjà découvert puis détruit en 1979 à l'occasion de travaux sur la Via Veneto, en face du Palais de la Commune. Un chapiteau ionique (fig.4) ainsi que quelques statuettes féminines en terre cuite, aujourd'hui exposés dans le musée, y furent récupérés. 
2. Tête d'un kouros en terre cuite

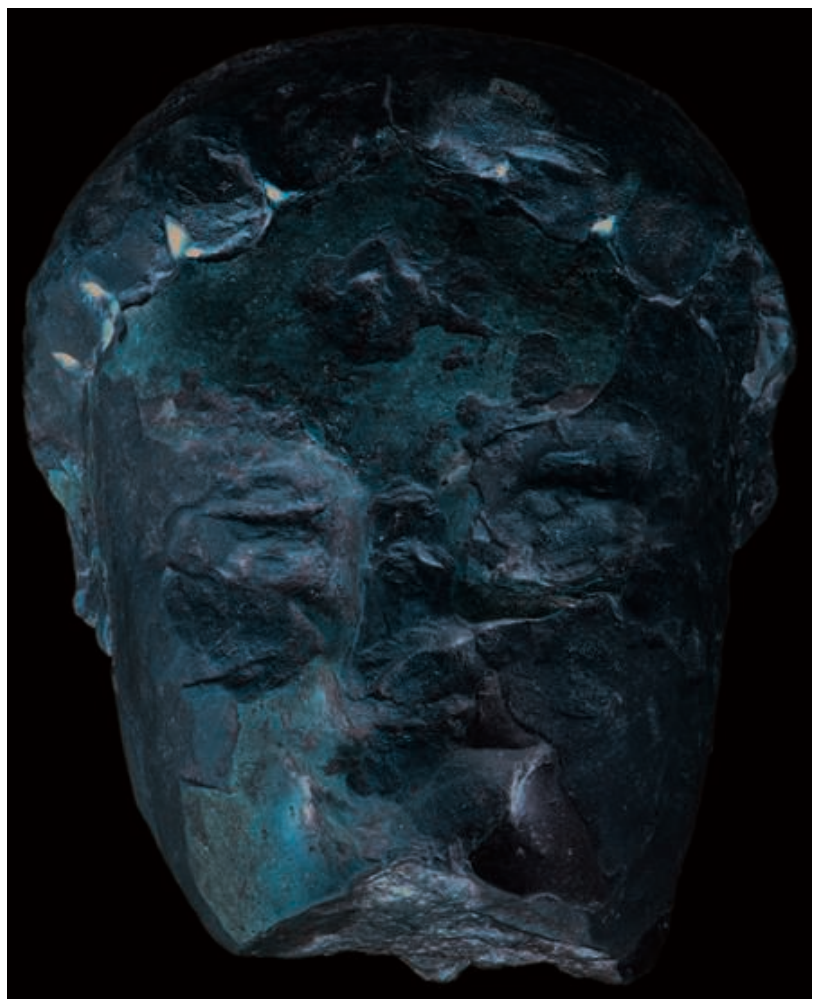

(c) J. Zbinden, université de Berne

\section{Autel}

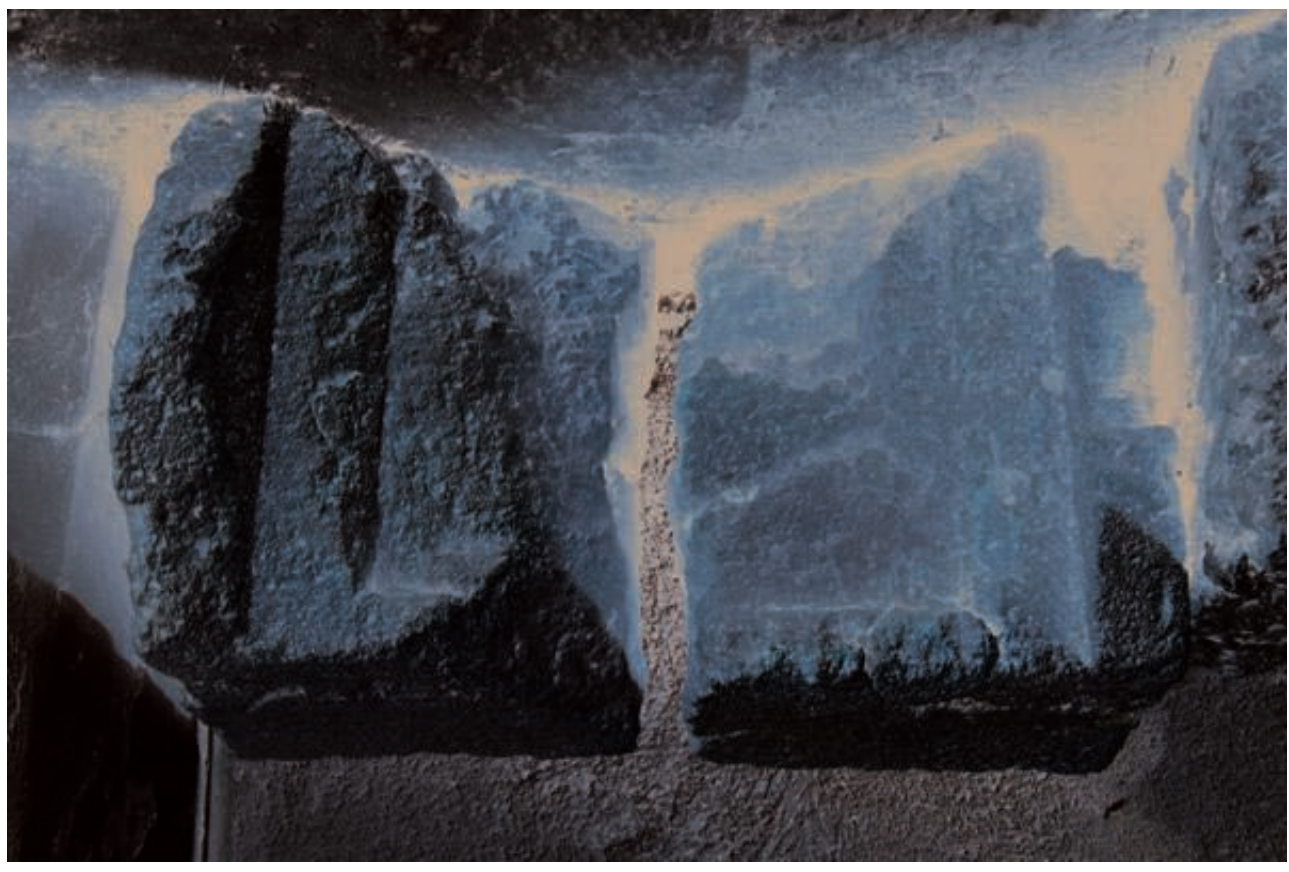

(c) J. Zbinden, université de Berne 
4. Chapiteau ionique

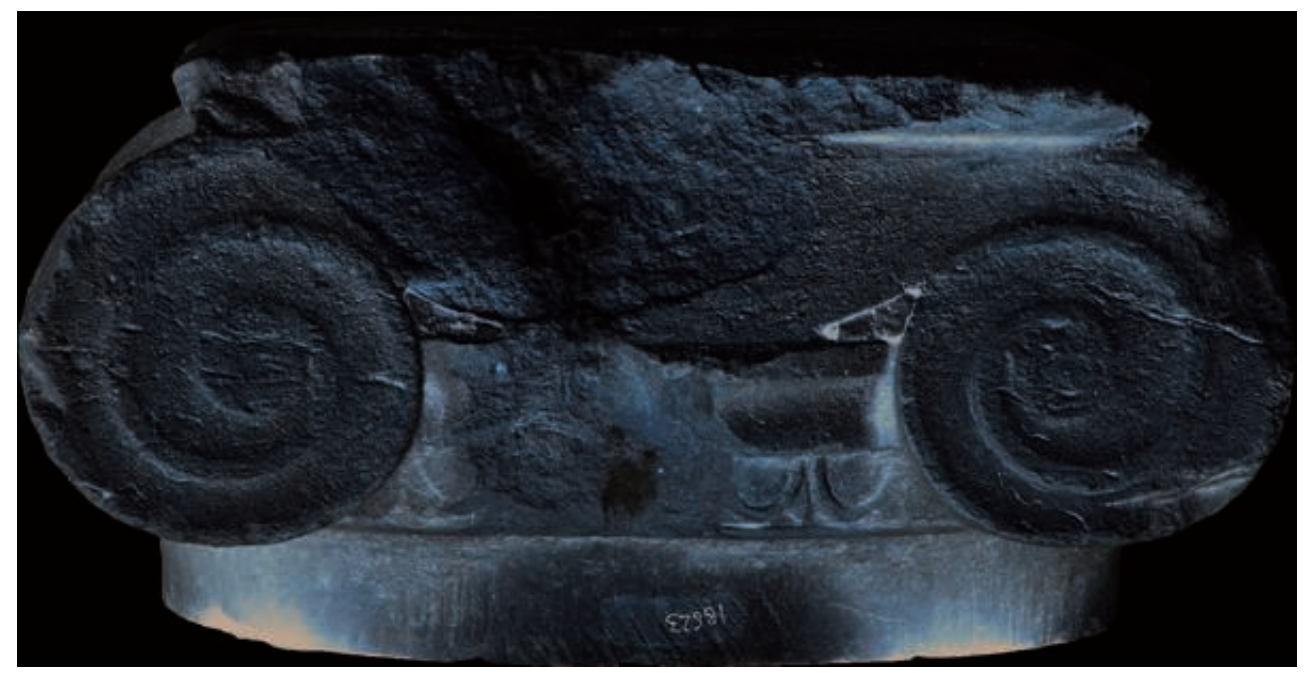

() J. Zbinden, université de Berne

3 On signale de plus un perirrhanterion archaïque en marbre, mis au jour dans une tranchée ouverte à proximité et aujourd'hui perdu. Un peu plus au sud, le long de la Via Firenze, on a récupéré des fragments d'antéfixes ornées de têtes de Gorgone. De plus, la partie supérieure d'une petite colonne en marbre présentant une fixation ronde qui pourrait avoir porté un objet, éventuellement un ex-voto ou une petite statue en métal, a été déposée récemment au musée (fig. 5). Elle provient également de la zone urbaine et constituerait une paire avec une colonne en marbre analogue retrouvée dans le sanctuaire d'Apollon Alaios, à Krimissa. 


\section{Fragment de colonne}

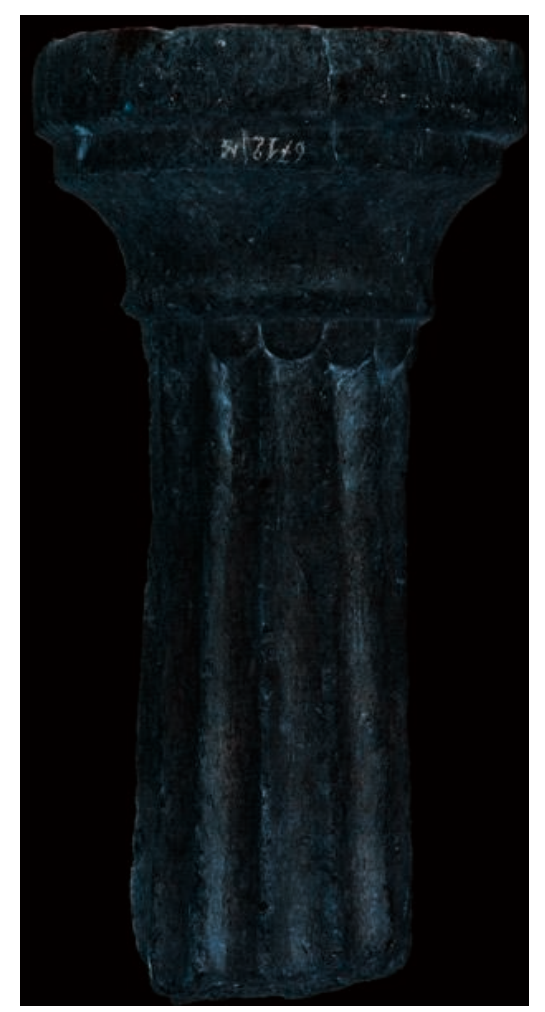

(c) J. Zbinden, université de Berne

\section{Héra}

4 Les sources classiques ne font pas mention d'un sanctuaire d'Héra dans la ville, mais son existence est très probable. De nombreux témoignages attestent l'importance de la déesse, en commençant par le célèbre héraion de Capo Colonna (voir l'article de Lorenz $\underline{E}$. Baumer). On a par ailleurs reconnu un espace sacré dédié à Héra dans un édifice découvert à Vigna Nuova (voir l'article de Lorenz E. Baumer), situé juste à l'extérieur de l'enceinte. Un autre indice pour la présence d'Héra dans la zone urbaine est amené par la stèle en marbre de Naxos provenant d'un chantier de construction (lotissements «Montedison» et «Pertusola») dans le quartier central de la ville antique, non loin d'une nécropole près du fleuve Esaro (fig. 6). 
6. Stèle en marbre

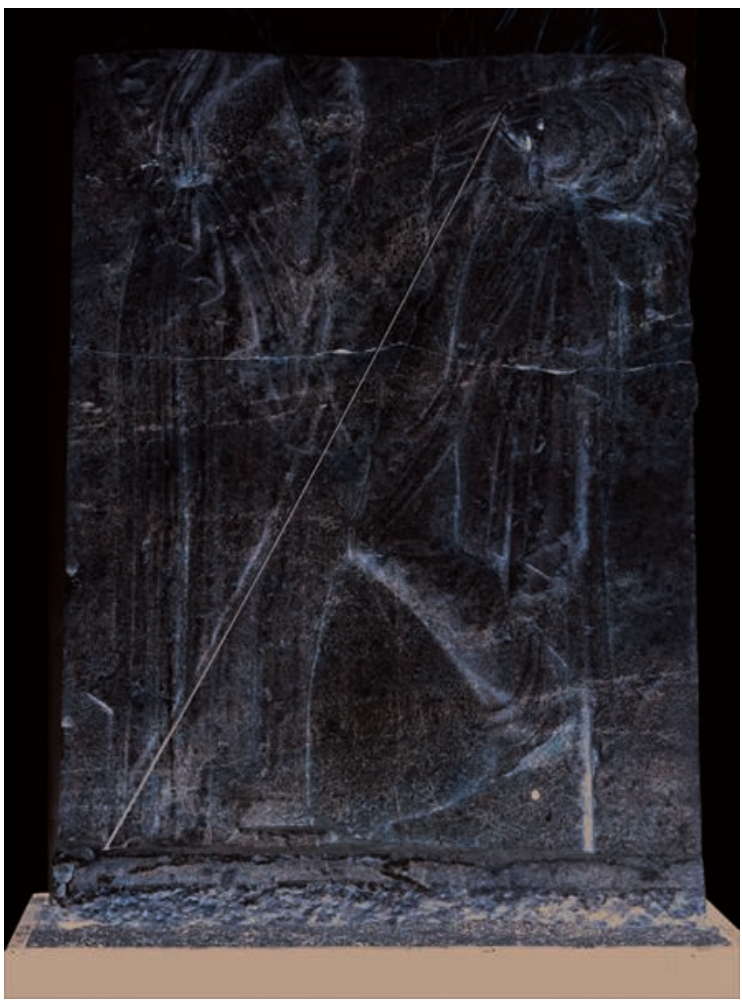

Museo nazionale di Crotone ㄷ J. Zbinden, université de Berne

5 Lors de sa découverte, le relief fut d'abord interprété comme un fragment de stèle funéraire produite par un atelier local à la fin du $\mathrm{V}^{\mathrm{e}}$ siècle avant J.-C., au style fortement influencé par l'art attique contemporain, en soulignant toutefois le caractère exceptionnel des insertions en marbre pour les extrémités des membres des deux figures représentées. On pensait alors que la scène figurait un homme et une femme en discussion.

6 Cette scène n'a pas de parallèle en Grande Grèce et surprend encore plus dans une région où la terre cuite fut souvent préférée à la pierre locale trop tendre, tandis que le marbre était réservé aux statues de culte et aux ex-votos dédiés aux divinités les plus importantes. Il ne peut s'agir d'une stèle funéraire, car le relief déborde sur le côté droit de la plaque, ce qui exclut l'existence d'un cadre architectonique imitant un naïskos typique des stèles funéraires de l'époque ${ }^{1}$ (fig. 7). 


\section{Stèle en marbre}

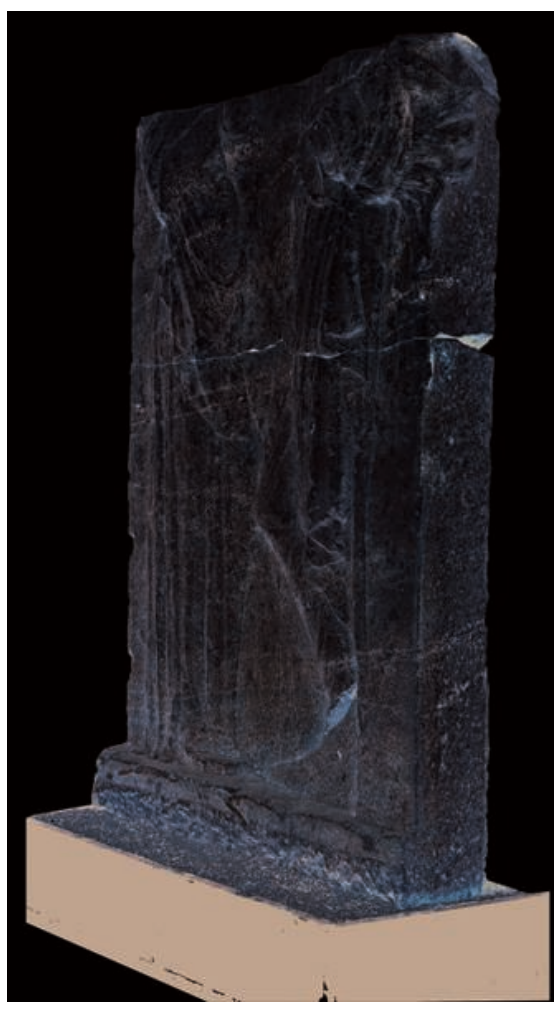

Museo nazionale di Crotone @ $\subsetneq$ J. Zbinden, université de Berne

7 La figure qui se trouve à droite est accoudée de son bras gauche sur un pilier, le coude enveloppé dans un manteau. Elle porte également un chitôn dont on voit encore quelques plis en dessus du bras. Ces vêtements prouvent qu'il ne s'agit pas d'un personnage masculin, mais d'une femme. Un petit trou oblique, placé sur le côté gauche de la base de la stèle, indique que la figure tenait dans sa main un élément rapporté en métal qu'il faut identifier comme un sceptre, tenu d'habitude par Héra et d'autres grandes divinités féminines, comme le prouvent maints parallèles iconographiques (fig. 6 et fig. 8). 
8. Reconstitution d'artiste de la stèle

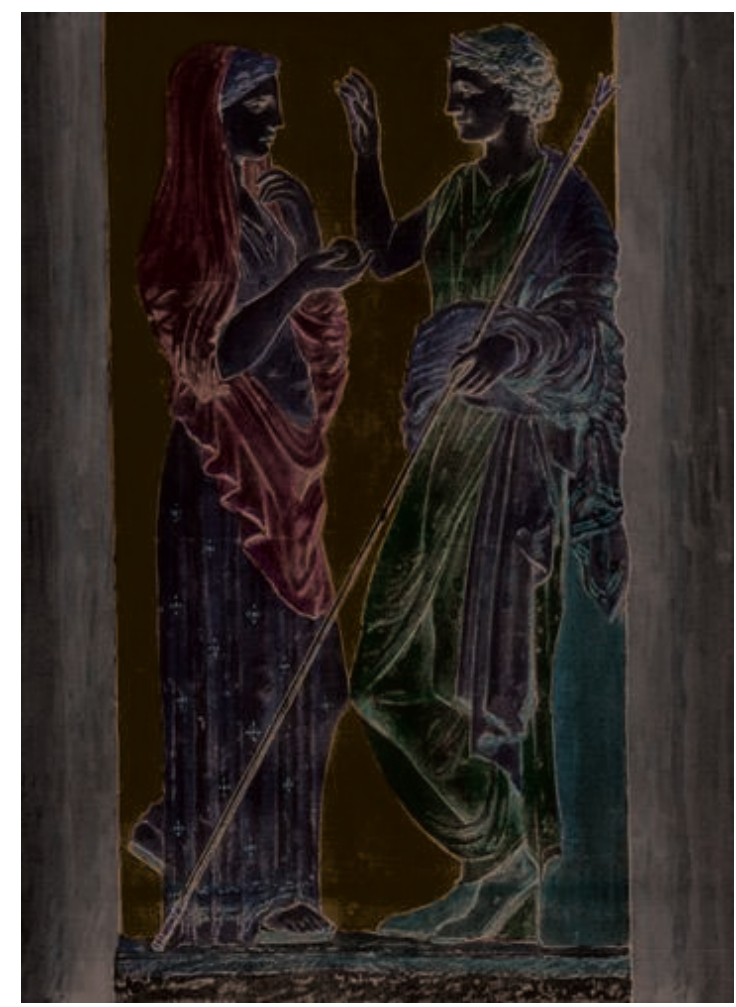

Dessin E. Malena, Cirò Marina

8 Cette nouvelle lecture permet de révéler un extraordinaire relief à caractère votif, que l'on peut attribuer au décor d'un édifice de prestige, cultuel selon toute vraisemblance. S'il s'agissait en effet d'un héraion urbain, celui-ci devait se trouver dans le quartier central de la ville actuelle, où l'on situe le centre civique et politique de la cité. On retrouverait alors à Crotone le même système cultuel qu'à Poséidonia-Paestum (héraion de Foce del Sele), autre colonie achéenne de Grande Grèce, où Héra joue un rôle aussi éminent.

9 Il est probable que cette sculpture soit une commande publique à cause de son format et de sa qualité exceptionnelle. Le traitement quasiment en ronde bosse des membres (et peut-être même des têtes) des deux figures n'est pas justifié par la volonté de réduire le coût de l'œuvre. L'utilisation de qualités diverses de marbre est en effet à l'opposé de l'usage bien attesté de réserver le marbre seulement pour quelques parties du corps et d'en exécuter le reste dans un matériau autre que la pierre (comme pour les acrolithes) ou dans de la pierre locale (comme pour les figures féminines sur les métopes du temple $\mathrm{E}$ de Sélinonte ${ }^{2}$ ).

Quant à l'identité des deux figures représentées en conversation, on peut reconnaître, comme on l'a vu, Héra dans celle de droite, qui avec son sceptre rappelle fortement les images de la déesse dans les deux fameux reliefs célébrant l'alliance d'Athènes et Samos $(403 / 402 \text { et 400/399 avant J.-C.) })^{3}$. Aussi le personnage qui lui fait face ne peut pas être humain, car elle est - autant que l'on puisse dire - de la même taille que la déesse. Il s'agit donc d'une autre figure divine ou d'une personnification, par exemple de la cité.

11 Même si elle est moins probable, l'hypothèse d'identifier les deux figures à un autre couple classique de divinités féminines ne peut être exclue: Déméter, déesse des 
moissons, et sa fille Koré (Perséphone), reine des Enfers, comme le montre le fameux Grand relief d'Éleusis ${ }^{4}$.

\section{Apollon}

Les estampilles apposées sur les tuiles plates fabriquées dans les ateliers de Crotone des débuts $d u v^{e}$ à la fin du Ive siècle avant J.-C. (fig. 9-13) attestent du lien unissant la cité à Apollon et à son sanctuaire à Delphes, que cette dernière désira imposer après sa victoire sur sa rivale Sybaris en 510 avant J.-C. Dès ce moment, Crotone emploie l'iconographie delphique dans tout document officiel, y compris les marques de garantie des produits des manufactures d'État. Depuis quelques décennies déjà, le monnayage transmettait ce même message. La responsabilité du choix du trépied à l'avers des monnaies (voir l'article de Matteo Campagnolo et Virginie Nobs), ainsi que d'un symbole également connoté au revers, est probablement due à un gouvernement sous influence pythagoricienne. En effet, les pythagoriciens encouragèrent le culte oraculaire d'Apollon Pythien, déjà connu dans la cité, par un sanctuaire urbain et peutêtre par la dédicace d'un trésor à Delphes, avant l'arrivée du philosophe de Samos.

\section{Tuile estampillée avec le trépied d'Apollon}

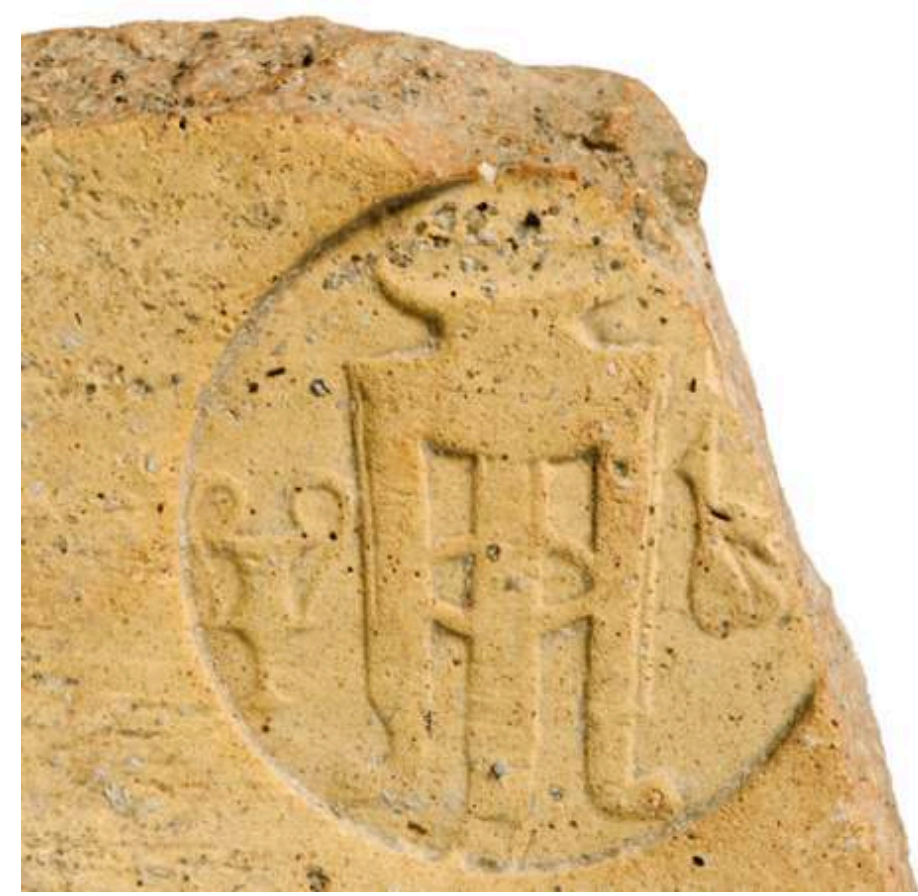

(C) J. Zbinden, université de Berne 
10. Tuile estampillée

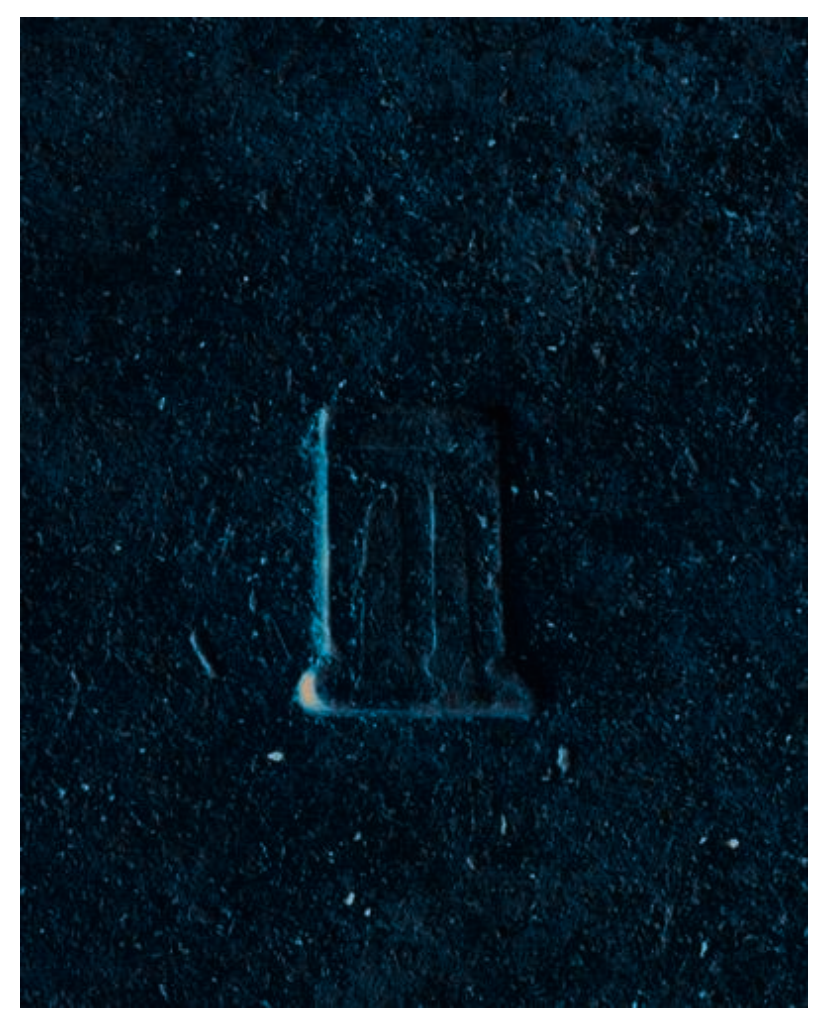

(C) J. Zbinden, université de Berne

\section{Tuile estampillée}

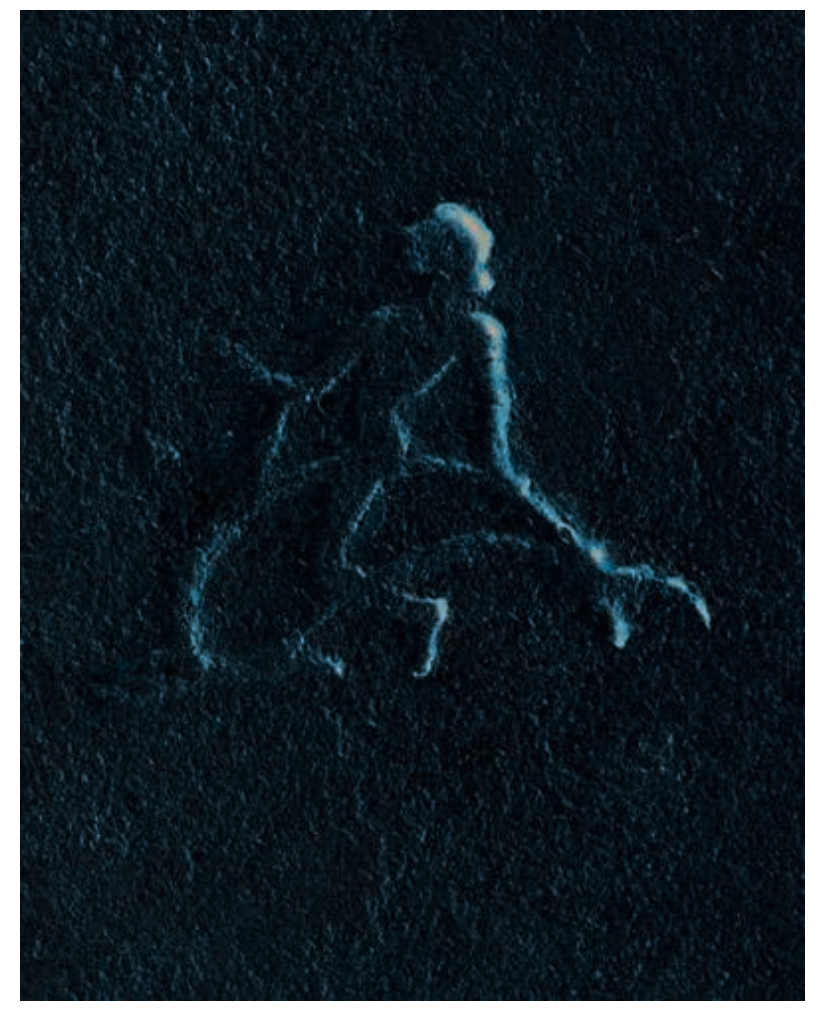

(c) J. Zbinden, université de Berne 
12. Tuile estampillée

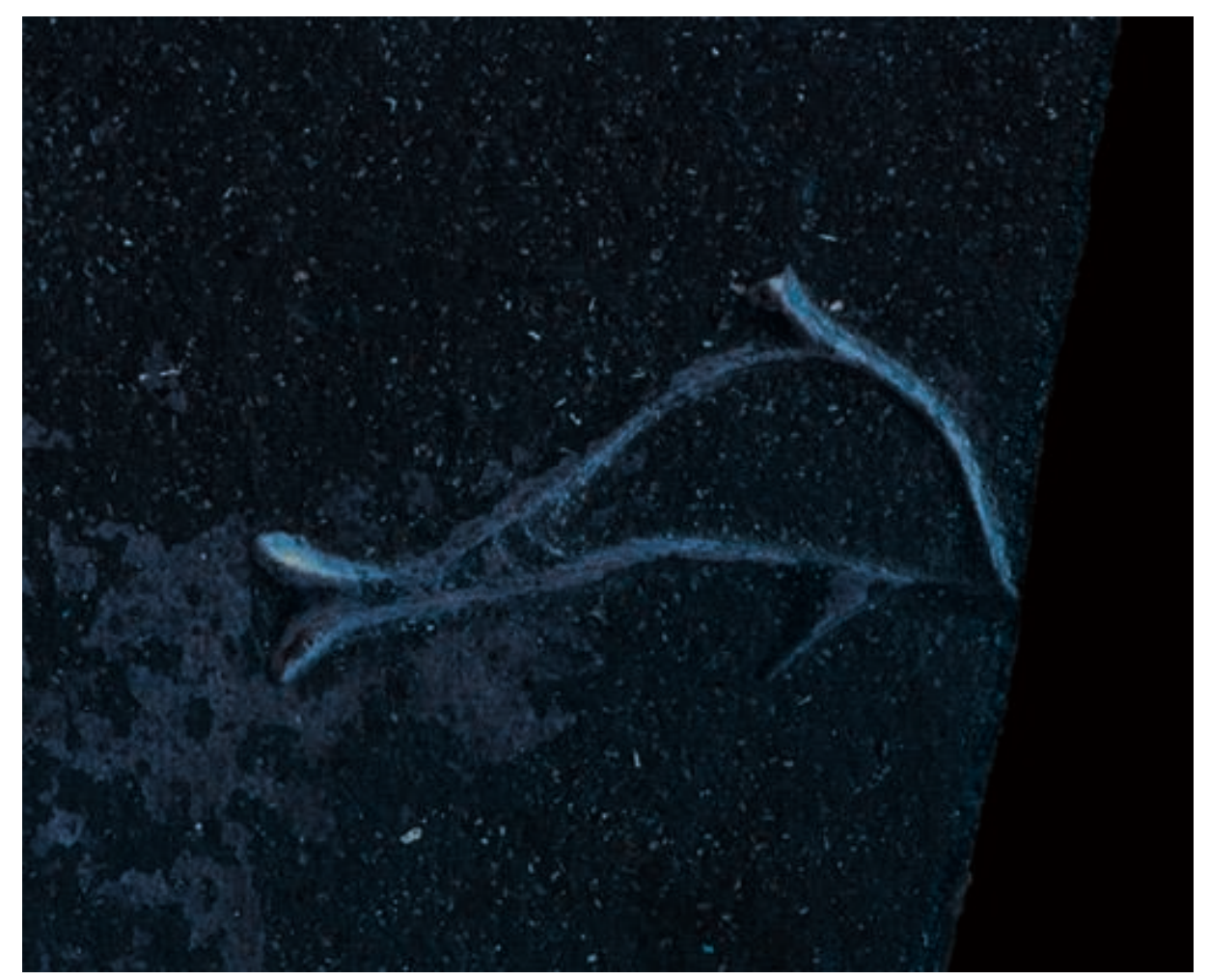

(C) J. Zbinden, université de Berne

13. Tuile estampillée

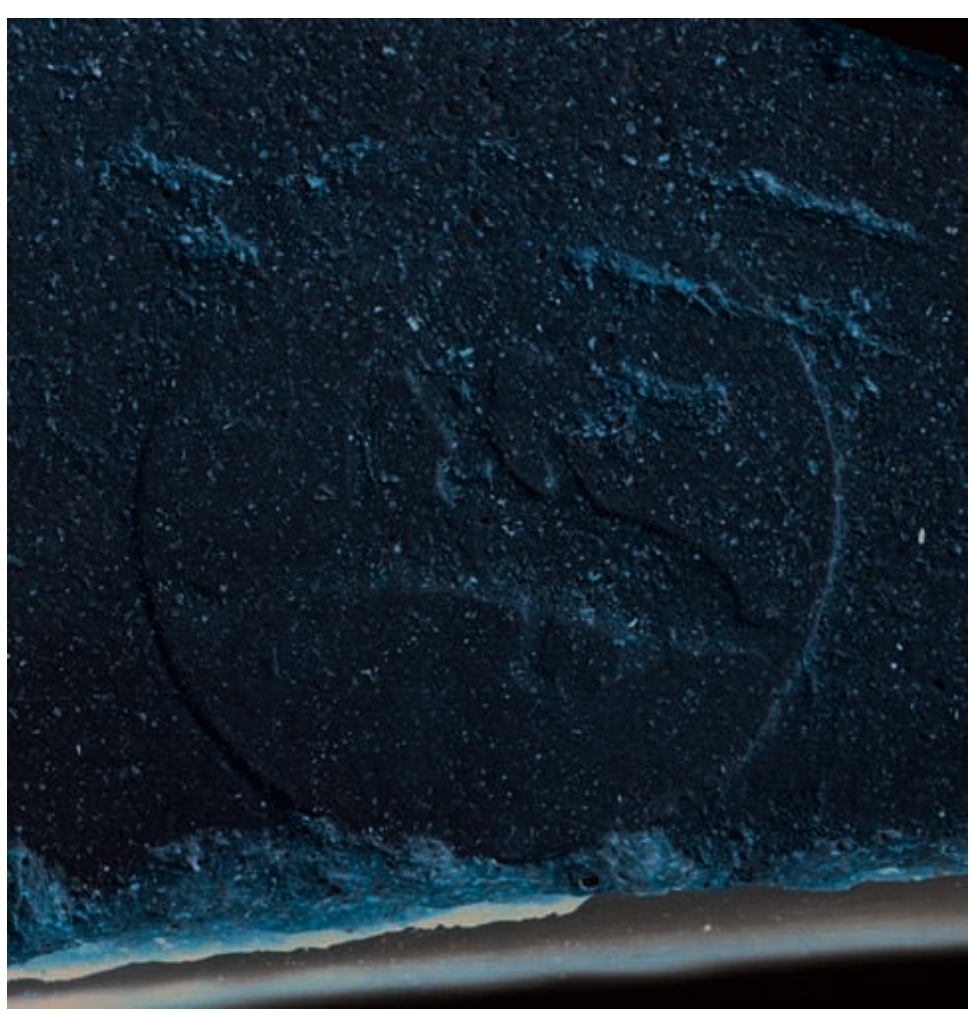

(c) J. Zbinden, université de Berne 
13 Une dédicace importante a été retrouvée dans la localité Quote Cimino, d'où provient également une petite tête de dieu en marbre, inspirée d'un modèle de la seconde moitié du IV siècle avant J.-C. et aujourd'hui exposée au musée de Crotone (cat. 2 et fig. 14-17). Une trouvaille analogue provient des fouilles de Paolo Orsi dans le sanctuaire d'Apollon Alaios. Cette dédicace amène l'hypothèse d'un autre sanctuaire du dieu à Capo Colonna.

\section{Tête d'Apollon}

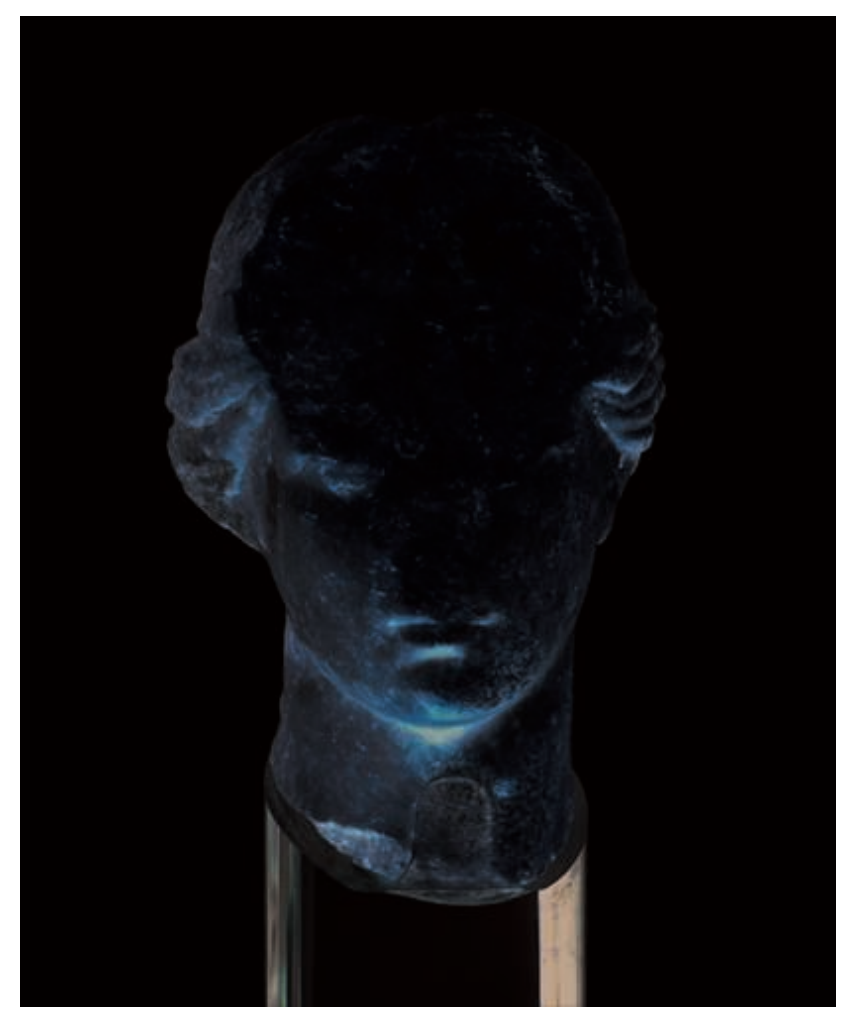

(c) J. Zbinden, université de Berne 
15. Tête d'Apollon

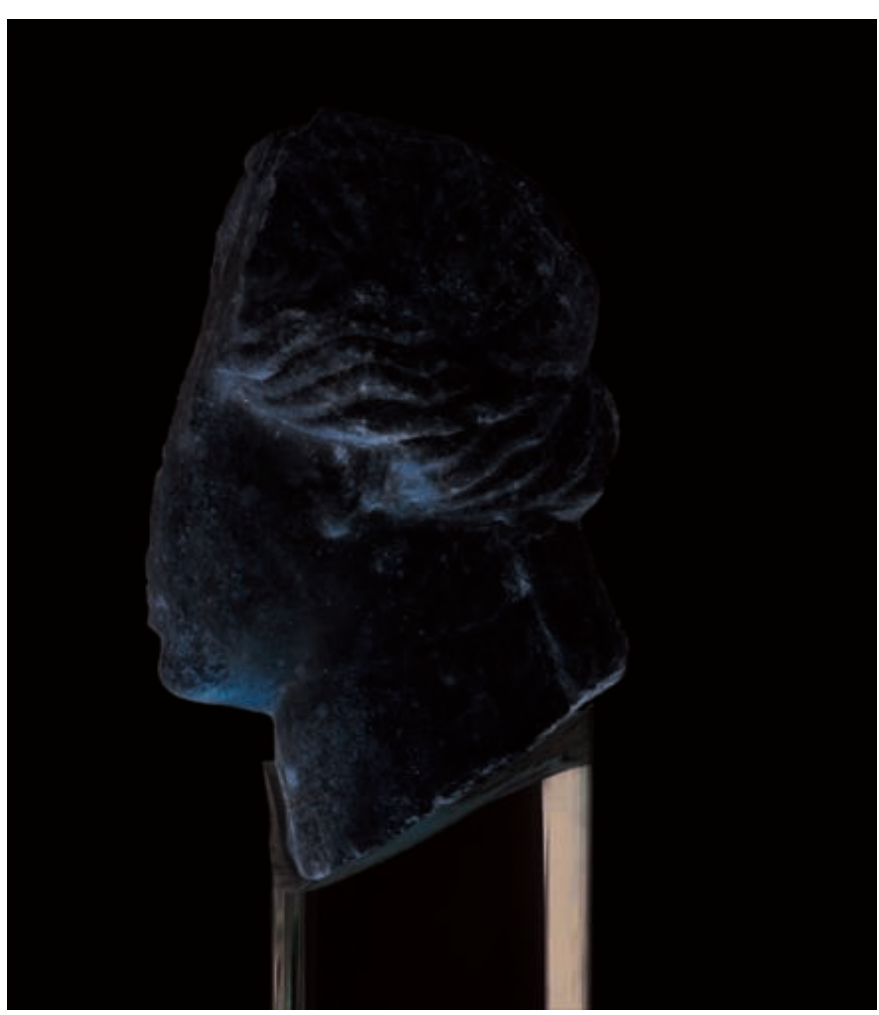

(c) J. Zbinden, université de Berne

\section{Tête d'Apollon}

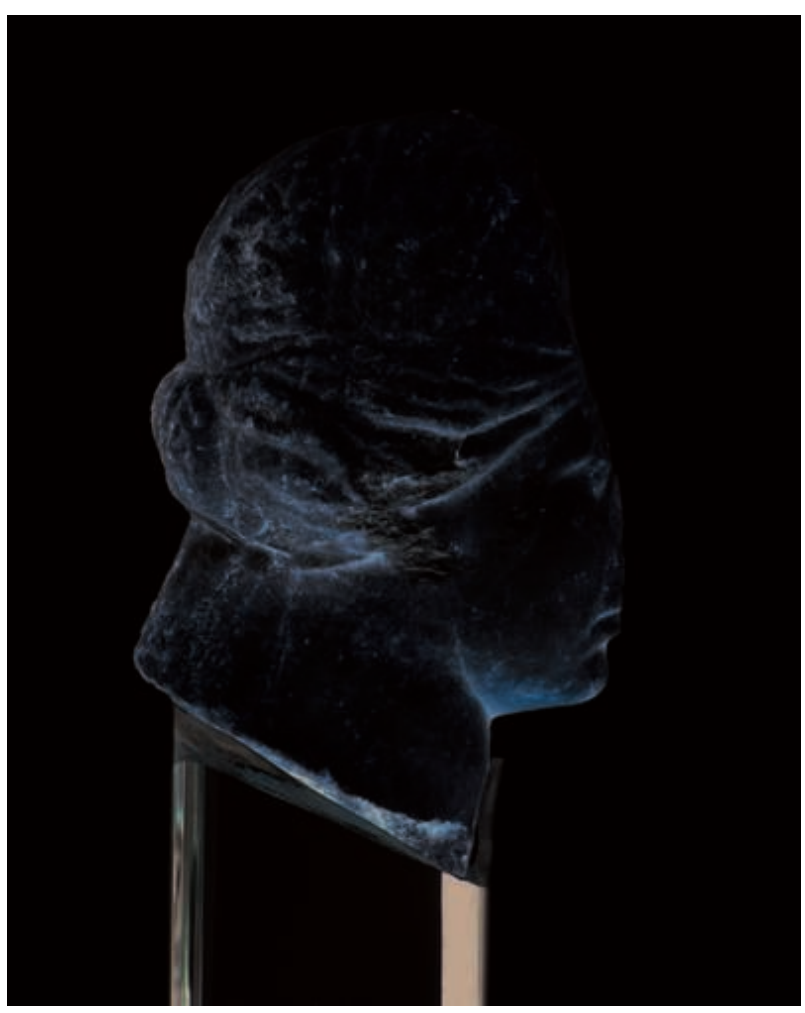

(c) J. Zbinden, université de Berne 


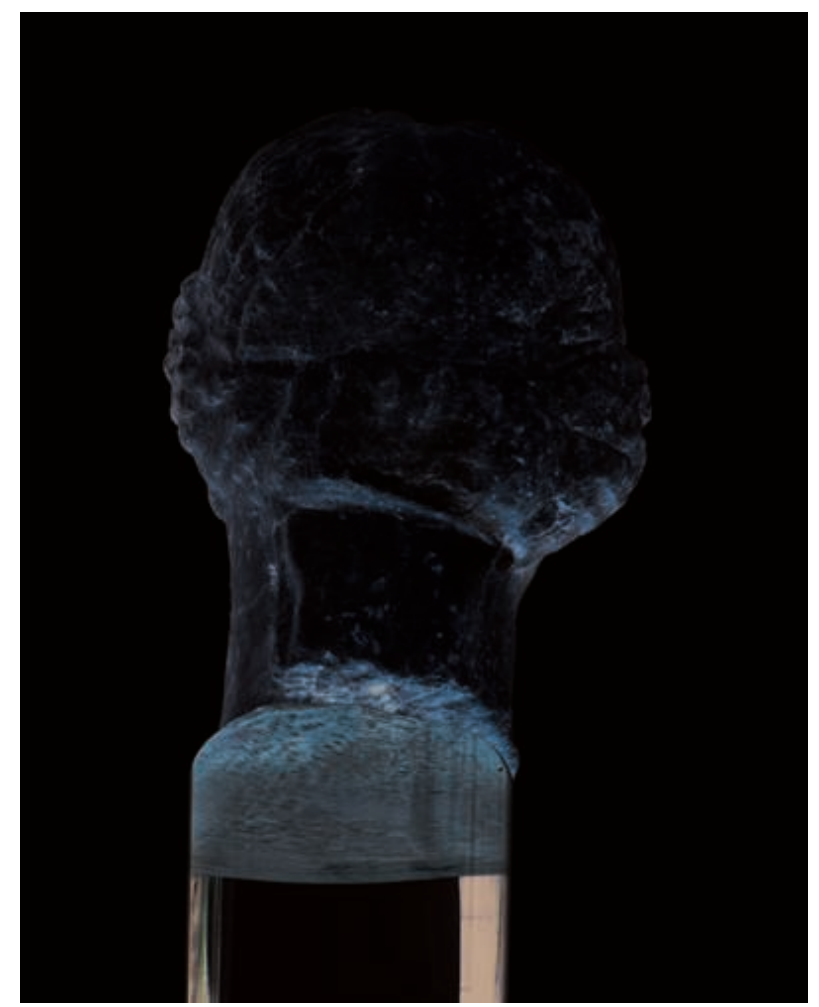

(C) J. Zbinden, université de Berne

Dans un premier temps, les objets en terre cuite portèrent un autre symbole apollinien que le trépied, longtemps interdit pour l'usage profane (car on y reconnaissait Apollon lui-même), et probablement aussi d'origine delphique. Il s'agit du dauphin, au début seul puis avec un cavalier (fig. 11-13). Les deux figures sont équivalentes et renvoient au rôle de guide et de protecteur-sauveur des marins. Ce cétacé est l'instrument du secours accordé par Apollon à celui qui doit affronter les nombreuses inconnues d'un voyage maritime, comme l'attestent les mythes de héros chevauchant des dauphins. L'Apollon-dauphin, que l'on retrouve aussi sur quelques-uns des premiers statères de Zancle et de Tarente, est célébré en temps que promoteur, artisan et garant de l'issue positive du mouvement colonial.

La dimension chtonienne d'Apollon se retrouve sur des estampilles crotoniates ainsi que sur une fine plaque de bronze provenant d'un sanctuaire italique à Rossano di Vaglio (province de Potenza) et daté du premier tiers du IV ${ }^{e}$ siècle avant J.-C. ${ }^{5}$ Le pouvoir apotropaïque d'Apollon estampillé, en personne ou sous forme de dauphin, sur les tuiles, se transmet aux bâtiments ainsi couverts. Le IV siècle privilégiera, nous l'avons dit, d'autres symboles apolliniens, par exemple le trépied (fig. 9 et 10) puis la svastika, la roue, le poulpe et l'étoiles à huit ou seize branches, liés à Delphes comme centre du monde. À la fin de la production, les estampilles évoluent encore et représentent la tête d'Athéna ou la massue d'Héraclès.

16 Alors que la marque du trépied était isolée au $\mathrm{V}^{\mathrm{e}}$ siècle avant J.-C., elle se trouve accompagnée du canthare et du phallus dès le milieu du IV ${ }^{e}$ siècle avant J.-C. et cela en un nombre d'exemplaires largement supérieur aux autres marques. Cela atteste la restructuration du tissu urbain à la fin de l'hégémonie syracusaine. Le recours au 
trépied après cette césure exprime la volonté de la cité, une fois libérée, de confirmer les liens traditionnels avec Delphes.

17 La stabilité du rapport entre la cité et le sanctuaire de Delphes est confirmée par la documentation numismatique. Une monnaie découverte dans le sanctuaire de Krimissa pourrait représenter la tête acrolithe retrouvée dans ce même temple.

\section{Athéna}

On peut admirer au Musée national de Crotone une tête féminine en marbre blanc provenant du chantier de la Via Tedeschi (cat. 3 et fig. 18-21). Malgré le mauvais état de conservation de la pièce (le visage est perdu), on observe encore des trous de boucles d'oreilles ainsi que deux trous circulaires assez profonds permettant la fixation d'un élément rapporté sur le crâne. D'après sa technique et son style, cette tête est très proche de celle de l'Apollon Alaios de Krimissa, célèbre et mieux conservée, exposée au Musée national de Reggio di Calabria ${ }^{6}$.

\section{Détail de l'acrolithe}

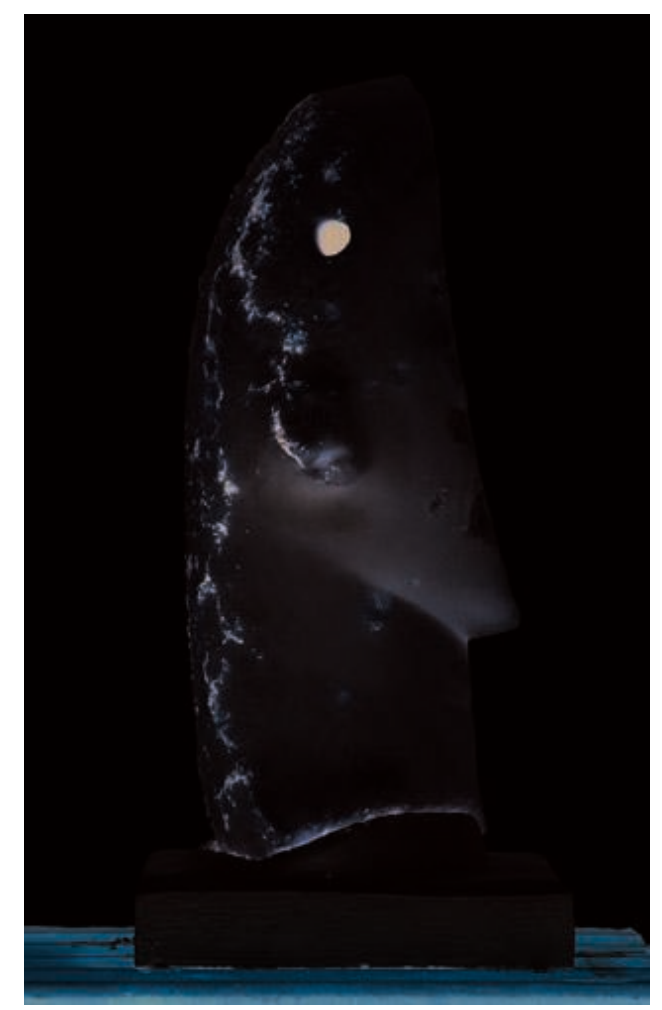

(c) J. Zbinden, université de Berne 
19. Détail de l'acrolithe

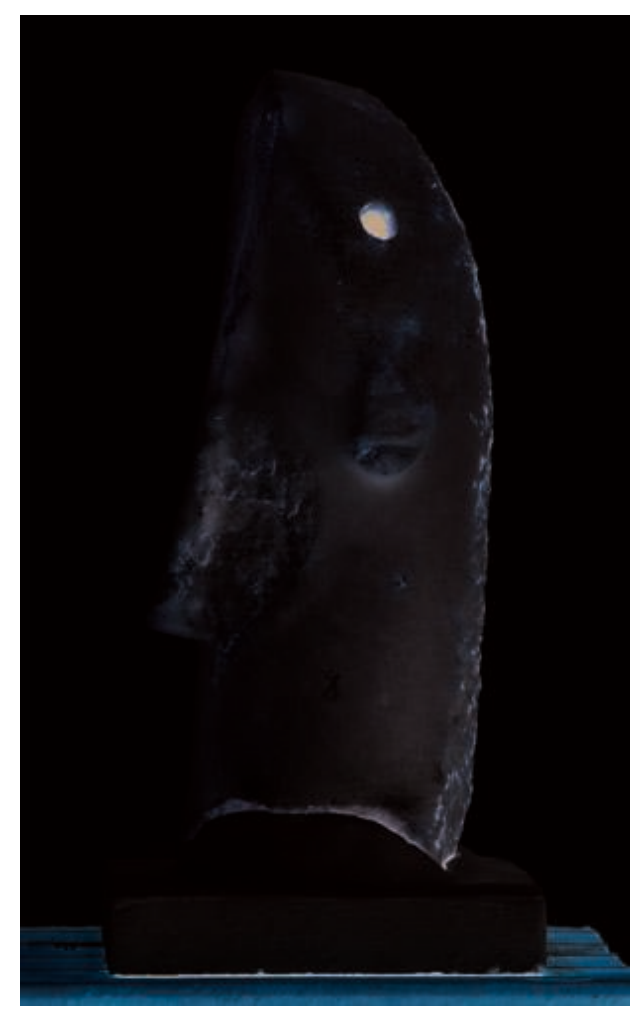

(c) J. Zbinden, université de Berne

\section{Détail de l'acrolithe}

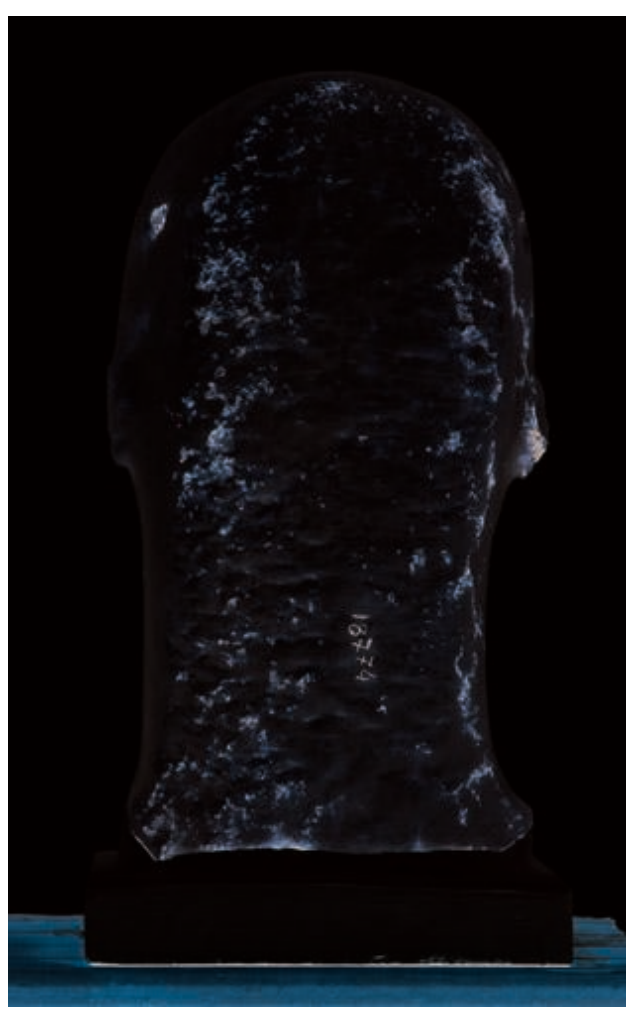

(c) J. Zbinden, université de Berne 


\section{Détail de l'acrolithe}

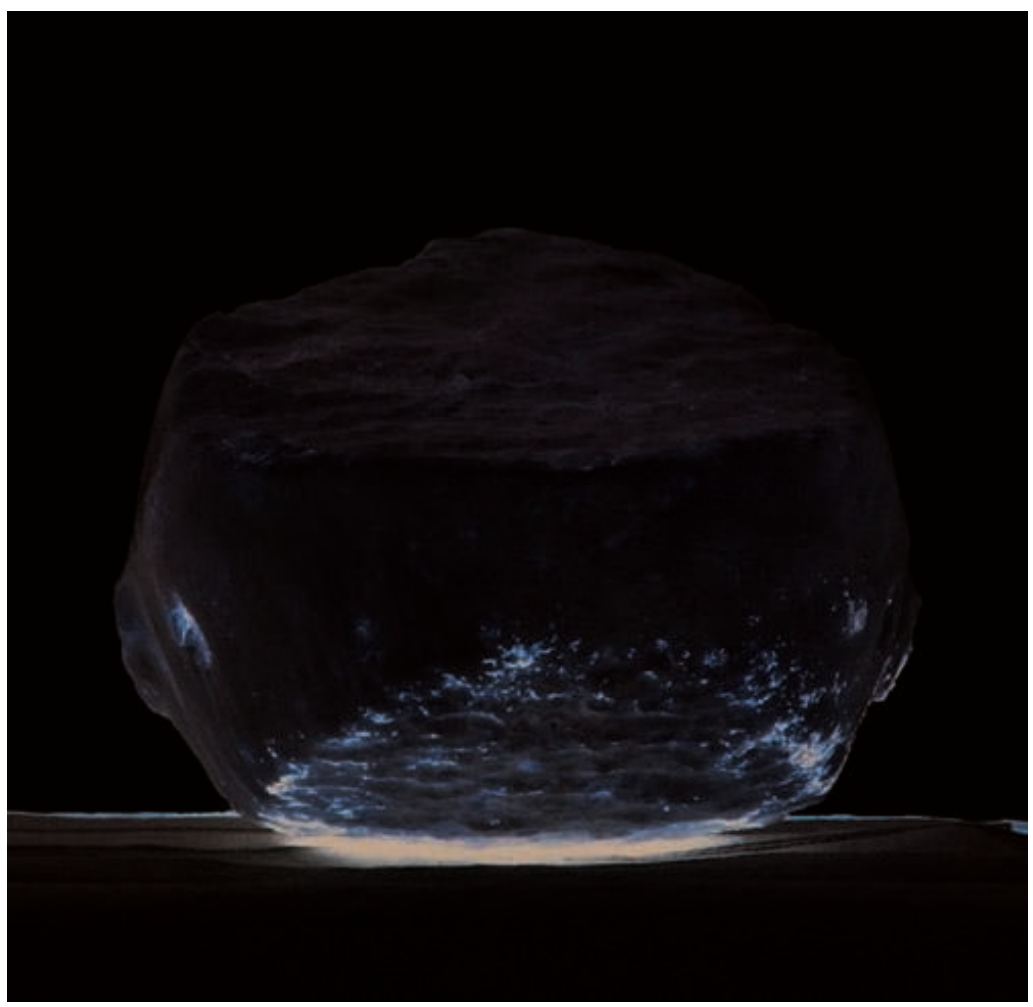

(c) J. Zbinden, université de Berne constituent un témoignage important de l'une des techniques adoptées par les écoles de sculpture de Grande Grèce pendant l'époque classique pour la fabrication de statues de culte. Le terme "acrolithe", qui définit ce type de statue, indique justement l'utilisation d'un matériau lithique pour les parties nues7. Les divers éléments de la statue étaient donc travaillés séparément en bois, pierre et métal, pour être assemblés ensuite sur une structure en bois, grâce à des systèmes d'attaches et de cavités. Le corps ainsi constitué était vêtu de riches vêtements et paré de bijoux précieux. La tête était complétée et ornée d'autres matériaux, pour la rendre plus vivante. Les yeux présentaient un dispositif d'insertion complexe: de la pâte de verre ou des pierres précieuses étaient fixées dans un globe oculaire en pierre et reproduisaient ainsi la luminosité et la couleur de l'iris et de la pupille. Ces globes oculaires étaient ensuite insérés dans des plaques de bronze dentelées afin de figurer les cils, elles-mêmes placées dans les orbites. Du bronze était également employé pour les accessoires rapportés.

Bien que la face manque, la tête de Crotone présente assez d'indices permettant son identification: les lobes des oreilles percées ainsi que la ligne gravée sur le cou indiquent un personnage féminin. Le travail préparatoire de la surface du crâne permet de déterminer qu'elle portait un casque. La tête de Crotone ne pouvait donc appartenir qu'à une représentation d'Athéna.

21 Outre notre tête, nous connaissons deux autres exemplaires d'acrolithes figurant la déesse, provenant de Grande Grèce et datables au v viècle avant J.-C.: la tête de Tarente ${ }^{8}$, où le sommet du casque corinthien avec protège-nez et protège-joues avait 
été élaboré à part puis inséré sur la tête en utilisant les trous forés; et la tête des musées du Vatican, encore discutée ${ }^{9}$. La datation de cette dernière n'est pas claire, soit au début du v viècle avant J.-C. pour certains, soit au milieu du v viècle pour d'autres. L'identité du personnage représenté est aussi disputée. À part Athéna - dans ce cas les trous auraient servi à fixer un casque - on a aussi proposé Héra Sospita. Ce serait alors des cornes qui y auraient été fixées, comme sur la statue de culte de la déesse, à Lanuvium. La tête acrolithe la plus connue d'Athéna reste celle de Priène, datée vers 470-460 avant J.-C. ${ }^{10}$

L'Athéna casquée figure aussi sur quelques séries monétaires de Crotone et parmi les estampilles des tuiles plates fabriquées dans les manufactures de la cité pendant la seconde moitié $\mathrm{du} \mathrm{V}^{\mathrm{e}}$ siècle avant $\mathrm{J} .-\mathrm{C}$. Au début du $\mathrm{XX}^{\mathrm{e}}$ siècle, un sanctuaire rural dédié à la déesse a été reconnu et la partie inférieure d'une statue en terre cuite plus petite que nature y a été découverte.

\section{Héraclès}

La tradition savante locale garde le souvenir d'un grand temple d'Héraclès à l'intérieur de la cité, qui n'a pas trouvé à ce jour de preuves tangibles. Cela n'exclut en rien que l'invincible fils de Zeus et d'Alcmène, vénéré par les Grecs à la fois comme un héros et comme un dieu, ait fait l'objet d'un culte important à Crotone. Certains aspects de la tradition mythique de la cité l'attestent, aussi bien que les choix iconographiques des ateliers monétaires. L'ensemble des images fait apparaître le caractère particulier d'Héraclès en terre crotoniate. Associé à Héra, il entretient un lien particulier avec Apollon et se rapproche ainsi des deux divinités les plus importantes de la cité.

Bien que le nom du héros reprenne celui de la déesse, le rapport entre Héraclès et Héra dans la tradition littéraire et mythologique est marqué par de constantes confrontations. Les hostilités commencent avec la tentative de la reine des dieux de provoquer la mort d'Héraclès nourrisson. Le petit Héraclès étouffe les deux serpents envoyés par Héra pour le tuer et montre ainsi dès son plus jeune âge sa force prodigieuse. L'épisode se retrouve sur le monnayage en argent de Crotone, du IV siècle avant J.-C., qui porte à l'avers la tête laurée d'Apollon. Le sanctuaire d'Héra de Vigna Nuova a livré une muserolle de cheval en bronze, illustrant cette même scène ${ }^{11}$. Cette trouvaille, ainsi que des cylindres munis de pointes, appartenant à un type particulier de mors (fig. 22) suggèrent un lien entre la déesse et le monde guerrier. En particulier avec les cavaliers, comme c'est le cas dans le sanctuaire d'Héra Hippia de PoséidoniaPaestum. Héraclès est également présent dans les héraia de Grèce continentale, à Sparte et Argos notamment. 


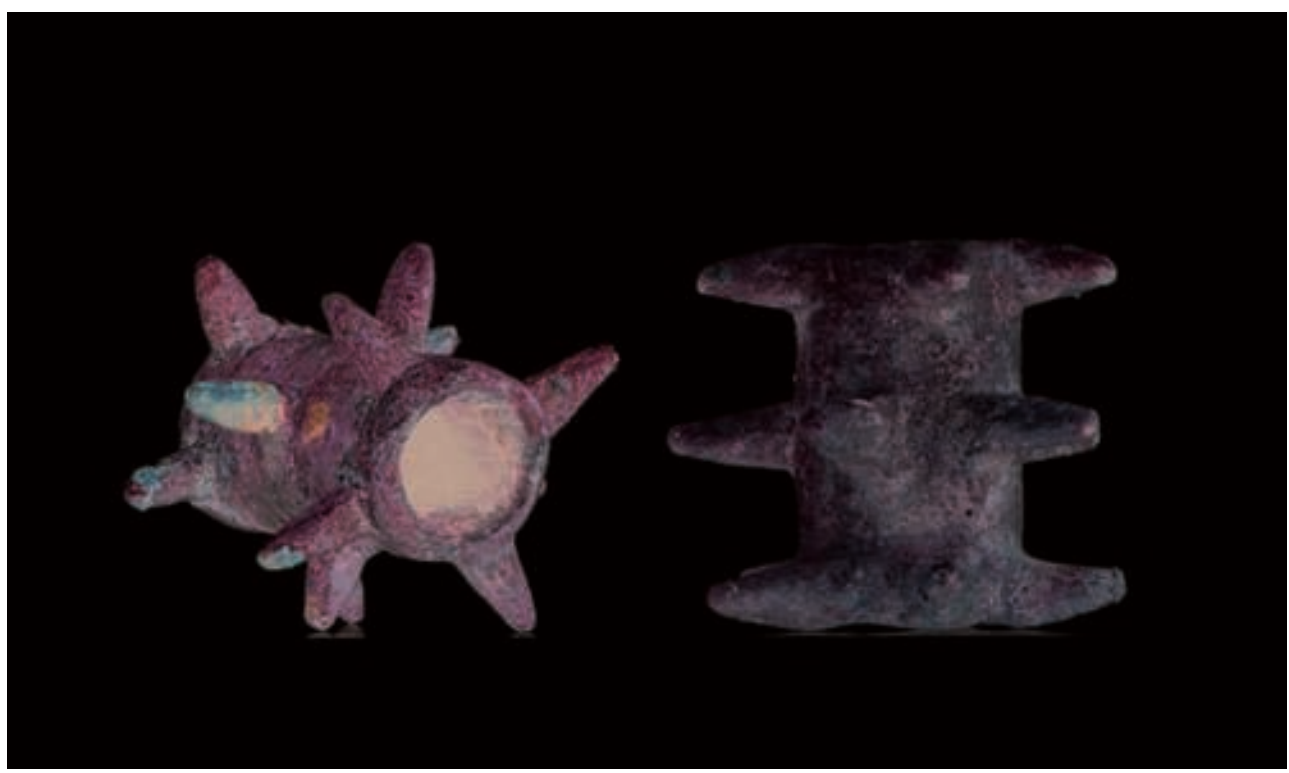

(c) J. Zbinden, université de Berne

À Paestum, Héraclès est représenté sur les fameuses métopes du temple archaïque du Sele et dans le sanctuaire méridional de la ville. À Métaponte, l'iconographie confirme, au milieu du $\mathrm{V}^{\mathrm{e}}$ siècle avant J.-C., l'importance d'Héraclès dans le contexte civique, qui remonte probablement à la fin de l'époque archaïque. La fameuse dédicace de Nicomaque, de la fin du VIe siècle avant J.-C., atteste la relation d'Héraclès avec le monde indigène, où le héros a toujours joui d'une faveur particulière. En outre, un grand nombre de statuettes italiques en bronze le représentent.

La fondation du sanctuaire d'Héra à Capo Colonna est rattachée à Héraclès par un mythe indigène : après le meurtre de l'innocent Kroton, l'expiation était la condition nécessaire pour l'instauration du nouvel ordre communautaire, établi justement par la fondation du sanctuaire et de la cité.

Dans une autre variante de la tradition, transmise par Ovide (Métamorphoses 15, 12-59), c'est Héraclès en personne qui, après avoir prédit la naissance de la cité, apparaît en songe au à Myscellos de Rhypes en Achaïe. L'oeciste mythique de Crotone l'invite à quitter son pays pour rejoindre le tumulus de Kroton, afin d'y fonder la cité homonyme. En souvenir de ce mythe de fondation, quelques monnaies en argent de Crotone de la fin du $\mathrm{V}^{\mathrm{e}}$ siècle avant J.-C. montrent le jeune Héraclès à l'avers, assis près d'un autel et tenant de la main droite un rameau de laurier qui atteste de l'accomplissement d'un rite de purification, lié à la fondation du sanctuaire (voir l'article de Matteo Campagnolo et Virginie Nobs). Sur d'autres statères, qui portent le visage d'Héra à l'avers, il tient par contre une œnochoé, alors qu'un trépied est représenté devant lui.

La représentation d'Apollon tuant le serpent Python au revers des premières monnaies mentionnées plus haut suggère une équivalence des actes de violence qui furent à l'origine des sanctuaires de Capo Colonna et de Delphes. Ce qui renforce le lien entre Héra et Héraclès, bien ancré dans la religion crotoniate. Les fêtes annuelles en l'honneur de la déesse au cap permettaient de revivre le deuil et l'expiation qui suivit. Les rites régulaient la dissolution périodique de l'ordre civique et son renouvellement, domaine relevant des compétences d'Héra. L'événement se déroulait sous le regard 
d'Apollon - l'existence d'un Apollonion à l'entrée du sanctuaire d'Héra est fort probable - puisqu'en présence d'un acte de violence grave, c'est Apollon qui se porte garant de la purification, condition impérative de tout recommencement.

Dans la documentation numismatique de Crotone, des monnaies du IV siècle avant J.-C. montrent au revers Héraclès debout et tenant sa massue, représenté d'après la légende comme oeciste, avec Athéna à l'avers ${ }^{12}$. D'autres proposent plus couramment seulement son profil, vêtu de la léonté et associé à l'aigle de Zeus ${ }^{13}$. D'autres monnaies encore le caractérisent par ses attributs traditionnels : massue, carquois ou arc. Ces images se retrouvent également sur des gemmes ou des bijoux, pour invoquer l'aide du héros à la force extraordinaire dans les difficultés de la vie quotidienne.

La massue se retrouve aussi sur les estampilles de tuiles de Crotone de la fin du Iv siècle avant J.-C, ainsi qu'en marbre dans un format réduit (fig. 23). Milon, prêtre d'Héra, pythagoricien et le plus grand champion de l'athlétisme crotoniate dans les compétitions panhélléniques, revêtit la léonté (peau du lion de Némée) et porta la massue lorsqu'il commanda l'armée dans la guerre contre Sybaris, en 510 avant J.-C., se présentant comme le nouvel Héraclès. La victoire sur Sybaris permit le transfert dans le sanctuaire d'Apollon Alaios de l'arc et des flèches du héros, qu'il avait laissés à Philoctète. Le héros thessalien, fondateur de plusieurs villes indigènes au nord du territoire crotoniate et du sanctuaire de Punta Alice, les avait obtenus après avoir allumé sur le mont đEta le bûcher d'Héraclès. La léonté et la massue furent par contre consumées par les flammes.

23. Massue en marbre, en format miniature

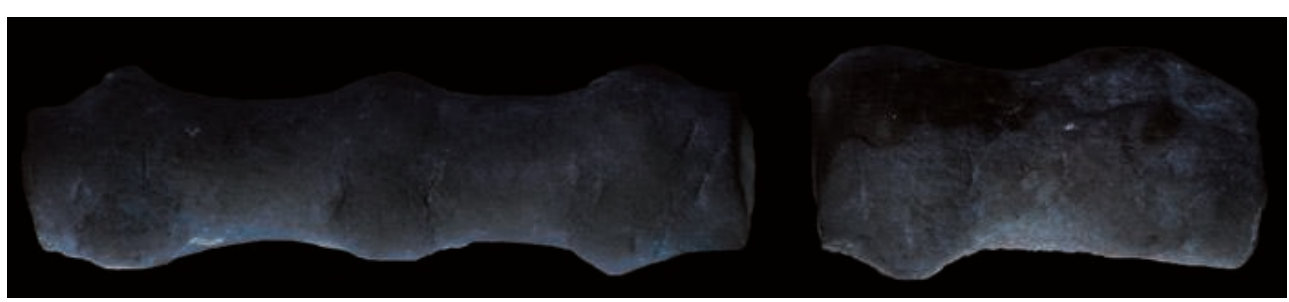

(C) J. Zbinden, université de Berne

\section{Bibliographie}

31 D. MARINO, M. CORRADO (dir.), o dei di Kroton! Luoghi e testimonianze del sacro dentro le mura, di Commercio, Crotone, 2009.

\section{NOTES}

1. [NdÉ : nous remercions François Queyrel pour sa relecture du texte] Voir par exemple les stèles funéraires de l'époque classique illustrées dans C. ROLLEY, La Sculpture grecque, 2. La période classique, Paris, 1999, p.168-169, fig. 152-153. 
2. A. STEWART, Greek Sculpture. An exploration, New Haven et Londres, 1990, p.139-140, fig. 257-260.

3. M. MEYER, Die griechischen Urkundenreliefs, Mitteilungen des deutschen archäologischen Instituts, Athenische Abteilung,

13. Beiheft, Berlin, 1989, p. 273-274 A 26 A 27, pl. 10, 1-2 ; STEWART, loc. cit., p.167, fig. 438.

4. ROLLEY, La Sculpture grecque, 2. La période classique, Paris, 1999, p.158, fig. 141.

5. D. MARINO, M. CORRADO (dir.), o dei di Kroton! Luoghi e testimonianze del sacro dentro le mura, Camera di Commercio, Crotone, 2009, p. 27, fig. 2.

6. Inv. 6499. U. STEININGER, Die archaische und frühklassische Grossplastik Unteritaliens und ihr Verhältnis zum Mutterland, Charybdis vol. 11, Munster, 1994, p. 78-79.

7. G.I. DESPINIS, Zu Akrolithstatuen griechischer und römischer Zeit, Nachrichten der Akademie der Wissenschaften zu Göttingen, I. Philologisch-historische Klasse 8, Göttingen, 2004.

8. E. HÄGER-WEIGEL,Griechische Akrolith-Statuen des 5. und 4. Jhs. V. Chr., Berlin, 1997, p. 74-78, pl. 20-21.

9. A. PATAY-HORVÁTH, Metallanstückungen an griechischen Marmorskulpturen in archaischer und klassischer Zeit, Tübingen Archäologische Forschungen 4, Rahden/Westf., 2008, p. 186-187, fig. 78-79.

10. J. C. CARTER, The Sculpture of the Sanctuary of Athena Polias at Priene, Reports of the Research Committee of the Society of Antiquaries of London XLII, Londres, 1983, p. 210-249, pl. 33-37.

11. J. DE LA GENIÈRE, « Note sur une muserolle disparue », dans J. DE LA GENIÈRE (éd.), Héra. Images, espaces, cultes. Actes du Colloque international du Centre de Recherches archéologiques de l'Université de Lille III et de l'Association P.R.A.C., Lille, 29-30 novembre 1993, Naples, 1997, p. 235-259 et 261-265.

12. Voir par exemple D. MARINO, M. CORRADO, $O$ dei di Kroton! Luoghi e testimonianze del sacro dentro le mura, Camera di Commercio, Crotone, 2009, p. 50, fig. 7.

13. Voir les exemples illustrés dans D. MARINO, M. CORRADO, O dei di Kroton! Luoghi e testimonianze del sacro dentro le mura, Camera di Commercio, Crotone, 2009, p. 50-51, fig. 9-15. 


\section{Catalogue}

\section{Virginie Nobs}

\section{Cat. 1.}

\section{Stèle en marbre}

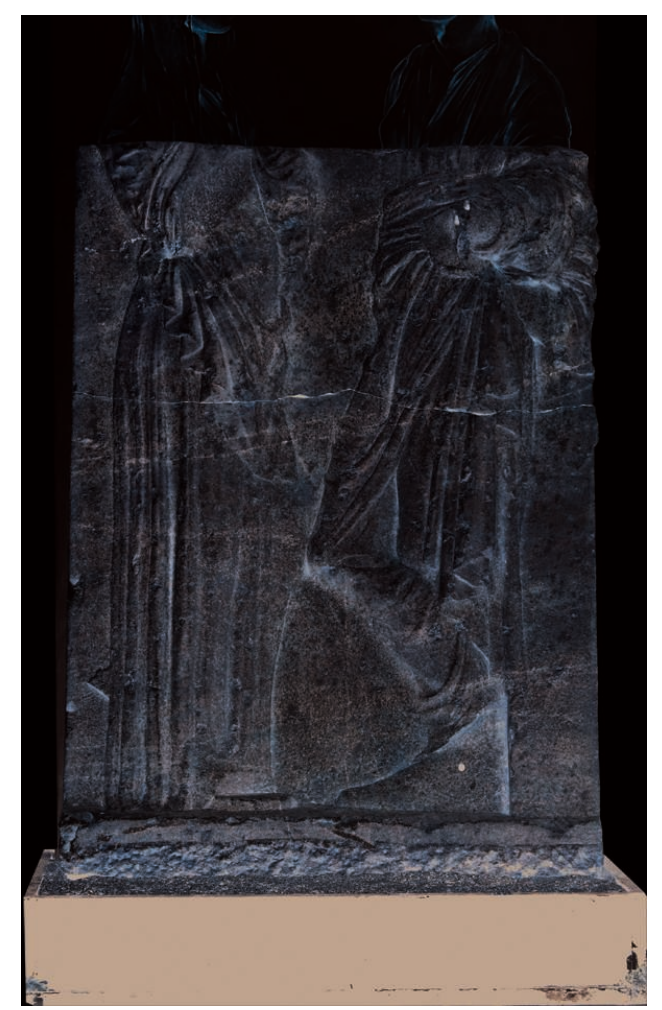

-Provenance : Via Cutro, Crotone

- Dimensions : hauteur maximum conservée : $125 \mathrm{~cm}$; hauteur du relief conservé : $113 \mathrm{~cm}$; largeur : 100 $\mathrm{cm}$; profondeur : $47 \mathrm{~cm}$.

- Matériel : marbre blanc à grain moyen, veiné de gris et présentant une légère patine jaune.

- Datation : 450-420 avant J.-C.

Museo nazionale di Crotone (c) J. Zbinden, université de Berne

Voir l'article de Margherita Corrado et Domenico Marino. 
1 Partie inférieure d'une stèle en marbre, retrouvée en deux fragments jointifs. Le relief est conservé jusqu'à la hauteur des seins des personnages, tous deux féminins. Deux mortaises rectangulaires creusées dans la tranche supérieure de la stèle et situées à l'aplomb de l'axe des corps des femmes, indiquent que la partie haute du relief était travaillée séparément.

\section{Détail de la stèle}

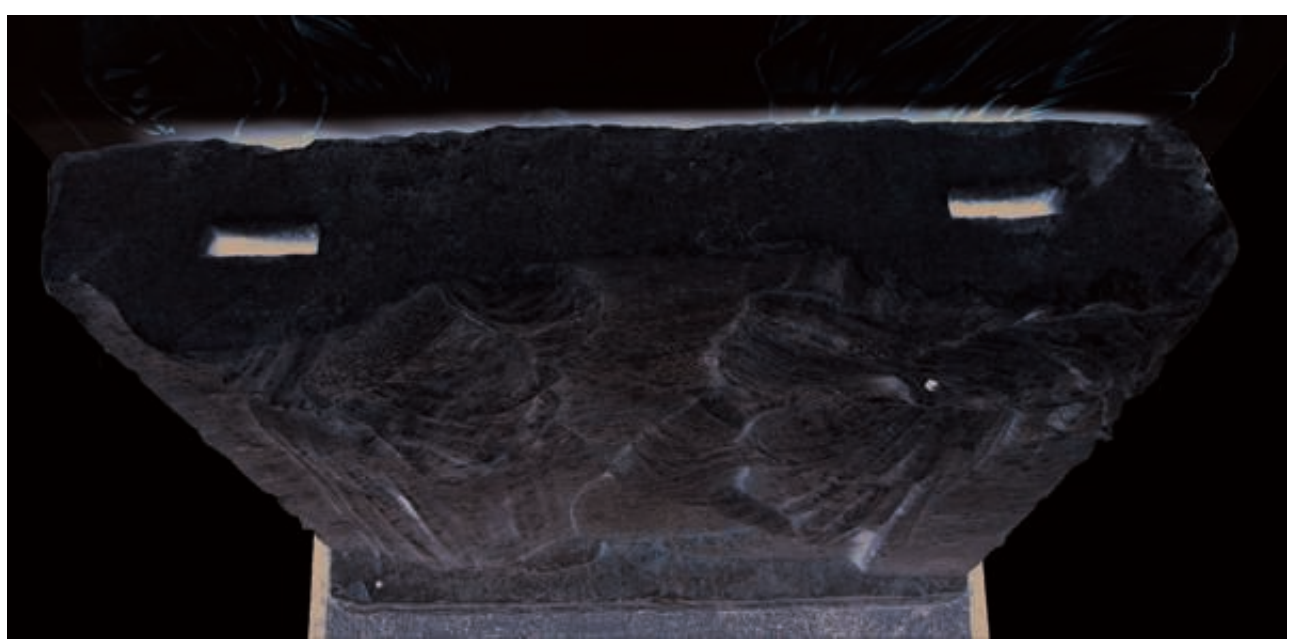

(c) J. Zbinden, université de Berne

2 La femme représentée à gauche porte un chitôn. Elle est en appui sur la jambe droite et sa jambe gauche est légèrement repliée. Elle levait les avant-bras, le droit était rapporté, dans un mouvement aujourd'hui perdu. Le personnage féminin représenté à droite porte également un chitôn, avec un lourd manteau : enroulé autour de son buste et de son bras gauche, le manteau repose en partie sur un pilier sur lequel elle s'accoude. La jambe droite, fléchie, passe devant sa jambe gauche. Le bras droit est complètement perdu mais on remarque que la main gauche avec le poignet était détachée du relief et devait saillir en partie en ronde bosse.

3 Des trous permettant la fixation d'objets ou de parties rapportés sont visibles. L'un sur la base, à côté du pied droit de la figure de gauche, où était inséré le sceptre de la figure de droite. Un deuxième assurait le pied travaillé dans un autre matériau de la figure accoudée alors que la troisième fixation se trouve dans son poignet. Le piquetage de la surface facilitait l'adhérence des éléments rapportés en marbre, les pieds et les mains des personnages représentés. Certains plis dont le modelé n'est pas achevé prouvent l'emploi de la peinture, qui a malheureusement entièrement disparu et qui jouait sans aucun doute un rôle important dans la perception du relief. 
Détail de la stèle

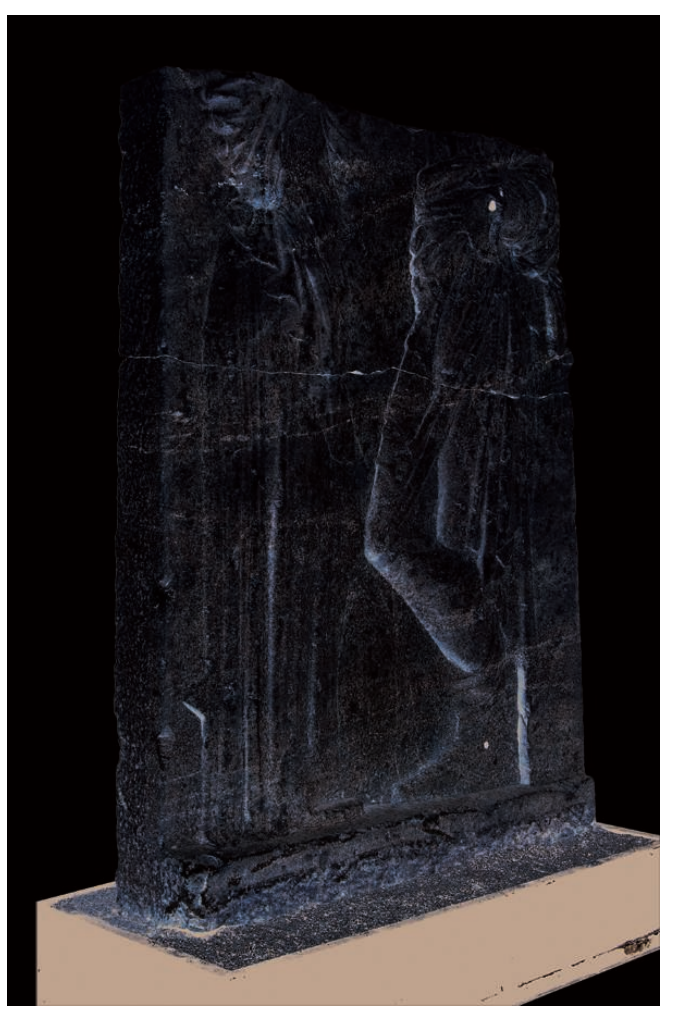

(c) J. Zbinden, université de Berne

4 Ce relief fut dans un premier temps interprété comme une stèle funéraire ${ }^{1}$, E. Lattanzi voyait dans le personnage de droite un homme et dans celui de gauche une jeune femme portant un péplos. Les vêtements permettent déjà d'infirmer cette interprétation : les deux personnages portent des chitôns et sont féminins. Par ailleurs, le marbre, qui manque en Grande Grèce, est réservé aux statues de culte et aux reliefs élevés par la cité aux dieux les plus importants, mais il n'est pas utilisé pour les stèles funéraires.

5 La femme de droite s'appuie sur un pilier et tenait dans sa main perdue un sceptre, exécuté en métal et rapporté. Il était, par ailleurs, fixé par le trou situé sur la base. Dans l'iconographie grecque, la divinité représentée avec un sceptre est Héra, épouse de Zeus et reine des dieux. Elle est usuellement vêtue d'un riche chitôn et d'un manteau. La femme qui lui fait face est de la même taille que la déesse, il ne peut donc pas s'agir d'une mortelle. Les parallèles iconographiques nous font alors envisager deux possibilités: le meilleur parallèle est constitué par le grand relief d'Éleusis pour l'attitude et l'habillement de la figure de droite. Il représente Déméter et Koré qui font le don du blé à Triptolème. Le geste de la jeune Koré est également très proche de celui de la femme à gauche sur le relief de Crotone. Un deuxième parallèle est constitué par une catégorie de stèles bien connue en Grèce, qui représentent deux divinités, pour symboliser l'accord conclu entre deux cités, ou encore une divinité et la personnification d'une cité. 

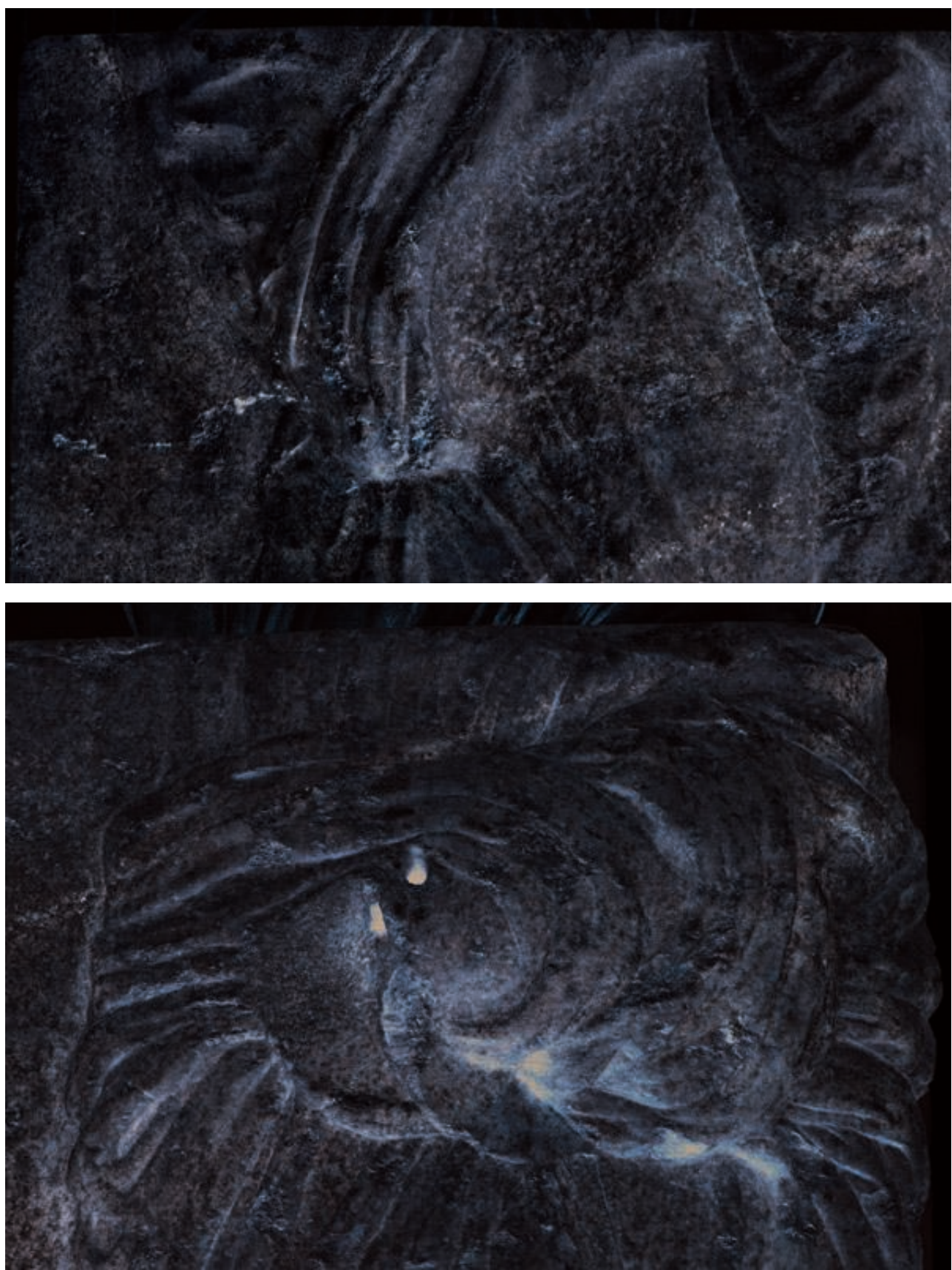

(C) J. Zbinden, université de Berne

6 Si le grand relief d'Éleusis ouvre une piste de recherche intéressante, la présence du sceptre et l'absence du jeune Triptolème sur la stèle de Crotone donnent une autre signification à la scène. Il est préférable d'y voir un accord entre la cité de Kroton personnifiée et Héra, divinité tutélaire de la région. La déesse devait également être honorée au cœur de la ville, ce que ce relief tend à confirmer.

\section{Bibliographie}

8 D. MARINO, M. CORRADO (dir.), O dei di Kroton! Luoghi e testimonianze del sacro dentro le mura, Camera di Commercio, Crotone, 2009, p. 30-39, fig. 1-3. 
E. LATTANZI, "Osservazioni su una stele frammentaria in marmo con scena di commiato ", dans R. BELLI PASQUA et R. SPADEA (dir.), Kroton e il suo terrotorio tra VI e V secolo a.C. Aggiornamenti e nuove richerche. Atti del Convegno di studi, Crotone, 3-5 marzo 2000, Crotone, 2005, p. 19-23, pl. 1-3.

\section{Cat. 2.}

\section{Tête d'Apollon}

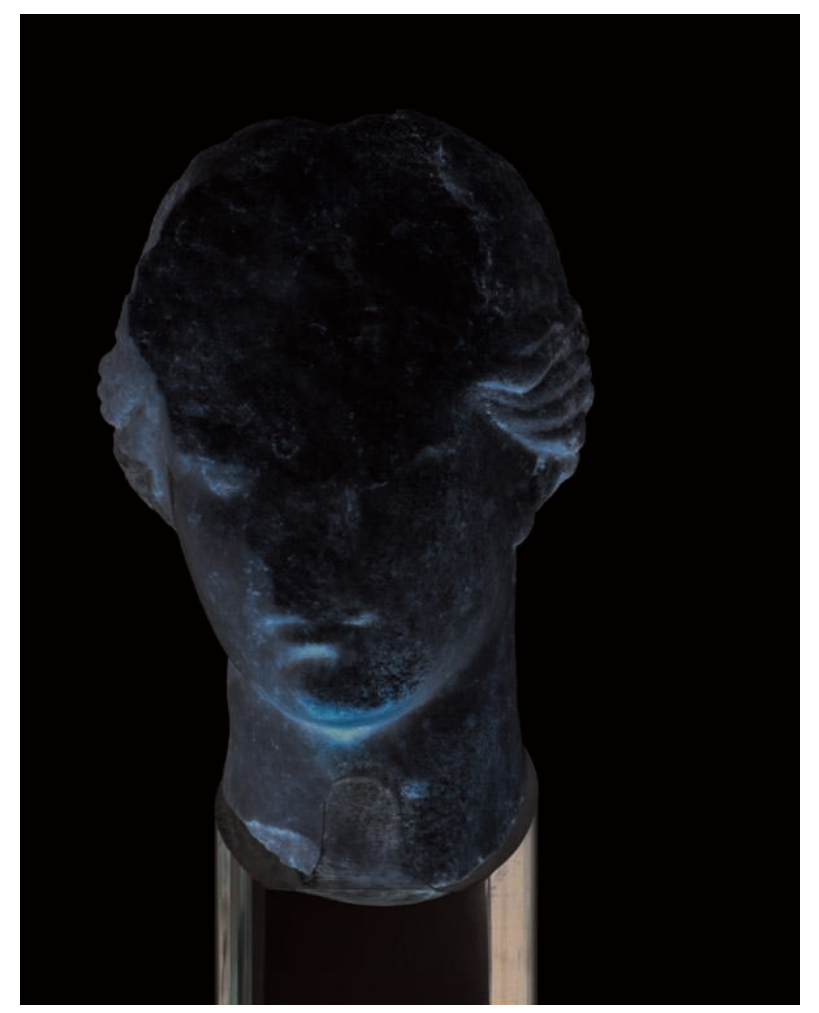

Provenance : Crotone, lieu-dit Quote Cimino.

- Dimensions : hauteur conservée : 9,6 cm ; hauteur de la tête : 7,2 cm; largeur maximum : 6,2 cm ; largeur du visage : $4,5 \mathrm{~cm}$; largeur de la bouche : $1,1 \mathrm{~cm}$.

- Matériel : marbre à grain fin, beige légèrement jaune, très homogène (absence de veines), provenant probablement du Pentélique.

- Datation : 350-300 avant J.-C.

Museo nazionale di Crotone, inv. 116196 @ J J. Zbinden, université de Berne

Voir l'article de Margherita Corrado et Domenico Marino.

9 Cette tête de statuette masculine est conservée jusqu'à la base du cou. Les vues de profil indiquent que la tête était relevée.

10 La partie avant de la coiffure et du visage a disparu, avec l'œil gauche et la partie supérieure de l'œil droit. Le nez et la moitié gauche de la lèvre supérieure manquent. Quelques cassures et marques récentes altèrent la surface. L'épiderme du marbre est endommagé dans la partie gauche du visage et du cou; il a été poli pour effacer les traces d'outils.

11 Le visage est ovale et les joues sont relativement plates en comparaison du modelé soigné des autres parties du visage. La partie de l'œil droit conservée présente une paupière supérieure incisée, contrairement à la paupière inférieure. Le bourrelet de chair qui reste sur l'arcade sourcilière est bien marqué et arrondi. La lèvre inférieure 
est finement modelée et les commissures de la bouche bien marquées. Le menton, petit et rond, présente également un modelé précis.

12 La coiffure est soigneusement travaillée au ciseau : le travail est fin mais en faible relief, les mèches sont plus gravées que modelées. La coiffure est constituée de mèches torsadées qui passent sur les côtés de la tête et se rejoignent à l'arrière du crâne où elles forment un nœud; les extrémités des mèches retombent sur la nuque. La raie médiane n'est pas parfaitement centrée. Le personnage tourne légèrement la tête sur sa droite, faisant saillir un muscle sur le cou.

13 On remarque une profonde marque de foret sur la nuque, à gauche des cheveux. La partie supérieure des oreilles est cachée par les mèches torsadées. Un diadème retenait la coiffure.

14 Cette tête masculine fragmentaire permet une analyse plus poussée que ne le laisserait présager son état de conservation. La présence de longs cheveux sur une tête masculine oriente immédiatement les recherches vers Dionysos ou Apollon. Cependant le diadème apporte un précieux complément d'information: il s'agit du double diadème du citharède, qui était très probablement Apollon.

15 Les proportions de cette tête d'assez petite taille et l'expression relativement figée du visage amènent à la dater dans la seconde moitié du IV siècle avant J.-C.

16 Bibliographie

17 D. MARINO, M. CORRADO (dir.), o dei di Kroton! Luoghi e testimonianze del sacro dentro le mura, Camera di Commercio, Crotone, 2009, p. 25-26, fig. 1a-b.

\section{Cat. 3.}


Tête acrolithe d'une statue

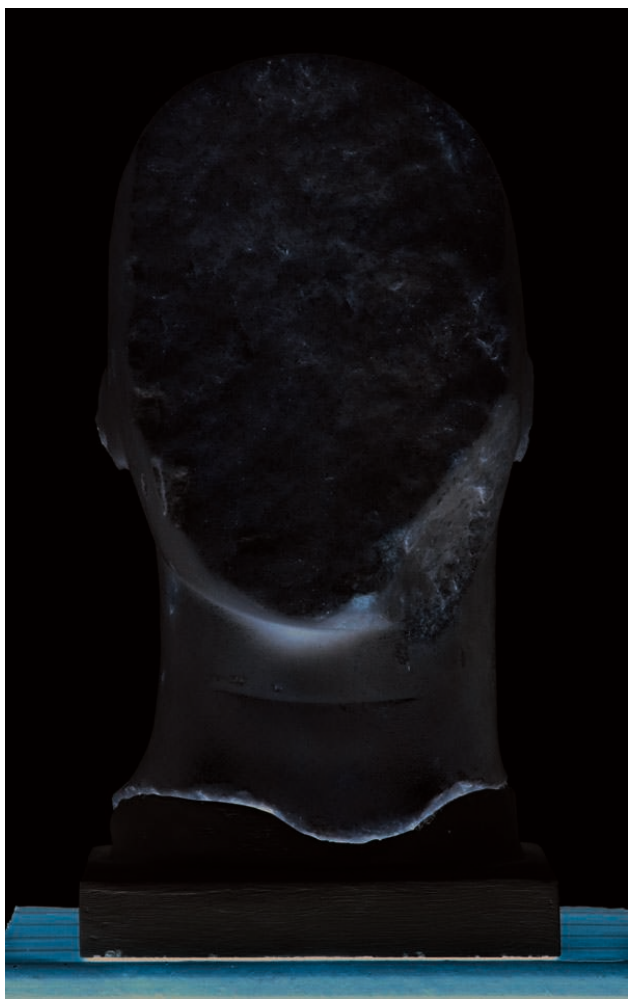

Provenance : Crotone, Via Tedeschi.

- Dimensions : hauteur conservée : 29,3 cm ; hauteur de la tête : $22 \mathrm{~cm}$; largeur du visage : 16,2 cm.

- Matériel : marbre à grain très fin, homogène et translucide, ne comprenant pas de veines mais

quelques inclusions. La surface antique a été perdue lors d'un nettoyage à l'acide.

- Datation : époque classique.

Museo nazionale di Crotone, inv. 18774 @ J. Zbinden, université de Berne

Voir l'article de Margherita Corrado et Domenico Marino.

18 La tête acrolithe est conservée jusqu'au bas du cou mais le visage dont seule la partie inférieure droite du menton subsiste, est perdu. En observant l'épaule et le cou on remarque que la tête est légèrement inclinée vers la droite.

19 Les restes du cou encore conservés présentent un travail sensible et très soigné. Une ligne gravée, pli typique des personnages féminins, est travaillée de façon à souligner le modelé de la chair. Les oreilles, particulièrement petites, sont fortement abîmées et ne laissent plus voir que des trous pour des boucles. La partie supérieure de l'oreille gauche n'est pas modelée, et on peut y observer encore des traces de ciseau. L'angle extérieur de l'orbite oculaire est conservé sur le profil droit.

20 L'angle que forment le visage et le crâne est marqué des deux côtés de la tête. La face arrière de cette dernière est plate et piquetée. Le piquetage de la partie supérieure suit la courbe du crâne vers l'avant. La partie inférieure du cou montre des traces de piquetage fin.

21 Toute la surface, malgré son nettoyage à l'acide, porte des traces d'outils, bien qu'elles soient émoussées. Le sommet de la tête montre l'emploi d'un ciseau très fin. Il faut noter la présence de cassures modernes également émoussées par l'acide sur la face, le profil droit et le profil gauche. 
22 Aucun élément de fixation n'est conservé, mais deux trous profonds, situés au dessus des oreilles, devaient permettre l'insertion d'éléments rapportés.

23 Le travail de la partie inférieure du cou, la forme légèrement triangulaire et la profondeur anormalement faible de la pièce permettent de déduire que cette tête en marbre est bien un acrolithe ${ }^{2}$. Cette technique, particulièrement prisée dans le monde grec d'Occident, comprend un assemblage de divers matériaux pour former une statue. Les parties visibles de la chair - tête, mains et pieds - sont travaillées en pierre puis insérées dans une structure en bois, probablement en partie doré. La statue ainsi constituée était habillée de riches vêtements et ornée de bijoux en métaux précieux.

24 Le piquetage des parties arrière et supérieure de la tête prouve une préparation de la surface pour l'ajustage d'une pièce rapportée. La prolongation du travail suivant une forme rectangulaire jusqu'au niveau des oreilles indique la présence d'un casque. Comme les oreilles percées et la ligne gravée sur le cou désignent un personnage féminin, la tête appartenait très probablement à une statue d'Athéna.

25 La présence d'une statue en marbre d'Athéna dans le centre ville de Crotone permet de soupçonner un sanctuaire urbain de la déesse, dont les sources littéraires ne parlent pas.

\section{Bibliographie}

27 D. MARINO, M. CORRADO (dir.), o dei di Kroton! Luoghi e testimonianze del sacro dentro le mura, Camera di Commercio, Crotone, 2009, p. 41, fig. 1a-b.

\section{Cat. 4.}




\section{Statuette d'Hermès}

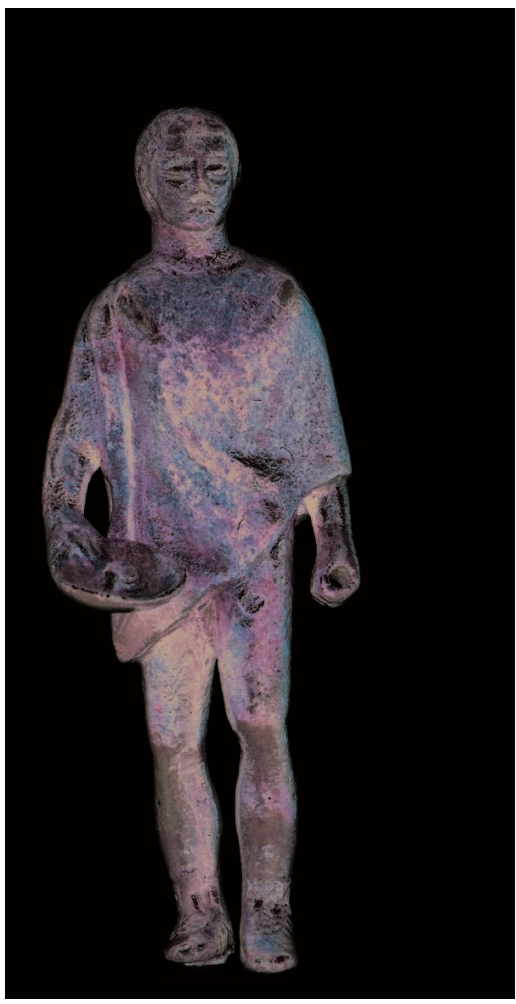

- Provenance : inconnue.

- Dimensions : 7,5 cm.

- Matériel : bronze à patine brun-noir et verte.

- Datation : époque classique.

Museo nazionale di Crotone (c) J. Zbinden, université de Berne

28 Statuette en bronze d'un personnage masculin aux cheveux courts, vêtu d'un manteau et de bottines ailées. Il tient une phiale dans sa main droite et portait dans la main gauche un deuxième objet, d'après la position des doigts qui enserrent un espace circulaire.

29 Le modelé de la statuette est peu marqué, la physionomie du visage n'est pas très détaillée. L'emploi de la technique de la fonte pleine pourrait expliquer ce manque de précision.

30 La présence de petites ailes à l'arrière des bottines permet d'identifier le dieu Hermès. Les ailes sont de dimensions particulièrement modestes si on les compare à d'autres représentations. Les bottines et le manteau sont également souvent présents dans les représentations du dieu. 
Vues de la statuette

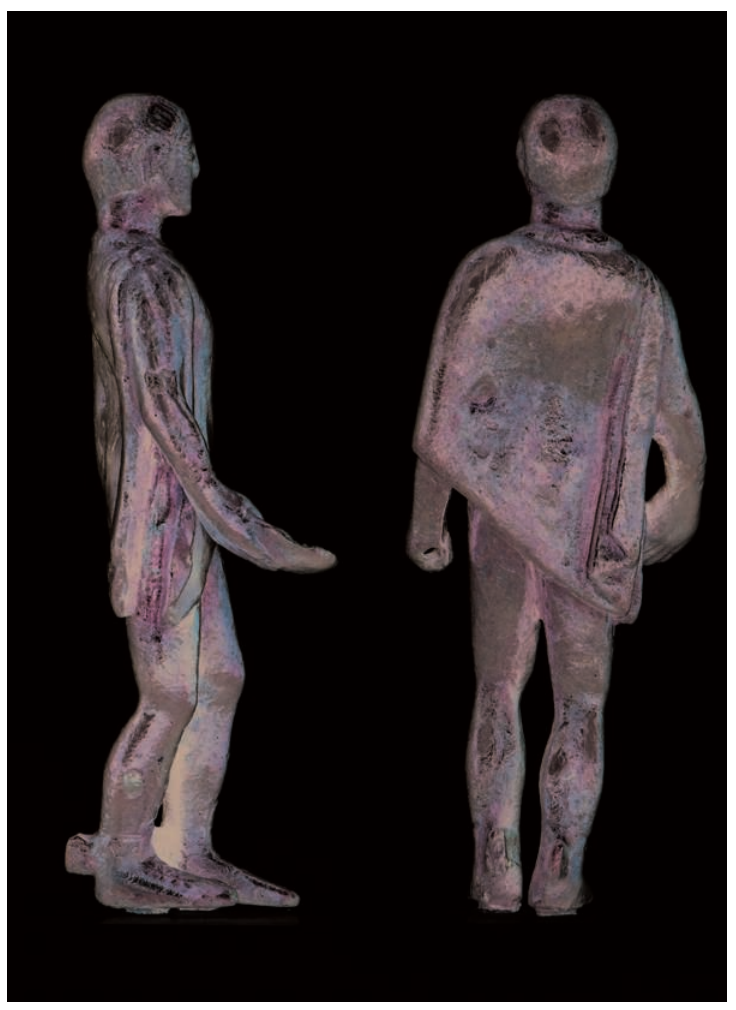

(c) J. Zbinden, université de Berne

31 Les statuettes de divinités se retrouvent fréquemment dans les sanctuaires. Ce petit Hermès constituait probablement une offrande votive mais comme on ignore son lieu de trouvaille, on ne peut approfondir l'analyse.

\section{Bibliographie}

33 D. MARINO, M. CORRADO (dir.), O dei di Kroton! Luoghi e testimonianze del sacro dentro le mura, Camera di Commercio, Crotone, 2009, p. 43, fig. 6.

\section{Cat. 5.}


Chaudron en bronze contenant des chaînes en fer
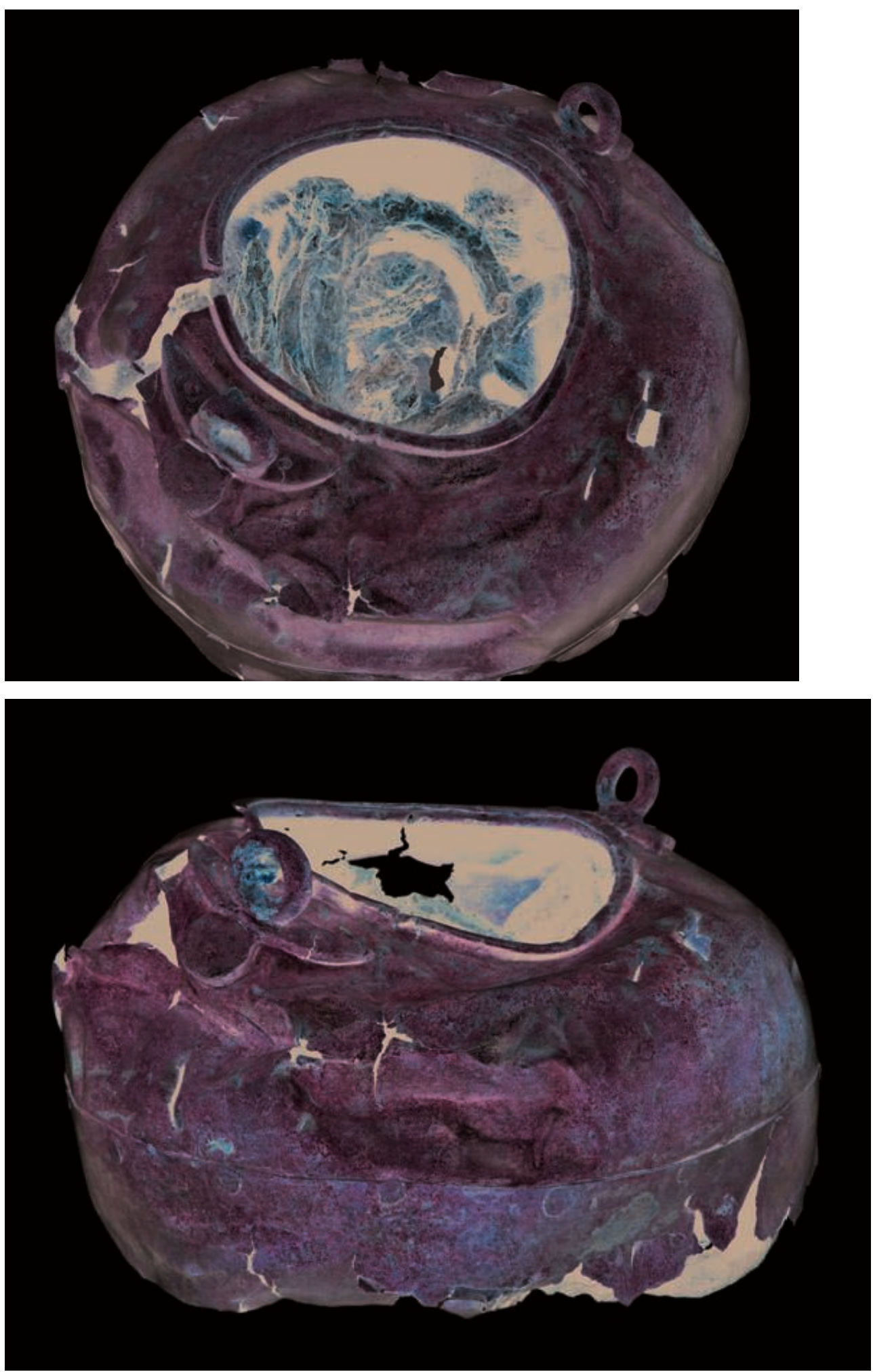

Provenance : Vigna Nuova.

- Dimensions : hauteur conservée de la cuve : $21 \mathrm{~cm}$; largeur maximum conservée : $29 \mathrm{~cm}$; épaisseur du métal : moins de $0,5 \mathrm{~cm}$.

- Matériel : chaudron en bronze à patine verte contenant des éléments en fer oxydé.

- Datation : période classique.

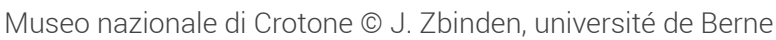

Voir l'article de Lorenz E. Baumer. 

exposées dans le temple d'Athéna Alea à Tégée ou les chaînes des Chalcidiens apposées sur les remparts de l'Acropole d'Athènes ${ }^{3}$.

\section{Bibliographie}

R. SPADEA, «Santuari di Hera a Crotone », dans J. DE LA GENIÈRE (dir.), Héra. Images, espaces, cultes. Actes du Colloque international du Centre de Recherches archéologiques de l'Université de Lille III et de l'Association P.R.A.C., Lille, 29-30 novembre 1993, Naples, 1997, p. 235-259 : 255-256, fig. 27a-b.

R. SPADEA, « La topographia », dans Crotone. Atti del ventitreesimo convegno di studi sulla Magna Grecia, Taranto, 7-10 ottobre 1983, Tarente, 1984, p. 145-150.

Cat. 6. 


\section{Talons de lance}

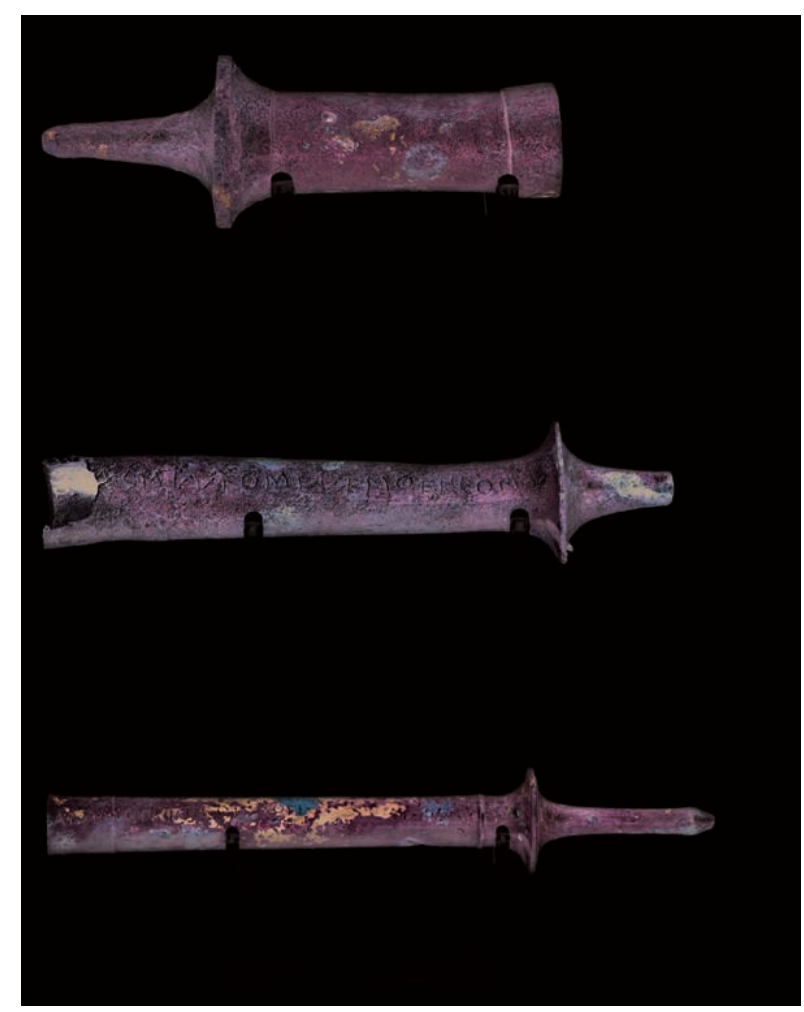

- Provenance : Vigna Nuova.

- Dimensions : 1) longueur maximum conservée : $14 \mathrm{~cm}$;2) longueur maximum conservée: 29 cm ; 3) longueur maximum conservée: 19,3 cm.

- Matériel : bronze présentant une importante patine verte à bleu-noir.

- Datation : 500-450 avant J.-C.

Museo nazionale di Crotone, inv. VN 818 /R, 18791 et 18790 (C) J. Zbinden, université de Berne

Voir l'article de Lorenz E. Baumer.

Les trois talons de lance en bronze dont deux portent des inscriptions en alphabet achéen, ont été découverts dans le sanctuaire de Vigna Nuova.

Inv. VN 818 /R: le plus petit talon de lance retrouvé à Vigna Nuova est également le modèle le plus simple. Il est constitué du fût en métal, plus large mais également plus court que les deux autres modèles, qui s'élargit en un disque et se finit en une pointe à l'extrémité arrondie.

Inv. 18791 : le mieux conservé du groupe (près de $30 \mathrm{~cm}$ sont préservés), cet exemplaire est également le plus travaillé. La pièce semble avoir conservé la totalité de sa longueur. Elle présente trois anneaux en relief ainsi qu'un cercle incisé près de son extrémité distale où le métal s'élargit pour former un disque. La corrosion a provoqué des soulèvements de divers fragments de l'épiderme du métal.

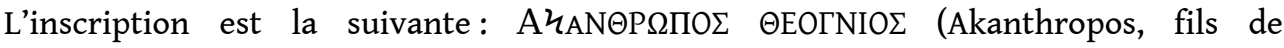
Theognios). Il s'agirait du dédicant de l'offrande.

Inv. 18790 : ce talon de lance est le moins bien conservé des trois. La partie supérieure est perdue, emportant aussi le début de la dédicace. Le fût n'étant pas rectiligne, l'extrémité inférieure de la pièce s'élargit en un disque et finit en une pointe tronquée. L'inscription mentionne: $\operatorname{AI} \Sigma \mathrm{XY} \Lambda \mathrm{O} \Sigma$ EXE $\Sigma \Theta E N E O \Sigma$ (Aischyles, fils d'Echesthenes) ; ici encore, il s'agit du nom du dédicant. 
Les objets aujourd'hui connus comme des talons de lance divisent les chercheurs quant à leur fonction précise. On a proposé d'y voir respectivement des éléments de sceptre, des pieds de mobilier ou des mâts de tente. Il est cependant généralement admis qu'il doit s'agir des parties inférieures de lances qui permettaient à la fois d'en équilibrer le poids lors du lancer et de les planter de façon stable dans le sol, tout en protégeant le manche en bois, plus fragile, pendant les périodes de repos. Ils pouvaient également être employés au combat en cas de besoin : Plutarque rapporte qu'un cavalier perse du nom de Masistios aurait été tué d'un coup de talon de lance dans l'œil en 479 avant J.-C. (Arist. 14,5).

De très nombreux talons de lance retrouvés dans des sanctuaires, notamment à Olympie, prouvent qu'ils constituaient des offrandes de choix ${ }^{4}$. Quatre types principaux ont pu être définis, les trois exemplaires retrouvés à Vigna Nuova appartiennent à la " catégorie III », c'est-à-dire aux talons de lance à pointe ronde. Un certain nombre de ces offrandes portent des inscriptions de dédicace. Les armes faisaient probablement partie de trophées, permettant aux visiteurs du sanctuaire à la fois de les admirer et de lire les inscriptions.

47 Les trois exemplaires retrouvés au sanctuaire de Vigna Nuova auraient donc été dédiés à l'occasion d'une victoire de la cité.

\section{Bibliographie}

49 R. SPADEA, «Santuari di Hera a Crotone », dans J. DE LA GENIÈRE (dir.), Héra. Images, espaces, cultes. Actes du Colloque International du Centre de Recherches Archéologiques de l'Université de Lille III et de l'Association P.R.A.C., Lille, 29-30 novembre 1993, Naples, 1997, p. 235-259 : 256-257, fig. 29-31.

R. SPADEA, « La topographia », dans Crotone. Atti del ventitreesimo convegno di studi sulla Magna Grecia, Taranto, 7-10 ottobre 1983, Tarente, 1984, p.145-146.

\section{Cat. 7.}




\section{Anse d'hydrie}

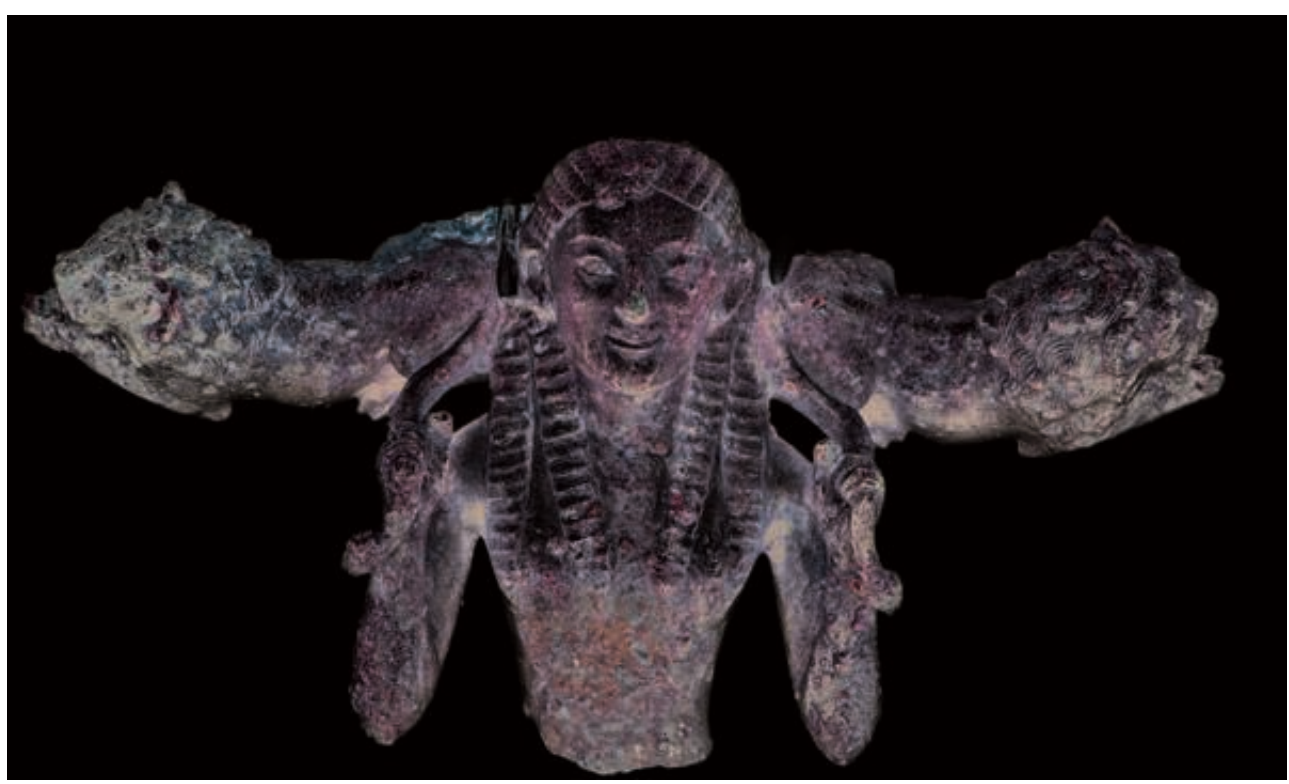

- Provenance : Crotone, Vigna Nuova.

- Dimensions : hauteur : $6,4 \mathrm{~cm}$ : largeur : $10,9 \mathrm{~cm}$

- Matériel : bronze présentant une patine verte.

- Datation : 550-530 avant J.-C.

\section{Anse d'hydrie vue de côté}

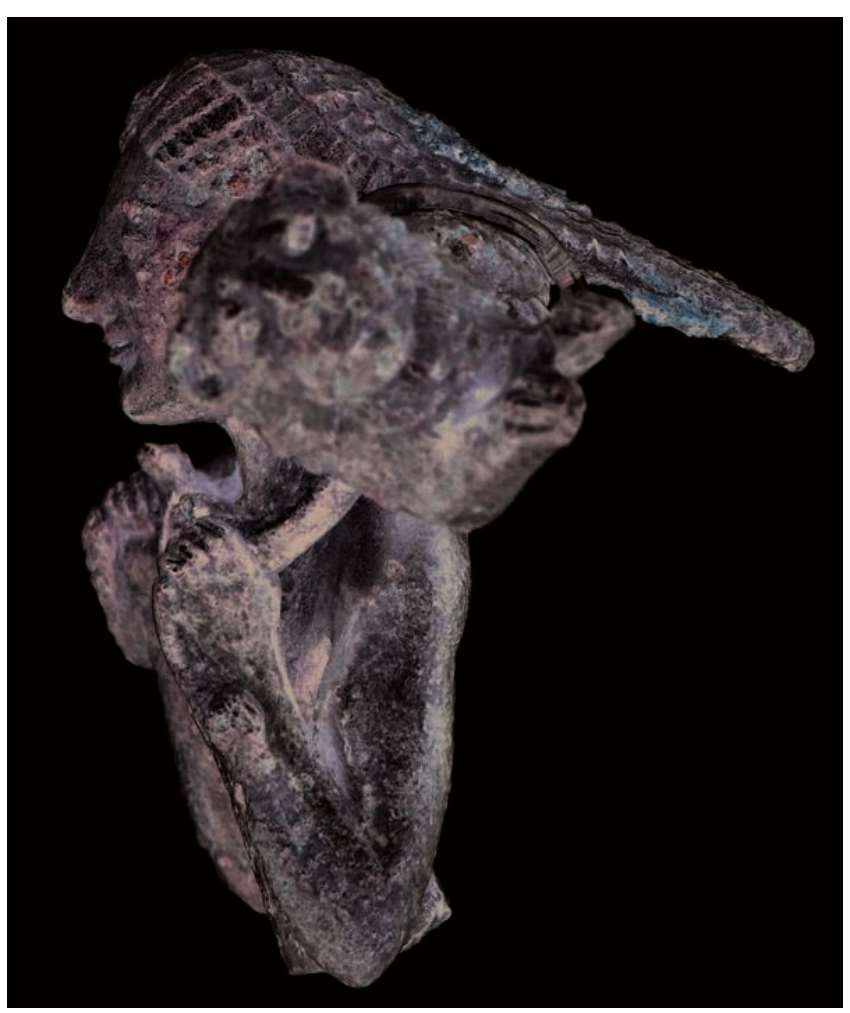


Anse d'hydrie vue du desssus

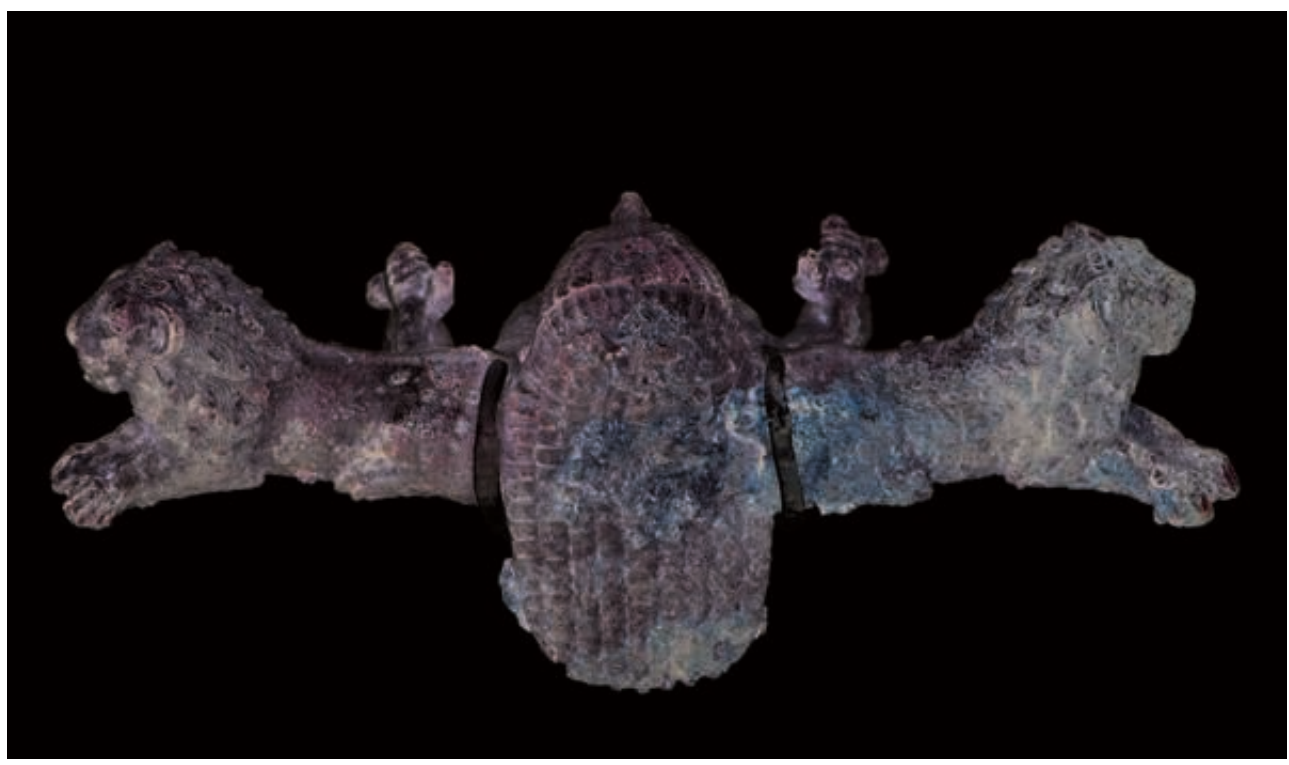

Museo nazionale di Crotone $@$ J. Zbinden, université de Berne

Voir l'article de Lorenz E. Baumer.

Attache de récipient en bronze en forme de kouros, la pièce est conservée jusqu'à la taille du personnage masculin. Deux lions partent horizontalement de part et d'autre du kouros, au niveau de ses épaules. Le personnage est torse nu et porte une coiffure ordonnée en longues mèches ; les deux bras relevés, il tient dans ses mains les queues des lions.

Cette anse plastique devait faire partie d'un récipient en bronze aujourd'hui perdu. Des parallèles typologiques permettent de déterminer qu'il s'agissait d'une hydrie ${ }^{5}$. Le style du kouros permet de le rapprocher de l'art laconien, notamment par sa coiffure longue. Un exemplaire de ce type, aujourd'hui conservé à Athènes ${ }^{6}$ et provenant de l'Acropole, a les pieds posés sur deux béliers. Les autres exemplaires connus n'ont pas conservé leurs supports. Il existe également des variantes, comme un exemplaire conservé à Berlin $^{7}$, où le personnage est agenouillé et ne tient pas des lions mais une languette rectangulaire à décor de palmettes.

La pièce est finement travaillée : le fin visage ovale avec une petite bouche et un nez bien marqué est typique de l'art laconien.

\section{Bibliographie}

54 R. SPADEA, « Oggetti figurati di bronzo », dans R. BELlI PASQUA, R. SPADEA (dir.), Kroton $e$ il suo territorio tra VI e V secolo a.C. Aggiornamenti e nuove ricerche. Atti del Convegno di Studi. Crotone, 3-5 marzo 2000, Crotone, 2005, 25-41, pl. 4-15 : p. 32-33, pl. 7-8.

R. SPADEA, «Santuari di Hera a Crotone », dans J. DE LA GENIÈRE (dir.), Héra. Images, espaces, cultes. Actes du Colloque international du Centre de Recherches archéologiques de l'Université de Lille III et de l'Association P.R.A.C., Lille, 29-30 novembre 1993, Naples, 1997, p. 235-259 : 255-256, fig. 28. 


\section{NOTES}

1. E. LATTANZI, «Osservazioni su una stele frammentaria in marmo con scena di commiato ", dans R. Belli Pasqua, R. Spadea (dir.), Kroton e il suo terrotorio tra $\mathrm{VI}^{e} V^{e}$ secolo a. C. Aggiornamenti e nuove ricerche, Atti del Convegno di studi, Crotone, 3-5 marzo, Crotone, 2005, p. 19-23.

2. Voir : G. I. DESPINIS, Zu Akrolithstatuen griechischer und römischer Zeit, Göttingen, 2004.

3. Voir SPADEA, «Santuari di Hera a Crotone », dans J. DE LA GENIÈRE (dir.), Héra. Images, espaces, cultes. Actes du Colloque international du Centre de Recherches archéologiques de l'Université de Lille III et de l'Association P.R.A.C., Lille, 29-30 novembre 1993, Naples, 1997.

4. H. BAITINGER, Die Angriffswaffen aus Olympia, Olympische Forschungen XXIX, Berlin 2001.

5. M. HERFORT-KOCH, Archaische Bronzeplastik Lakoniens, Munster, 1986

6. Athènes, Musée national, inv. 6588 et 6650.

7. Berlin, Staatlische Museen, inv. 1961.2. 


\title{
Les sanctuaires urbains de Crotone dans la tradition littéraire et les sources antiquaires
}

\author{
Margherita Corrado et Domenico Marino \\ Traduction : Patrizia Birchler-Emery, Virginie Nobs et Lorenz E. Baumer.
}

1 La tradition antiquaire crotoniate connaît un tournant au milieu du XVII siècle avec l'œuvre de Giovan Battista di Nola Molisi, Cronica dell'Antichissima, e Nobilissima città di Crotone e della Magna Grecia, imprimée à Naples en $1649^{1}$. L'origine des informations est inconnue lorsque l'auteur ne se réfère pas explicitement aux sources classiques, en dépit de son affirmation d'avoir tiré ses informations d'un texte en latin de 1523, œuvre de Camillo Lucifero, qu'il dit avoir perdu après l'avoir consulté. La crédibilité des données est de plus réduite par l'absence ou le caractère générique des indications permettant la localisation des espaces sacrés mentionnés, ainsi que, parfois, par le laps de temps écoulé entre les faits rapportés et la rédaction du texte qui les documente. De plus, l'interprétation souvent fantaisiste de faits invérifiables de nos jours entame leur crédibilité et conseille la prudence. 


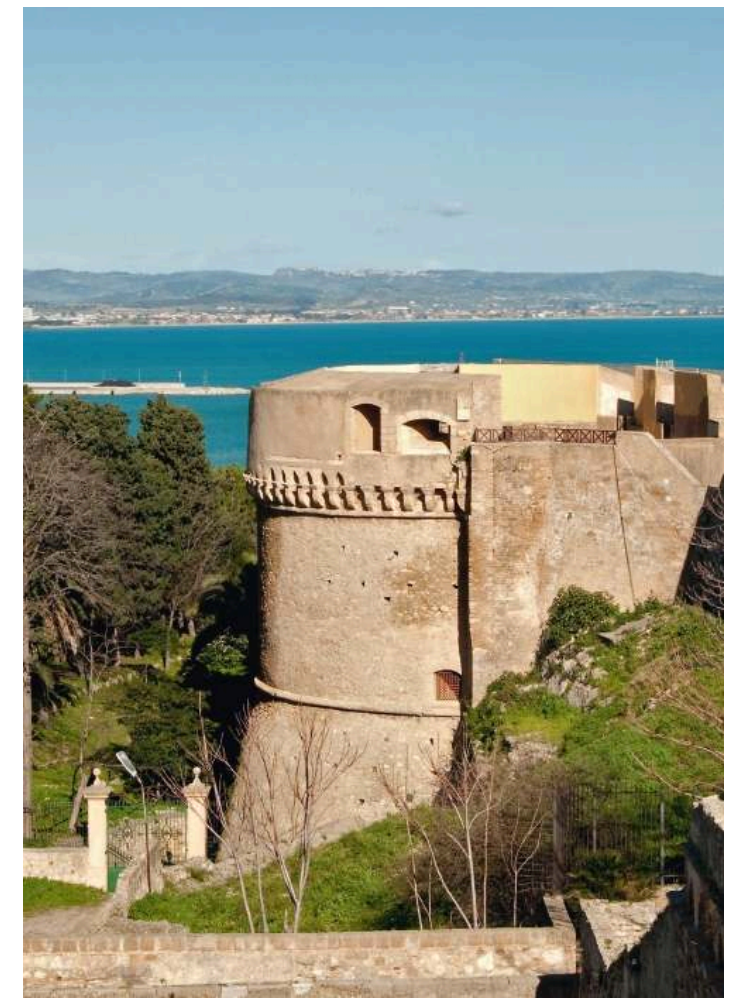

(c) J. Zbinden, université de Berne

2 Se basant sur des passages de divers auteurs antiques, Nola Molisi relate : « Il y avait là le temple de Cérès, déesse des blés, édifié par Crotone après la mort de Pythagore, dans la maison même de Pythagore, comme le dit Valérius Maximus dans son huitième livre du seizième volume [...] » (p. 51, voir fig. 2-5). Cérès est évidemment la Déméter grecque, qui a probablement eu un culte dans l'espace urbain de Crotone, comme le démontrent quelques témoignages archéologiques, figurines de femmes en terre cuite portant un flambeau et un porcelet, ainsi que certaines séries monétaires en bronze, toutes postérieures, toutefois, à l'époque archaïque. Dans l'arrière-pays de la ville, plusieurs sanctuaires ruraux de la déesse ont été identifiés, à Cirò Marina dans la localité de Bivio Alice, de Zinga di Casabona, ainsi qu'un troisième dans la région de Carfizzi.

Suivant les sources classiques, Nola Molisi signale: «Il y avait le Temple de Jupiter Omarius, conformément à ce que dit Polybe, dans le deuxième livre de son histoire, [...]» (p. 51); ou encore : «Jamblique, dans la vie de Pythagore, dit que les Crotoniates, sur le conseil de Pythagore qui affirmait qu'Hercule avait illustré de son nom la ville de Crotone et qu'il l'avait toujours tenue en sa protection, construisirent un très grand Temple à Hercule et lui érigèrent une très grande statue, au milieu de la vaste Place. Ce temple fut toujours tenu en grande estime et vénération par les Crotoniates [...]» (p. 50).

4 Selon Nola Molisi, « Il y avait le Temple de Junon Lacédémonienne auprès duquel on voyait selon Pausanias dans son sixième livre la statue d'Astilus le Crotoniate [...]» (p. 51); «Il y avait le Temple d'Apollon, que mentionne Jamblique, quand il dit que les Crotoniates avaient abandonné leurs concubines sur les admonestations de Pythagore et l'avaient prié entre autres choses de pouvoir raisonner leurs enfants dans ledit 
Temple d'Apollon. Dans ce Temple fut déposé par les Crotoniates l'arc d'Hercule après l'avoir emporté de force du Temple d'Apollon Alaios [...] » (p. 51-52).

5 En citant l'œuvre perdue de Lucifero, l'auteur enrichit le paysage religieux de Crotone de trois autres sanctuaires, dédiés aux muses, à Mars et à la Victoire qui, à l'exception du premier, ne se retrouvent pas dans les textes antiques. Ils pourraient en effet être liés à l'interprétation des ruines imposantes de certaines sections de l'enceinte de Crotone : « Il y avait le Temple des muses construit par les Crotoniates comme le disent Jamblique et Nicolò Scutellico dans la vie de Pythagore, ainsi qu'Aulu-Gelle dans le premier livre, pour que la cité se maintienne dans une perpétuelle concorde. [...] ce Temple était situé à l'intérieur de la Cité sur un mont sublime nommé aujourd'hui encore la Cappellina ainsi désigné d'après le nom de la prêtresse de ce Temple, qui était la ville d'Apius le Crotoniate, selon ce que dit Camillo Lucifero dans son manuscrit de l'année 1523.» (p. 52) La Cappellina se trouve être la Timpa della Capperrina, la colline qui fut le siège de la cité médiévale. Concernant le sanctuaire de Mars, Nola Molisi indique : « Il y avait le Temple de Mars situé à l'intérieur de la Cité, aussi sur un mont dit Caudino, parce qu'on y retrouva quelques queues de serpents et que par conséquent sous les pieds de Mars étaient sculptés des serpents, ce mont s'appelle aujourd'hui la Rotonda [...]. Ce Temple fut aussi construit par les Crotoniates sur le conseil de Pythagore, suite à la victoire obtenue contre les deux cités battues par les Crotoniates, nommées Temsa et Cleta, la statue de Mars avait tout le corps en argent et la tête en or, or et argent provenant du pillage de ces deux cités conformément à ce que dit Camillo Lucifero.» (p. 52-53) En 1905, dans ses Ricordi sugli avanzi di Crotone, Nicola Sculco signale la coïncidence du toponyme Rotonda avec le moderne Torretonda où il décrit, quelques restes de murailles antiques mis à part, "une forteresse, qui flanquait le temple voisin ». Même aujourd'hui, des blocs en calcaire,récupérés éventuellement de constructions d'époque grecque, peuvent en effet toujours être reconnus dans les murs de la tour et de certains édifices résidentiels de la zone, mais sans pouvoir prouver l'hypothèse.

6 Assez fantomatique est aussi le sanctuaire de la Victoire ; d'après Nola Molisi, « il y avait un autre Temple dédié à la Déesse de la Victoire, construit encore sur le conseil de Pythagore et situé sur un autre mont qui à l'époque se trouvait à l'intérieur de la Cité [...], lequel mont se nommait Egregorio. [...] aujourd'hui ce mont se nomme Maccoditi et c'est justement celui qu'aujourd'hui on appelle la Torre di Mangioni, des gentilshommes de cette Cité ; ce Temple fut aussi érigé après que les Crotoniates eurent vaincu les deux cités déjà nommées de Temsa et Cleta et du produit de leur pillage ils firent aussi le corps tout en argent de la statue de la Victoire et la tête en or, comme on l'a déjà dit pour celle de Mars ; tout ce que j'ai dit est conforme au manuscrit du déjà nommé Camillo Lucifero » (p. 53). Sur la base des sources d'époque médiévale et plus récentes, la colline Maccoditi/Maccodito/Maccuditi a été localisée à gauche de l'Esaro et de son affluent, le Lampus-Papaniciaro, non loin de la localité Torre Tonda déjà mentionnée et dans une position qui domine la plaine de l'ancienne zone industrielle et où des traces de l'enceinte de la cité ont été retrouvées. 
2-5. Reproduction des pages 50-53 de l'ouvrage de Giovan Battista di Nola Molisi, La Cronica dell'Antichissima, e Nobilissima città di Crotone e della Magna Grecia, Naples, 1649.
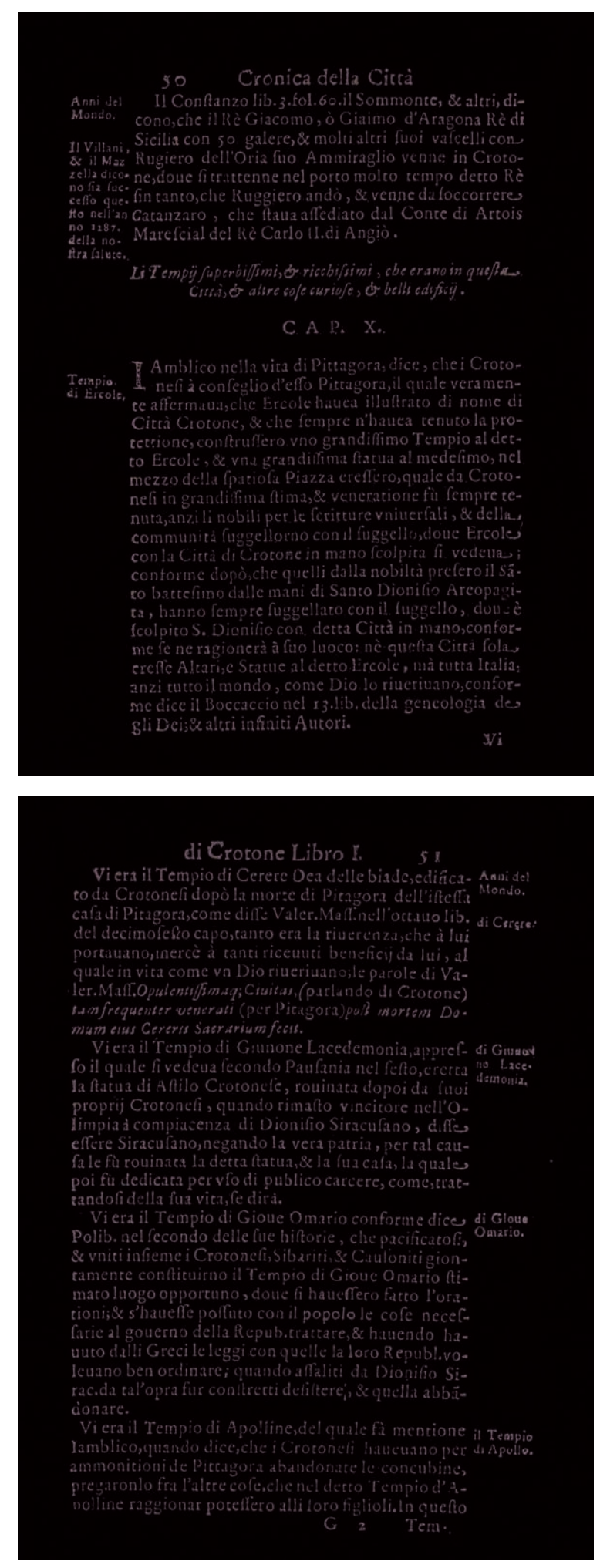

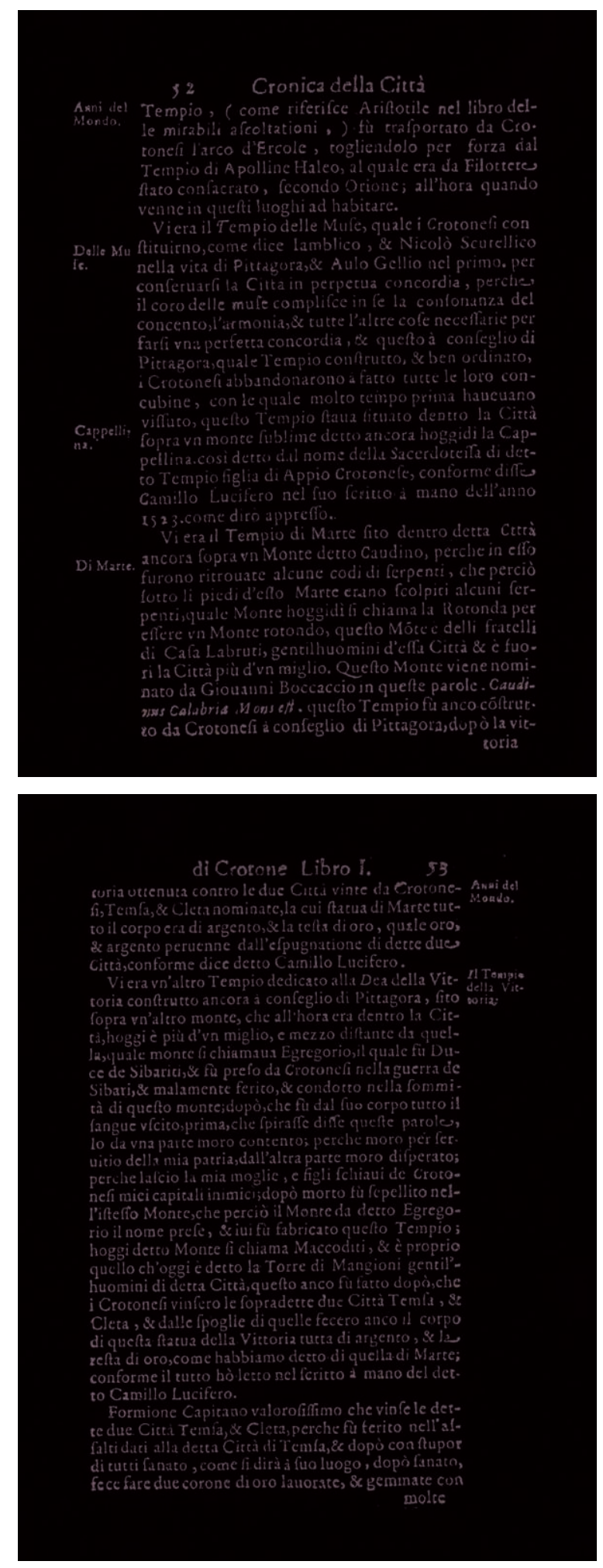


\section{NOTES}

1. NdÉ : nous remercions François Queyrel pour sa relecture du texte. 


\section{Le territoire de Crotone}

\section{Domenico Marino}

1 La Calabre centre-orientale rencontre ses limites géographiques avec les fleuves Trionto au nord et Ancinale au sud, tandis que la mer Ionienne et le plateau de la Sila constituent respectivement les limites orientale et occidentale (fig. 1). A l'intérieur de ce vaste territoire, la chora de Crotone (Kroton dans l'Antiquité), située entre les bassins hydrographiques des fleuves Tacina au sud-ouest et Neto au nord, montre des caractéristiques géologiques et morphologiques unitaires qui la distinguent du reste de la région ${ }^{1}$. 


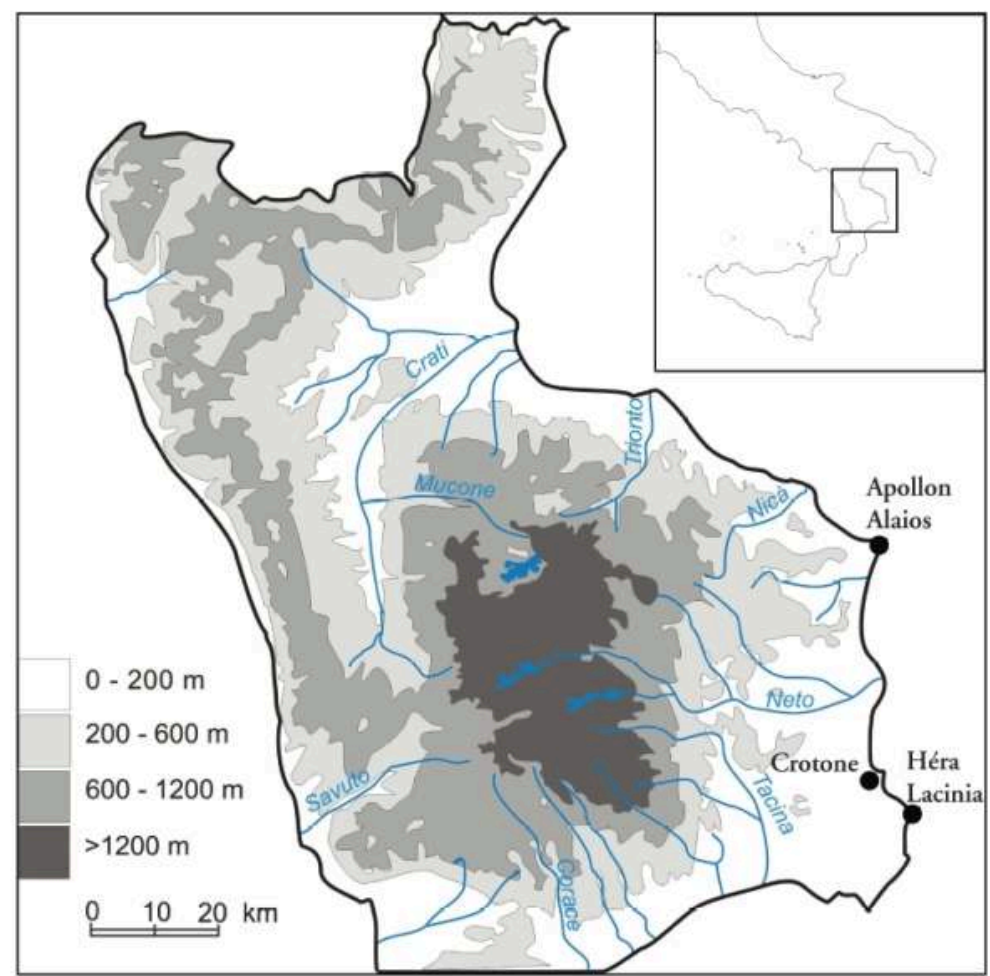

(c) Lorenz E. Baumer

2 Ce territoire est structuré selon une série de plans, situés à des altitudes différentes et constitués exclusivement d'importants dépôts de terrasses marines pliopléistocéniques, dont la plupart sont légèrement inclinées vers l'est. Leur altitude maximale est atteinte par le relief Antenna (202 $\mathrm{m}$ au-dessus du niveau de la mer) et la terrasse de Cutro $(230 \mathrm{~m})$, tandis que la minimale est formée par la grande terrasse submergée au sud-ouest de Le Castella, située à une profondeur moyenne de $30 \mathrm{~m}$. Ces plans trouvent leur extension maximale à Capo Colonna, Prestica, Piano delle Croci, Pianura Marina, Stumío, Campo Lungo et Capo Rizzuto.

Morphologiquement parlant, les promontoires constituent les extrémités de certaines terrasses marines, placés à une altitude moyenne de 8-10 m (Capo Piccolo et la pointe Le Castella) ou de 17-18 m (Capo Rizzuto, Capo Bianco et Capo Cimiti). On peut relever à ce propos la hauteur notable $(42 \mathrm{~m})$ du bord occidental de la terrasse entre Campolongo et Torre Brasolo.

4 Les différents plans sont séparés par une série de vallées disposées de manière radiale par rapport à la ligne côtière; celles-ci sont marquées par l'érosion aussi bien météorologique que marine ou due aux événements géologiques.

5 Les terrasses présentent des contours mouvementés, dus à l'érosion qui, le long de la ligne côtière, a eu comme résultat la formation de talus très raides et, à l'intérieur, des calanques et des crêtes.

6 Les diverses hauteurs et inclinaisons des plans côtiers ouvrent d'incroyables panoramas, comme depuis la pointe centrale du Capo Cimiti d'où, à travers la pointe septentrionale, on peut entrapercevoir Capo Colonna. 
7 Le littoral alterne entre tronçons sableux et rocheux. Les dépôts littoraux sont en moyenne peu profonds, comme au lieu-dit Irto, entre Crotone et Capo Colonna, et à Tagliere ; ils atteignent leur profondeur et développement maximum au nord de Capo Donato, de Capo Pellegrino a Marinella, de Punta Fratte a Capo Rizzuto et, enfin, de Seleno a Santa Domenica; ils se prolongent de manière continue à travers une bonne partie du Golfe de Squillace à partir de Barco Vercillo en direction de Punta di Stalettì, où la côte s'élève à nouveau en une terrasse rocheuse imposante et à pic.

8 La ligne côtière uniforme de la Calabre orientale se brise à proximité de la zone crotoniate (connu sous le nom de Marchesato) et s'étend brusquement vers le sud-est en de nombreuses langues de terre, constituées des divers promontoires, en un ensemble que Pline comparait à une feuille de chêne ${ }^{2}$.

9 Il est nécessaire de résumer les événements tectoniques complexes qui ont déterminé la genèse de ce territoire. Il y a environ cinq millions d'années, le territoire de l'actuelle péninsule est dominé par la mer qui vient effleurer les quelques hauteurs émergées de l'Apennin calabrais. Sur les fonds marins orientaux de ces « îles », la mer pliocénicocalabraise dépose des sédiments d'argile gris-azur ou gris-jaunâtre riches en fossiles qui atteignent une épaisseur de 240-300 m. Il s'agit du dénommé «bassin sédimentaire de Crotone", où sont déposées des argiles marneuses et des argiles limoneuses, intercalées avec de minces couches de limon, sables et grès tendres, et du ciment calcaire, provenant de l'érosion des terres émergées voisines. Sous la poussée des forces tectoniques qui continuent encore actuellement de modeler la chaîne calabro-sicule, commence au néozoïque (il y a deux millions d'années) l'émersion progressive du fonds marin pliocénique, accompagnée de variations répétées du niveau de la mer, successives aux divers épisodes glaciaires. Cette émersion tectonique de type intermittent forme les nombreuses terrasses que l'on peut observer de nos jours à des niveaux différents. Dans la zone de Capo Colonna, l'antique promontoire Lacinium, on peut compter jusqu'à cinq niveaux.

10 À chaque intervalle d'émersion, les terrasses sont érodées le long de la ligne du rivage et sont transformées par l'air dans les parties émergées. Il ne faut pas oublier que le climat connaît aussi des transformations, radicales parfois, avec des conséquences inévitables sur l'environnement. Dans les fonds profonds du littoral se sédimente un dépôt, très différent de celui du pliocène, que l'on peut relever aujourd'hui dans la plate-forme supérieure d'une épaisseur de 2 à 10 mètres, constituée de sables et grès quartzeux à ciment calcaire, souvent à stratification croisée, de calcarénites avec des calcaires blioclastiques et algaux, intercalés occasionnellement avec des conglomérats et des graviers, ainsi que de rares bancs argileux.

11 Durant la dernière période du pléistocène (130 000-10 000 avant J.-C.), probablement au cours de la grande glaciation de Würm, le niveau de la mer descend à sa valeur la plus basse. C'est ainsi que les flancs des terrasses sont incisés par la ligne du rivage de cette époque, aujourd'hui submergée, suite à la transgression post-würmienne qui amène la mer à un niveau proche de l'actuel. Certains signes de cette érosion peuvent être reconnus sur les terrasses submergées, parfois incisées par les vallées fluviales jusqu'à $500 \mathrm{~m}$ de l'actuelle ligne de rivage. Sur la surface des dépôts marins pléistocéniques, désormais émergés, l'action érosive des eaux météorologiques et les transformations provoquées par le couvert végétal créent un sol peu profond et léger, constitué de sables bruns ou brun-rouge, mêlés à des graviers. Il s'agit d'un terrain particulièrement 
fertile et adapté à des pratiques agricoles peu technologiques, l'agriculture dite «à sec ».

Pendant l'holocène (de 8000 avant J.-C. à nos jours), le couvert végétal subit des transformations continues, avec une régression voyante des conifères boréaux, qui seront remplacés le long de la côte par des chênaies mixtes. La couche pléistocénique, après les derniers affleurements ayant provoqué la désagrégation de son caractère compact, est soumise durant l'holocène à une forme particulière d'érosion sur son bord externe, proche de la mer. Là où la terrasse pléistocénique affleure partiellement le long de la ligne côtière, le dépôt s'érode avec une extrême facilité, compromettant la stabilité de la couche supérieure. Même aux endroits où n'affleure que la couche rocheuse, la couche pléistocénique étant donc couverte, le bord externe des terrasses connaît un effritement inexorable. Le même phénomène survient dans les hauts-fonds.

Cette vaste érosion a sans aucun doute induit une diminution de la surface d'origine du territoire, qui s'est peu à peu modelé pour devenir ce qu'il est actuellement ${ }^{3}$.

Le territoire crotoniate se distingue du reste de la Calabre centro-orientale aussi par la morphologie de ses fonds marins, caractérisés par une bathymétrie modeste : l'isobathe minimum de $5 \mathrm{~m}$ est dépassée en moyenne à $200 \mathrm{~m}$ du rivage, sauf à proximité des promontoires de Capo Colonna et Capo Cimiti. Dans certains cas, l'isobathe minimum s'étend jusqu'à 600-800 $\mathrm{m}$ de la côte, comme à l'ouest de Torre Brasolo, au sud-est de $\mathrm{S}$. Domenica, au sud-sud-ouest de Capo Bianco et au nord-est de Capo Donato. L'isobathe successive de $10 \mathrm{~m}$ est atteinte à de plus grandes distances encore, de presque 1300-1500 m au sud de Le Castella et de Soverito. Dans ces deux premiers champs bathymétriques, on peut mettre en évidence les terrasses submergées de Torre Brasolo, Capo Piccolo et Capo Pellegrino-Capo Alfiere, ainsi que les grandes surfaces de hautsfonds. Les hauts-fonds qui se trouvent en deçà de l'isobathe minimum sont ceux de Le Castella $(3,5 \mathrm{~m})$, Soverito $(4 \mathrm{~m})$ et Séleno $(4,8 \mathrm{~m})$, ces deux dernières situées au sudouest et au sud-est de Capo Piccolo. Ce profil bathymétrique singulier crée des « canaux » entre les hauts-fonds et les promontoires voisins.

Le secteur septentrional de la zone étudiée, dit des "cités de Philoctète", entre le fleuve Trionto et le promontoire crotoniate, montre différentes caractéristiques géologiques et morphologiques. En partant du Sud, on rencontre une plaine alluviale, peu profonde, qui s'élargit à proximité de l'ample embouchure du fleuve Neto ${ }^{4}$, mais est partiellement occupée par les dépressions que forment certaines lagunes côtières, aujourd'hui en grande partie asséchées et transformées par l'agriculture. Au-delà du Neto, la plaine se poursuit avec une largeur constante jusqu'à la Pointe de la Petrara, une enclave de conglomérats du miocène - dérivant des roches métamorphiques et granitiques de la Sila - dans un territoire dominé par le plio-pléistocène, situé légèrement au sud de l'habitat de Torre Melissa. Dans cette première partie, la côte est dominée par des terrasses argileuses du pléistocène, dont les flancs sont striés par les calanquestypiques; le banc pléistocénique supérieur n'y est pas toujours conservé, à cause de la très forte érosion. Les terrasses sont coupées, à angle droit par rapport à la côte, de petites vallées traversées de cours d'eau à régime saisonnier torrentiel. L'étroite plaine alluviale se poursuit au nord de Punta de la Petrara. Dans la zone de Cirò, entre les bassins hydrographiques du Lipuda et du Nicà, sont conservés d'importants cordons de dunes, de formation éolique holocénique, qui recouvrent souvent les terrasses argileuses du miocène et du pliocène, ainsi que le banc de sable et de grès plio-pléistocénique. 
L'existence d'une dépression lagunaire sur Punta Alice, légèrement à l'est du temple d'Apollon Alaios, est d'un grand intérêt: il s'agit du lac des Vurghe, séparé de la mer par un cordon de dunes bien visible sur les photographies aériennes, qui a pu fonctionner comme escale.

Dans cette partie du territoire, lorsqu'on se déplace vers l'intérieur, le paysage devient brusquement mouvementé et présente des formations de collines, dérivant de terrasses de sable et de conglomérats surmontant de puissants bancs argileux du miocène. À travers des changements d'altitudes successifs on remonte graduellement vers le plateau de la Sila. On retrouve la même configuration géologique et morphologique au nord du fleuve Nicà, jusqu'au fleuve Trionto qui constitue la limite septentrionale du territoire étudié.

\section{NOTES}

1. En ce qui concerne la description des aspects géomorphologiques, le texte est basé sur E. Infantino, Mar Dioscoron, Soveria Manelli (CZ), 1992, p. 23-26.

2. Pline l'Ancien, Histoire naturelle, III, 96.

3. Les affleurements pléistocéniques, plus vulnérables, sont présents un peu partout au niveau moyen de la mer. Cette condition détermine une fragilité particulière de la bordure côtière, également dans les zones où la couche pléistocénique est placée à quelques mètres du fond. On a pu quantifier l'érosion de la bordure côtière dans les derniers 80-100 ans en comparant les relevés cartographiques de l'IGM (Istituto Geografico Militare) et de l'IIM (Istituto Idrografico della Marina) du siècle passé aux plus récents. Le recul de la bordure externe de la péninsule a été considérable à proximité des versants exposés aux vagues dominantes très importantes : on a ainsi relevé des variations de $150 \mathrm{~m}$ au sud de Capo Colonna, à l'est de Le Castella et à l'est de Capo Bianco ; d'environ $100 \mathrm{~m}$ au nord-est de Capo Colonna, d'environ $75 \mathrm{~m}$ à Capo Donato, au nord-est de Capo Rizzuto et au sud-ouest de Le Castella (Il Telegrafo). Le phénomène se poursuit dans toutes les zones, dans certaines de manière particulièrement grave, comme sur le versant septentrional de Capo Colonna et à Capo Cimiti.

4. Le Neto est l'un des plus grands fleuves de Calabre avec un bassin de 117954 hectares. 


\section{Bibliographie générale}

R. BELLI PASQUA, R. SPADEA (dir.), Kroton e il suo territorio tra VI e V secolo a.C. Aggiornamenti e nuove ricerche, Atti del Convegno di Studi, Crotone, 3-5 marzo 2000, Crotone, 2005.

Crotone e la sua storia tra IV e III secolo a.C., Università degli studi di Napoli "Federico II", dipartimento di discipline storiche, Centro di studi per la Magna Grecia, Naples, 1993.

Crotone. Atti del ventitreesimo convegno di studi sulla Magna Grecia, Taranto, 7-10 ottobre 1983, Instituto per la storia e l'archeologia della Magna Grecia, Tarente, 1984.

J. DE LA GENIÈRE (dir.), Héra. Images, espaces, culte, Actes du Colloque international du Centre de Recherches archéologiques de l'Université de Lille III et de l'Association P.R.A.C. Lille, 29-30 novembre 1993, collection du Centre Jean Bérard 15, Naples, 1997.

G. GENOVESE, I santuari rurali nella Calabria greca, Rome, 1999.

D. MARINO, M. CORRADO (dir.), o dei di Kroton! Luoghi e testimonianze del sacro dentro le mura, Camera di Commercio, Crotone, 2009.

D. MARINO, Prima di Kroton. Dalle comunità protostoriche alla nascita della città, Crotone, 2008.

F. MAZZA (dir.), Crotone. Storia, cultura, economia, Soveria Mannelli, 1992.

G. B. DI NOLA MOLISI, Cronica dell'Antichissima, e Nobilissima città di Crotone e della Magna Grecia, Naples, 1649.

G. PUGLIESE CARRATELLI (dir.), The Western Greeks : classical civilization in the Western Mediterranean, Londres, 1996.

R. SPADEA (dir.), Kroton. Scavi e ricerche archeologiche a Crotone dal 1985 al 1998, Catalogo della mostra, Milan, 1998. 